Portland State University

PDXScholar

$12-30-2020$

\title{
Examining Bicycle and Motorized Vehicle Speeds and Their Relationships in the Context of Urban Roadways
}

Jaclyn Sue Schaefer

Portland State University

Follow this and additional works at: https://pdxscholar.library.pdx.edu/open_access_etds

Part of the Civil and Environmental Engineering Commons

Let us know how access to this document benefits you.

\section{Recommended Citation}

Schaefer, Jaclyn Sue, "Examining Bicycle and Motorized Vehicle Speeds and Their Relationships in the Context of Urban Roadways" (2020). Dissertations and Theses. Paper 5638.

https://doi.org/10.15760/etd.7510

This Thesis is brought to you for free and open access. It has been accepted for inclusion in Dissertations and Theses by an authorized administrator of PDXScholar. Please contact us if we can make this document more accessible: pdxscholar@pdx.edu. 
Examining Bicycle and Motorized Vehicle Speeds and Their Relationships in the Context of Urban Roadways

\author{
by
}

Jaclyn Sue Schaefer

A thesis submitted in partial fulfillment of the requirements for the degree of

\author{
Master of Science \\ in \\ Civil and Environmental Engineering
}

Thesis Committee:

Miguel A. Figliozzi, Chair

Christopher M. Monsere

Avinash Unnikrishnan

Portland State University

2020 
(C) 2020 Jaclyn Sue Schaefer 


\begin{abstract}
This thesis presents a compilation of papers exploring passenger car and bicycle speeds through their interactions with each other and with urban roadway factors.

First, following a concern raised in part of the traffic literature that a large mode shift toward bicycling may cause travel time delays and potentially exacerbate congestion instead of alleviate it unless bicycle lanes are installed, an empirical study detailing how the presence of bicycles on urban roads without bicycle lanes may affect passenger car speeds is presented. Pneumatic tube data from six predominantly low speed, low volume roads in Portland, Oregon were utilized to identify observations of passenger cars (class two vehicles) belonging to one of two vehicle following scenarios. In scenario (i), a passenger car was directly preceded by a bicycle (class one vehicle), and in scenario (ii), a passenger car was directly preceded by another passenger car. Speed distributions were examined, and the mean, the 50th, and the 85th percentile speeds of scenario (i) and scenario (ii) vehicles for both peak-hour and 24-hour traffic were compared using $t$-tests and confidence intervals. A few statistically significant differences between scenario (i) and scenario (ii) were found, but the actual differences in speed were generally on the order of one mile per hour or less. Thus, from a practical perspective, the presence of bicycles on these roads without bicycle lanes was deemed to have negligible effects on passenger car speeds.
\end{abstract}

Following the results of the initial study, a second study was conducted to address limitations in the initial study regarding the homogeneity of site characteristics. This second study also expanded the research to explore how oncoming (opposing direction) 
traffic and the availability of overtaking opportunities might affect passenger car speeds when a bicycle was present on an urban road without bicycle lanes. A large number of datasets $(n=75)$ from locations in Portland with a variety of geometric, roadway, and traffic characteristics were chosen for examination. As with the initial study, vehicle observations belonging to the previously defined scenarios (i) or (ii) were selected for analysis. Comparisons of the mean and 85th percentile speeds of scenarios (i) and (ii) were performed using $t$-tests. Relationships between scenario (i) speeds and gap times in oncoming traffic were also investigated. The results of this expanded study support the findings of the initial research in that bicycles did not reduce passenger car speeds by more than one mile per hour at most sites (92\%), suggesting bicycles are not likely to cause practical speed reductions on lower speed and volume roads without bicycle lanes. The propensity for significant speed reductions was lower when adequate gaps in oncoming traffic existed for overtaking, and at sites with a lower functional class or where sharrows were present.

After exploring how bicycles might affect passenger car speeds, the focus of the third paper was shifted to the site-level determinants of bicycle speed. Bicycle speed is typically assumed to be a constant value for planning and design purposes. However, the probability of the success of projects aimed at improving bicycle infrastructure and routing may be enhanced if more accurate estimates of bicycle speed can be applied. Prior studies have attempted to model bicycle speed from a mix of site factors and factors related to the individual cyclist, requiring more complex data collection methods, and generally resulted in low $\mathrm{R}^{2}$ values. In this paper, widely utilized pneumatic tubes were 
once again leveraged to collect traffic data for bicycles and passenger vehicles. This traffic data was combined with additional site-level geometric and roadway data to predict mean bicycle speed using generalized linear regression. The adjusted $\mathrm{R}^{2}$ of the final model was 0.63 , suggesting a reasonable fit. The regression analysis revealed that grade, negatively associated with the mean bicycle speed, is the most important determinant, accounting for $79 \%$ of the final model's explanatory power. The average passenger car speed, the segment length, the percentage of bicycle traffic, and the presence of a shared bikeway facility had statistically significant $(\mathrm{p}<0.05)$ positive effects on the mean bicycle speed. On shared roads, the interaction of the bicycle facility type and the percentage of bicycles was found to have a moderating effect on the mean bicycle speed. 


\section{Acknowledgments}

First and foremost, thank you to Josh. You have been my biggest supporter since day one and I am eternally grateful that you were by my side throughout this journey. Thank you for always going out of your way to make sure I had what I needed to be successful. Thank you for being my rock, my sounding board, and my hype man. Also, thank you for making sure I was fed all those nights when I could not pull myself away from the computer - the mark of a true MVP! I am forever indebted to you.

Of course, I must thank my family - mom, dad, Jessi, and Jennifer. Thank you for cheering me on and celebrating all my victories, big and small. Thank you for always believing in me.

I also must share my appreciation for my fellow classmates and friends, especially Chelle, Katherine, Mike, Darshan, Travis, Gabby, and Rohan. Thank you for the mutual exchange of knowledge, ideas, laughter, and occasional frustrations. You all helped me feel like I had a second family.

Next, I extend my gratitude to my professors. Particularly, thank you to my advisor, Dr. Miguel Figliozzi for the invaluable guidance and feedback you have given me over the past two years, and for affording me many opportunities to step outside of my comfort zone. Thank you, also, to Dr. Avinash Unnikrishnan for sharing your wisdom with me and thank you to Dr. Christopher Monsere for unknowingly teaching me that writing code can be fun.

Finally, I would like to acknowledge the Federal Highway Administration's Dwight D. Eisenhower Transportation Fellowship Program (DDETFP), the National 
Institute for Transportation and Communities (NITC), and the Coral Sales Company for their financial support through this endeavor. 


\section{Table of Contents}

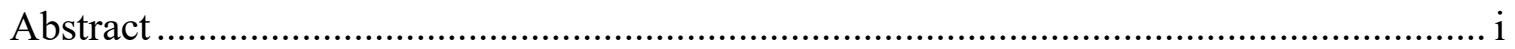

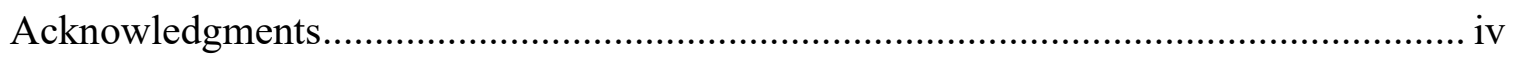

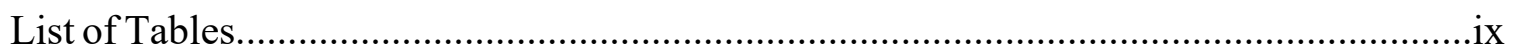

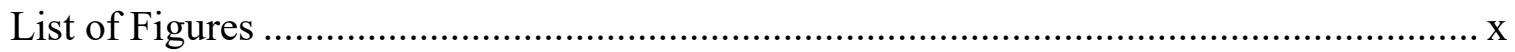

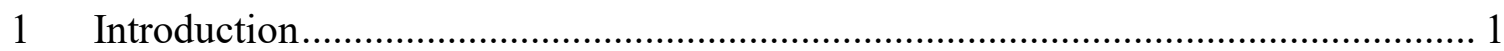

2 Evidence from Urban Roads without Bicycle Lanes on the Impact of Bicycle Traffic on Passenger Car Travel Speeds ............................................................................. 4

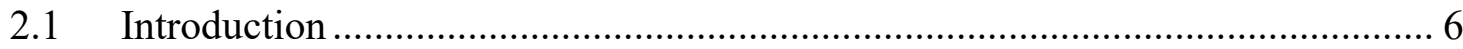

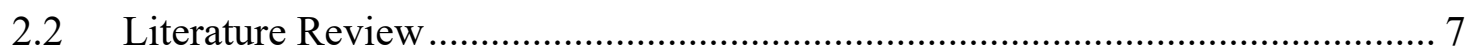

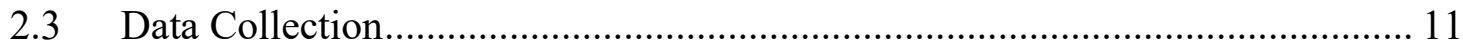

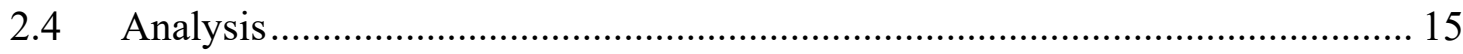

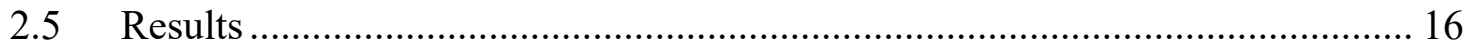

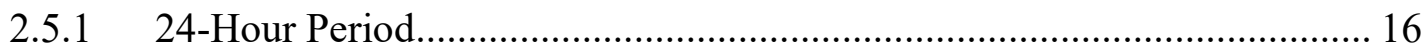

2.5.2 Peak-Hour Period................................................................................... 22

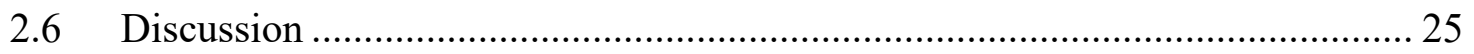

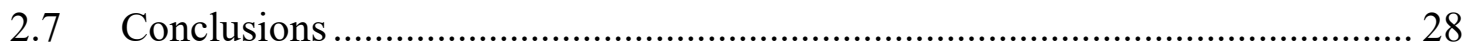

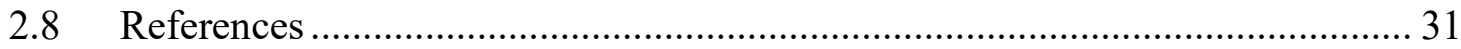


3 An Empirical Study of the Impacts of Bicycles on Passenger Car Speeds on Urban

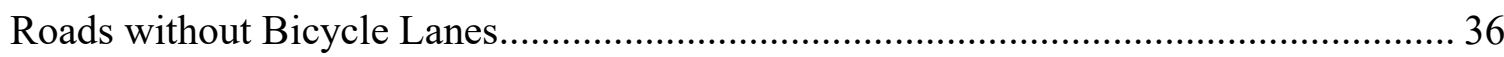

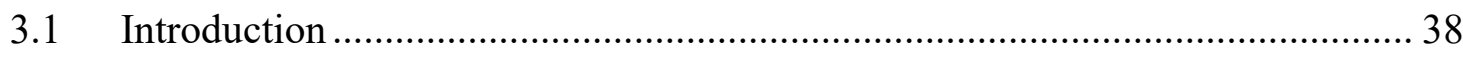

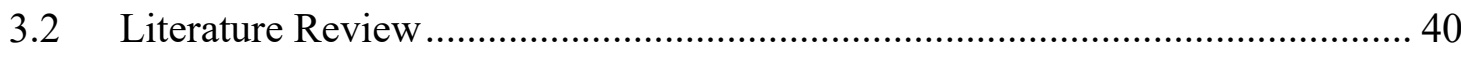

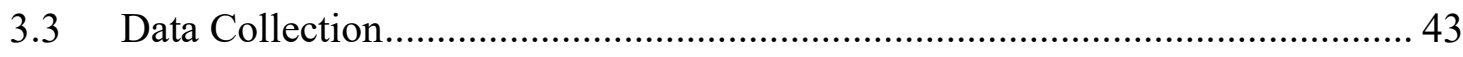

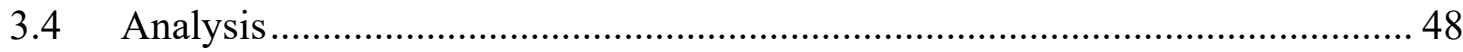

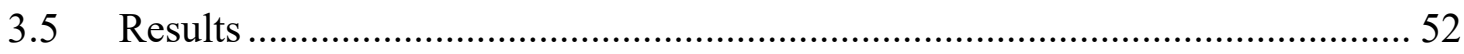

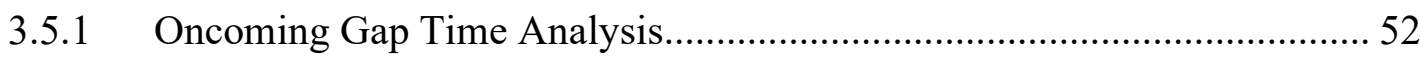

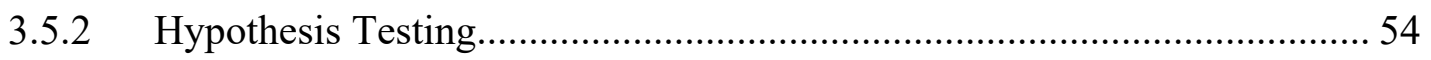

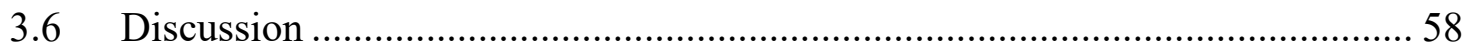

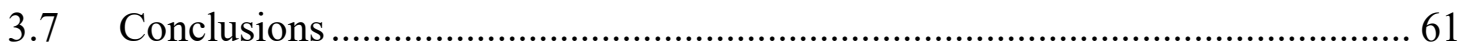

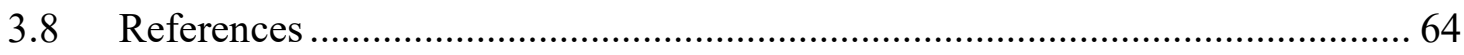

4 Utilizing Pneumatic Tube Data to Predict Bicycle Speed on Urban Roads ............. 71

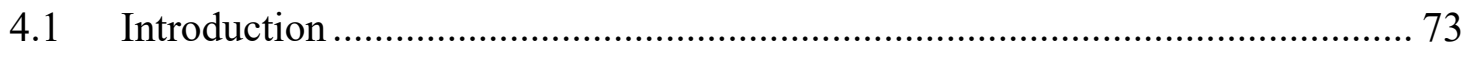

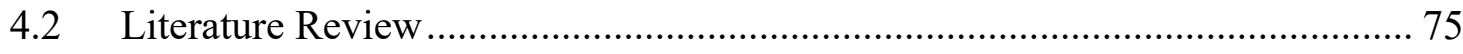

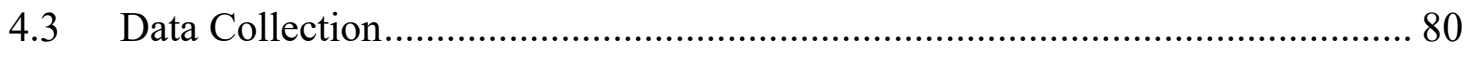

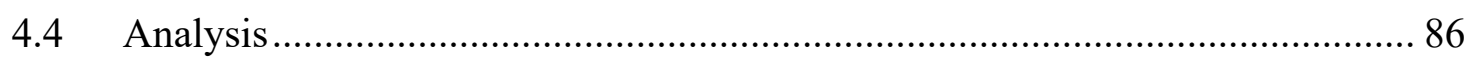

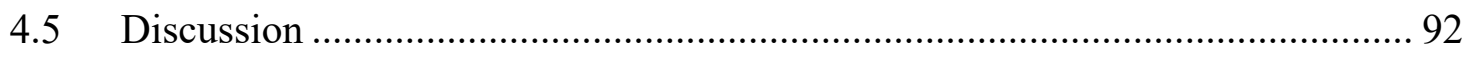

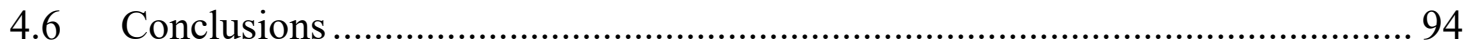




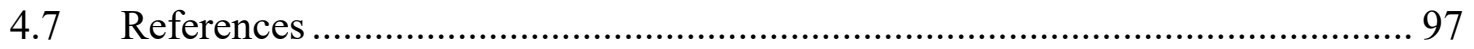

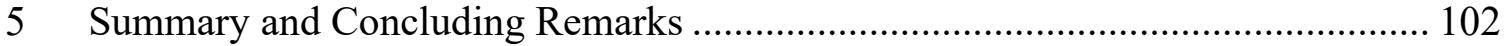




\section{List of Tables}

Table 2.1 Characteristics of the Data Collection Sites .............................................. 12

Table $2.2 t$-Test between Mean Speeds .................................................................... 19

Table $2.350^{\text {th }}$ Percentile Speeds and 95\% Confidence Intervals .................................. 21

Table $2.485^{\text {th }}$ Percentile Speeds and 95\% Confidence Intervals .................................. 22

Table $2.5 t$-Test between Mean Speeds for Peak Hours ............................................... 23

Table $2.650^{\text {th }}$ Percentile Speeds and 95\% Confidence Intervals for Peak Hours ........... 24

Table $2.785^{\text {th }}$ Percentile Speeds and 95\% Confidence Intervals for Peak Hours ............ 25

Table 3.1 Hypothesis test results for the six datasets using all observations that reject the

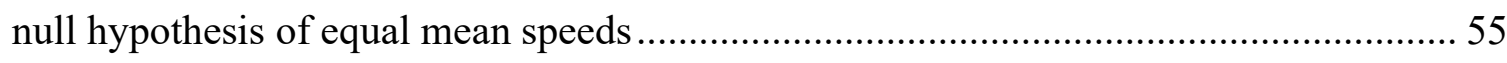

Table 3.2 Summary of hypothesis testing results for all data and all subsets.................. 57

Table 4.1 Descriptive statistics of the collected variables ....................................... 83

Table 4.2 Cross-tabulation of mean class two speeds by bicycle facility type and select

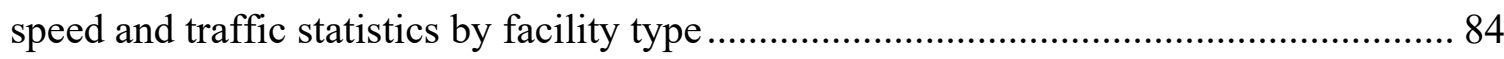

Table 4.3 Results from the two-variable combination regression analyses.................... 89

Table 4.4 Coefficients of the regression analysis model ......................................... 91 


\section{List of Figures}

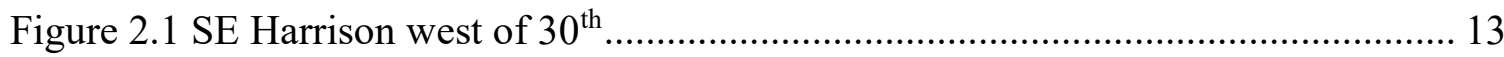

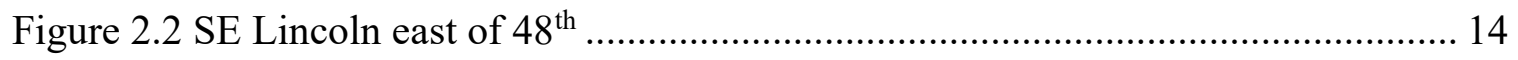

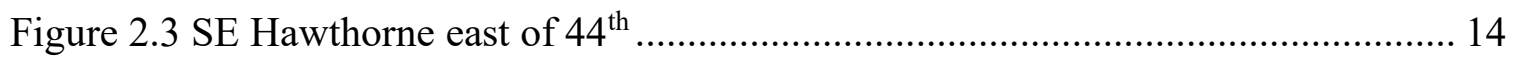

Figure 2.4 Class one speed distributions for the SE Harrison west of $30^{\text {th }}$ location......... 15

Figure 2.5 Gap analysis plots for SE Harrison west of $23^{\text {rd }}$, westbound ........................ 17

Figure 2.6 Gap analysis plots for SE Harrison west of $23^{\text {rd }}$, westbound, observations

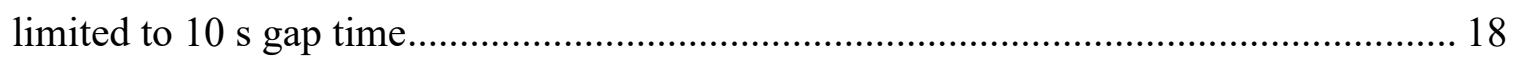

Figure 2.7 Empirical distributions with mean speeds for westbound SE Harrison east of

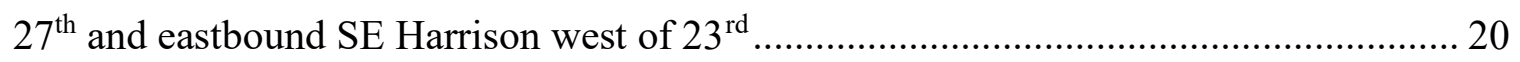

Figure 2.8 Empirical distributions with the $85^{\text {th }}$ percentile speeds for westbound SE

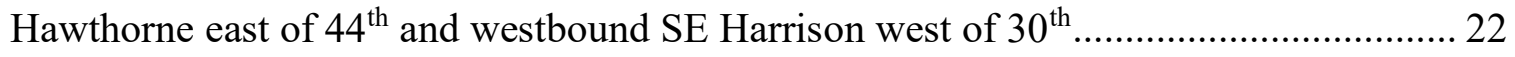

Figure 3.1 Neighborhood greenway local street without a centerline ......................... 45

Figure 3.2 Urban collector with dotted yellow centerline ........................................ 46

Figure 3.3 Urban collector with double yellow centerline ....................................... 46

Figure 3.4 Class one speed distributions including motorized vehicles and non-motorized

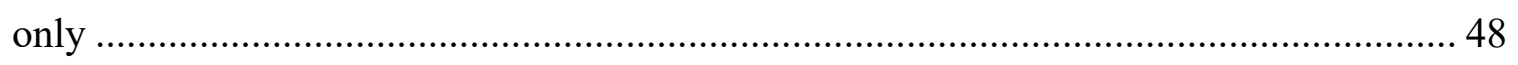

Figure 3.5 Diagram of vehicle-following gaps and gaps with oncoming vehicles.......... 51

Figure 3.6 Scatterplots of scenario (i) speeds according to the PO-i gaps and the SO-i

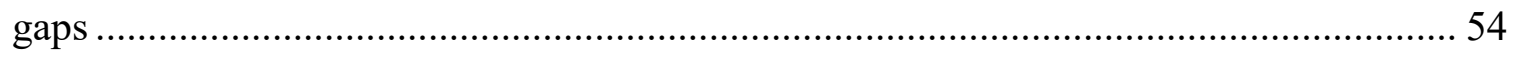

Figure 3.7 Scatterplots of scenario (i) speeds according to the PO-i gaps and SO-i gaps

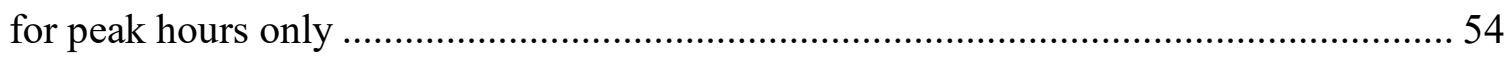


Figure 4.1 Class one speed bimodal distribution with class two speed distribution

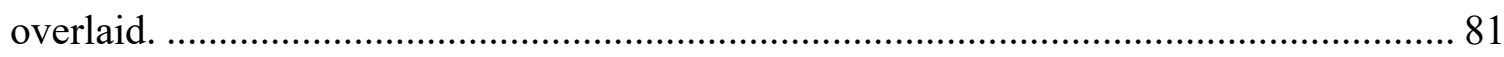

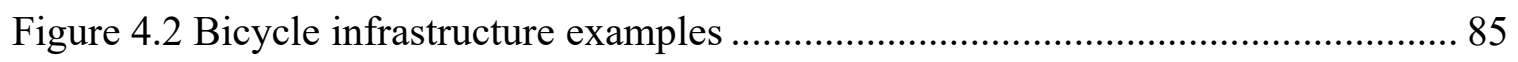

Figure 4.3 Correlogram of the mean class one speed and all collected variables. ........... 87 


\section{Introduction}

Historically, the body of bicycle traffic literature has been largely overshadowed by the body of motorized traffic literature, owing to the longstanding dominance of the passenger car for personal transportation. In recent years, a push for reducing personal automobile usage in favor of alternative travel modes such as cycling has brought heightened attention to the gaps in the bicycle research. A thorough understanding of motorized and non-motorized vehicle behaviors and their interactions is necessary for the design of safer, more efficient, and more attractive transportation networks that incorporate a larger share of non-motorized users such as cyclists.

Mitigating congestion and environmental concerns are commonly cited by cities as motivation for setting aggressive goals to increase the bicycle mode share. However, the consequences of these large mode shifts are not yet well understood, which serves as one example of the need for more bicycle research. A concern raised by some motorists, discussed in part of the traffic literature, is that an influx of bicycles in urban areas will create its own congestion issues unless bicycles are separated from motorized vehicle modes through the use of bicycle-specific lanes or other segregated facilities. Although such a separation of modes is generally preferred from both a safety and a comfort perspective, limited right-of-way and transportation budgets hinder the creation of segregated facilities on every route. Apart from physical or monetary constraints, bikeway guidance from world leaders in bikeway design, the Danish, advise that separation of motorized vehicle and bicycle modes is often unnecessary on low speed, low volume roads. In fact, many cities, including Portland, Oregon, have utilized streets 
like these to expand and enhance the existing bicycle network. By exploring the relationships between motorized vehicle speed, bicycle presence and speed, and other traffic and site-level factors on shared roads or roads without bicycle lanes, cities can more accurately anticipate and plan for future needs.

A thorough understanding of the factors affecting the speed behaviors of cyclists is a requisite component in achieving the ambitious mode share goals and highlights a further example, deeply integrated with the former, of the need for more bicycle research. In planning, design, and traffic simulation activities, bicycle speed is typically assumed to be a constant value. However, the ability to predict bicycle speed at a given site based on its geometric, traffic, and roadway attributes has implications for improving mode and route choice modeling, traffic signal progression and phase timing, and travel time estimations. In turn, creating routes and facilities that better serve cyclists may provide an incentive to bicycle for new cyclists or to increase the ridership of existing cyclists without impinging on the mobility of motorized vehicles.

This thesis is comprised of five chapters. The first chapter describes the background and motivation behind this thesis. The second chapter presents a detailed comparative analysis of passenger car speeds on six, low speed, low volume urban roads without bicycle lanes when following a bicycle versus when following another passenger car. The third chapter presents a study which expands upon that of chapter two by incorporating 75 directional traffic speed datasets from urban roads without bicycle lanes, emphasizing a wider variety of geometric, traffic, and roadway characteristics. The expanded study of chapter three also discusses the implication on passenger car speed of 
oncoming (opposing direction) traffic and opportunities for overtaking a bicycle. The fourth chapter explores the geometric, traffic, and roadway features that influence bicycle speed through correlation and regression analyses. The fifth chapter summarizes the studies of chapters two through four and provides concluding remarks. 


\section{Evidence from Urban Roads without Bicycle Lanes on the Impact of Bicycle Traffic on Passenger Car Travel Speeds}

Jaclyn S. Schaefer, Miguel A. Figliozzi, and Avinash Unnikrishnan

This is a published paper and can be found using the following citation:

Schaefer JS, Figliozzi MA, Unnikrishnan A. Evidence from Urban Roads without Bicycle Lanes on the Impact of Bicycle Traffic on Passenger Car Travel Speeds. Transportation Research Record. 2020 Jun 12. 


\begin{abstract}
A concern raised by some motorists in relation to the presence of bicycles on urban roads without bicycle lanes, discussed in part of the traffic literature, is that cyclists will slow down motorized vehicles and therefore create congestion. This research answers this question: do bicycles reduce passenger car travel speeds on urban roads without bicycle lanes? To answer this question, a detailed comparative analysis of the travel speeds of passenger car (class two vehicles) on lower volume urban roads without bicycle lanes is presented. Speed distributions, the mean, and the 50th and 85 th percentile speeds for two scenarios were examined: (i) a passenger car that was preceded by a bicycle and (ii) a passenger car that was preceded by another passenger car. Peak hour traffic and 24-h traffic speeds were analyzed using $t$-tests and confidence intervals. Although a few statistically significant differences between scenarios (i) and (ii) were found, the actual speed differences were generally on the order of one mile per hour or less. Therefore, differences in class two (motorized passenger) vehicle speeds with and without cyclists were found to be negligible from a practical perspective.
\end{abstract}




\subsection{Introduction}

Bicycling is a vastly underutilized mode throughout most of the U.S.A., comprising just half of one percent of commuters throughout the nation [1]. Given its potential for greater flexibility in route choice and lower costs for infrastructure and operation compared with transit, there is a substantial opportunity for cities to expand bicycling as a primary transportation mode. Congestion mitigation and environmental concerns from rising urban populations have been significant factors cited by communities as they push for greener transportation policies and travel modes.

According to the Portland Bureau of Transportation, in 2017, 6.3\% of commuters traveled by bicycle [2]. The Portland Bike Plan has established a goal to increase that mode share to $25 \%$ by the year 2030 [3]. With this mode shift toward bicycling, it is necessary to study the impacts these changes may have on the existing transportation network and motorized vehicles. In support of the Portland Bike Plan's goal to reach a $25 \%$ bicycle mode share, the city authorities expect to add nearly $100 \mathrm{mi}(161 \mathrm{~km})$ of bikeways to the existing $385 \mathrm{mi}(620 \mathrm{~km})$, approximately $36 \%$ of which are currently shared-use roadways [2].

Although it is generally favored to segregate bicyclists and motor vehicles, it is infeasible and often unnecessary to create such infrastructure on every road. For example, Danish bicycle design guidelines suggest that mixed traffic conditions are acceptable for roadways with speed limits less than approximately $35 \mathrm{~km} / \mathrm{h}(22 \mathrm{mph})$ and average daily traffic (ADT) less than approximately 2,500 vehicles [4]. 
Shared-use roads can be an economical solution to a growing demand for bicycle facilities. However, this sharing of space presents its own challenges in the contexts of safety and mobility. Several research studies have been conducted on vehicle-bicycle interactions, many of them focused on lateral positioning and passing behavior. Of particular interest, however, is the effect of bicycle traffic on motorized traffic speed, capacity, and flow.

A general concern of motorists in relation to the presence of bicycles on roads without bicycle lanes is that they will impede motor vehicles because of their differing performance characteristics, which may serve to increase congestion and vehicle emissions - two consequences of urbanization that a larger bicycle mode share seeks to mitigate. Recent discussions based on a simulated traffic study have warned that traffic congestion and travel time delay will worsen as the bicycle mode share increases unless bicycle lanes are installed [5-6]. To the authors' knowledge, there have not been any studies to date using empirical data of passenger cars on shared roads or roads without bicycle lanes that explore the validity of this claim. This paper seeks to expand the knowledge on vehicle-bicycle interactions by studying the impact of bicycles on the travel speed of passenger cars on roadways without bicycle lanes.

\subsection{Literature Review}

Shared roads or roads without explicit bicycle lanes can constitute a considerable portion of an urban bicycle network. Danish bikeway design guidelines suggest that mixed traffic conditions are acceptable for roadways with low speed limits (less than 
$35 \mathrm{~km} / \mathrm{h}$ [22 mph]) and low traffic volumes (less than 2,500 ADT) [4]. The FHWA lays out similar guidelines, advising shared roadways are suitable in urban areas on streets with speeds of $25 \mathrm{mph}(40 \mathrm{~km} / \mathrm{h})$ or less and a maximum of 3,000 ADT [7-8]. The National Association of City Transportation Officials also recommends a target speed of 20-25 mph (32-40 km/h) and traffic volumes below 1,500 vehicles per day for shared streets to be appropriate for all ages and abilities [9].

In light of the growing trend of bicycling as a transportation mode, there is a considerable need for additional research into how bicycles affect traffic operations, particularly in these mixed traffic contexts. Relatively few studies have attempted to model vehicle-bicycle interactions as they relate to travel speed or delay.

Bicycles may interact with motor vehicles in several ways, including their position relative to each other and their lateral movements. Conflicts can arise when bicycles and motor vehicles attempt to occupy the same space because of lane changes and merging, turning movements, or shared roadways. The differential in performance characteristics between bicycles and motor vehicles, particularly on roadways with significant positive grades, contributes to the potential for these conflicts as motor vehicles frequently operate at higher speeds and desire to overtake slower moving bicycles.

Jia et al. [10] described two types of influence bicycles may impose on motor vehicles, namely friction interference and block interference. Even when a bicyclist is riding within a dedicated bicycle lane, a motor vehicle may slow down when passing on account of safety. This is referred to as friction interference. Block interference occurs 
when a bicyclist occupies a portion of the motor lane, causing a trailing motor vehicle to reduce its speed. On shared roadways, it has been demonstrated that shared lane markings encourage bicyclists to ride farther from the curb in a more central position within the lane [11-13] which may increase instances of block interference on shared roads.

In the absence of empirical data, simulations have been used to study vehiclebicycle interactions. Oketch [14] designed a model using a deterministic car-following rule to simulate heterogeneous traffic behavior in which multiple types of non-motorized vehicles were present along with conventional motor vehicles. Speed-flow relationships were developed, and trends in capacity and saturation flows were analyzed for a two-lane road with $3 \mathrm{~m}$ (10 ft) lane widths. The average desired speed was set to $80 \mathrm{~km} / \mathrm{h}(50 \mathrm{mph})$ with a flow of 1,000 vehicles per hour to model a typical urban arterial road. Results of a simulation comprised of $25 \%$ bicycles and $75 \%$ private cars showed a $36 \%$ decrease in capacity versus a homogenous traffic stream of private cars. This decrease in capacity was attributed to a reduction in the mean free flow speed. However, it is important to note that the desired motor vehicle speed and traffic flow values utilized in these simulations far exceed the bicycle design recommendations for mixed traffic roadways.

Bicycle lane provisions and bicycle volume have been found to affect the average velocities of cars in China. Researchers in Beijing collected and analyzed field data for three sections of road with designated bicycle lanes of varying width and $3.7 \mathrm{~m}(12 \mathrm{ft})$ motor vehicle lanes using photography to quantify the impact bicycles exert on vehicles in mixed urban traffic. The researchers observed that, as the number of bicycles increased or the width of the bicycle lane decreased, motor vehicles were increasingly affected by 
block interference as opposed to friction interference because of the overflow of bicycles into the motor vehicle lane, which offered insufficient space to pass. The average velocities of cars on the three road sections when no interference occurred ranged from $35.15 \mathrm{~km} / \mathrm{h}$ to $41.56 \mathrm{~km} / \mathrm{h}(21.84-25.82 \mathrm{mph})$. Compared with conditions where no interference occurred, a $17-21 \%$ decrease in average velocity was observed when friction interference was present. Under block interference conditions, a $29-37 \%$ decrease in average velocity was observed as compared with no interference [10].

Bicycle lane width, motor vehicle lane width, and traffic volume—-both motor vehicle and bicycle — influence lateral movements and passing behavior, which may, in turn, affect speed and travel time. Using a simulation of a two-lane urban roadway and based on a motor vehicle speed of $37.4 \mathrm{mph}(60 \mathrm{~km} / \mathrm{h})$, Gosse and Clarens [6] found that a 10\% bicycle mode share incurred travel time delay costs when shared travel lanes were not sufficiently wide to allow heavy vehicles to pass safely. This effect was magnified on sections with a positive $4 \%$ grade. In their simulations, the researchers concluded that a curb-to-curb road width of $8.6 \mathrm{~m}(28.2 \mathrm{ft})$ or greater provided adequate space for larger vehicles to pass and resulted in reduced travel time delay costs with a $10 \%$ bicycle mode share.

Unlike previous (cited) studies that utilized simulations to analyze motorized traffic delays because of the presence of cyclists, this research utilizes empirical traffic speed and vehicle classification data that was collected at six different locations with different roadway geometric design and topography in Portland, Oregon. 


\subsection{Data Collection}

The City of Portland, Oregon is well known throughout the U.S.A. for its bicycling culture. There are currently $385 \mathrm{mi}(620 \mathrm{~km})$ of bikeways in Portland with an additional $95 \mathrm{mi}(153 \mathrm{~km})$ being installed in the next 5 years. Over $100 \mathrm{mi}(161 \mathrm{~km})$ of the existing bikeways are shared roadways [2]. To investigate the effect bicycles may have on passenger car travel speeds on shared-use roadways or roads without bicycle lanes, traffic speed survey data was sourced from the Portland Bureau of Transportation (PBOT). PBOT uses pneumatic tubes configured to record vehicle speed and classify the vehicle according to the number of axles and the axle spacing detected. PBOT uses a modified FHWA Scheme F [15] to classify vehicles, with bicycles included as class one and passenger cars as class two. Pneumatic tubes are commonly used for short-term traffic counts. Although pneumatic tubes have a general tendency to undercount bicycles, Nordback et al. [16] found that the JAMAR tubes performed better than two other brands of classification counters tested and that manually computed bicycle speeds were in agreement with those reported by the JAMAR model. PBOT has been using JAMAR brand tube counters for many years and the crews are experienced in relation to appropriate placement of the tubes to gather counts and speeds for both motorized vehicles and bicycles.

The data, collected at six different sites, was sourced from available PBOT speed data collection efforts, and selected based on the availability of data within the context of roadways without bicycle lanes. Bidirectional data was available for five of the six sites, 
producing a total of eleven datasets. The posted speed limit at the time of collection for all sites was $25 \mathrm{mph}(40 \mathrm{~km} / \mathrm{h})$. Grades ranged from flat to greater than $4 \%$, all positive in the eastbound direction. Table 2.1 describes the basic geometric and traffic characteristics of each site including the percentage of class one vehicles and estimated ADT.

Table 2.1 Characteristics of the Data Collection Sites

\begin{tabular}{|c|c|c|c|c|c|c|c|}
\hline \multirow[b]{2}{*}{ Location } & \multirow{2}{*}{$\begin{array}{l}\text { Road } \\
\text { Markings }\end{array}$} & \multirow{2}{*}{$\begin{array}{c}\text { Grade } \\
\%\end{array}$} & \multirow{2}{*}{\begin{tabular}{|c} 
Road Width \\
(ft.)
\end{tabular}} & \multicolumn{2}{|c|}{ ADT } & \multicolumn{2}{|c|}{ \% Class 1} \\
\hline & & & & EB & WB & $\mathbf{E B}$ & WB \\
\hline $\begin{array}{l}\text { SE Harrison } \\
W \text { of } 23^{\text {rd }}\end{array}$ & Sharrow & 4.1 & 35.5 & 663 & 1084 & 67 & 46 \\
\hline $\begin{array}{l}\text { SE Harrison } \\
\mathrm{W} \text { of } 26^{\text {th }}\end{array}$ & Sharrow* & 4.0 & 35.5 & 553 & 923 & 22 & 34 \\
\hline $\begin{array}{l}\text { SE Harrison E } \\
\text { of } 27^{\text {th }}\end{array}$ & Sharrow & 4.3 & 35.5 & 1249 & 1462 & 17 & 24 \\
\hline $\begin{array}{l}\text { SE Harrison } \\
\mathrm{W} \text { of } 30^{\text {th }}\end{array}$ & Sharrow* & 1.6 & 35.5 & 1594 & 1450 & 31 & 34 \\
\hline $\begin{array}{l}\text { SE Lincoln E } \\
\text { of } 48^{\text {th }}\end{array}$ & Sharrow & 1.4 & 34 & 642 & 719 & 6 & 13 \\
\hline $\begin{array}{l}\text { SE Hawthorne } \\
\text { E of } 44^{\text {th }}\end{array}$ & \begin{tabular}{|l|}
$\begin{array}{l}\text { Center left- } \\
\text { hand turn lane }\end{array}$ \\
\end{tabular} & 0 & $\begin{array}{c}51 \text { with } 12 \mathrm{ft} . \\
\text { center lane }\end{array}$ & na & 6568 & na & 2 \\
\hline
\end{tabular}

Note: $\mathrm{EB}=$ eastbound, $\mathrm{WB}=$ westbound, na $=$ not applicable.

*Double yellow lines at these sites are only placed within $40 \mathrm{ft}$. of a traffic control device.

SE Harrison St and SE Lincoln St are classified by the City as local streets.

Additionally, they are designated as neighborhood greenways - streets with low speed limits and low volumes where bicyclists are encouraged to travel. The speed limit and traffic volume on these streets can be considered within the design recommendations for mixed traffic roadways. These streets are two-way, two lanes, and parallel parking is permitted on both sides of the street, although it is minimally utilized along Harrison and moderately utilized along Lincoln. Formerly a double yellow center lane was present along SE Harrison St. However, it has been allowed to fade to a nearly imperceptible 
state except within roughly 40 feet $(12 \mathrm{~m})$ of a traffic control device. Lane markings along SE Lincoln St are only present near traffic control devices. Sharrows (shared lane markings) are present along both SE Harrison St and SE Lincoln St. Bicycle lanes are absent at all locations presented in Table 2.1.

SE Hawthorne Blvd is classified as a district collector. It is a two-way road with one lane in each direction and a center turn lane. Parallel parking is also permitted on both sides of the road and is frequently occupied. No sharrows are present at this location.

A few of the data collection sites have additional, noteworthy characteristics. Allway stop signs are present at the intersection of SE Harrison and $30^{\text {th }}$ and the intersection of SE Harrison and $26^{\text {th }}$. The Lincoln site is situated midway between two speed humps, approximately 460 feet $(140 \mathrm{~m})$ apart. Figures 2.1 through 2.3 provide street level views of a representative site along SE Harrison, the SE Lincoln site, and the SE Hawthorne site, respectively [17-19].

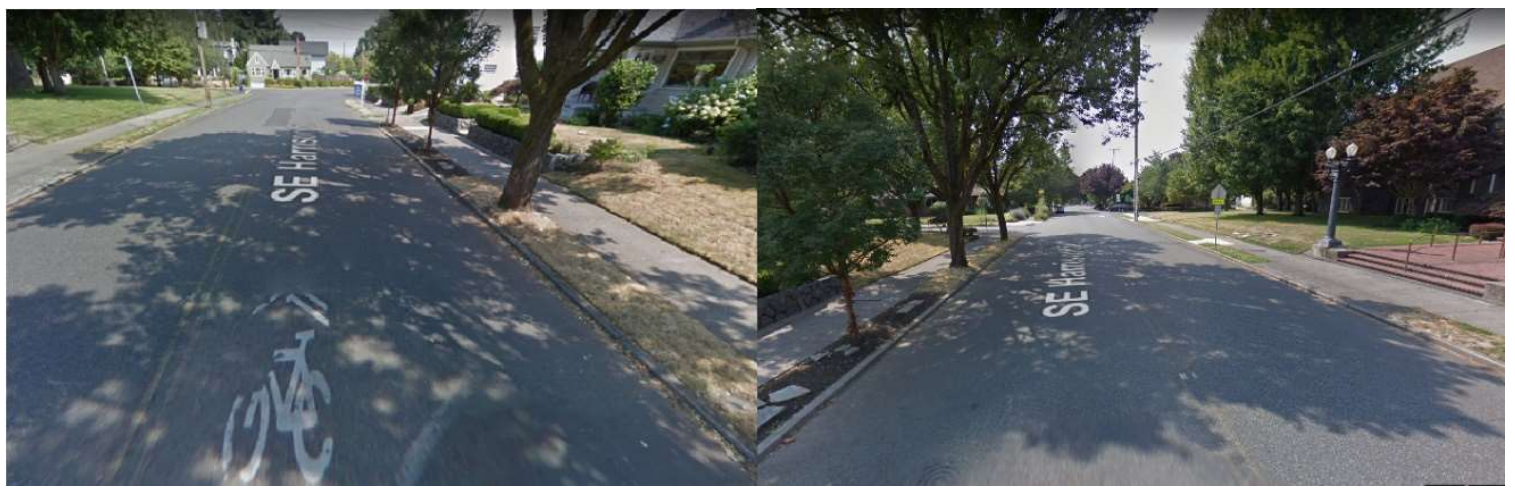

Figure 2.1 SE Harrison west of $30^{\text {th }}$, looking east (left) and west (right) [17]. 


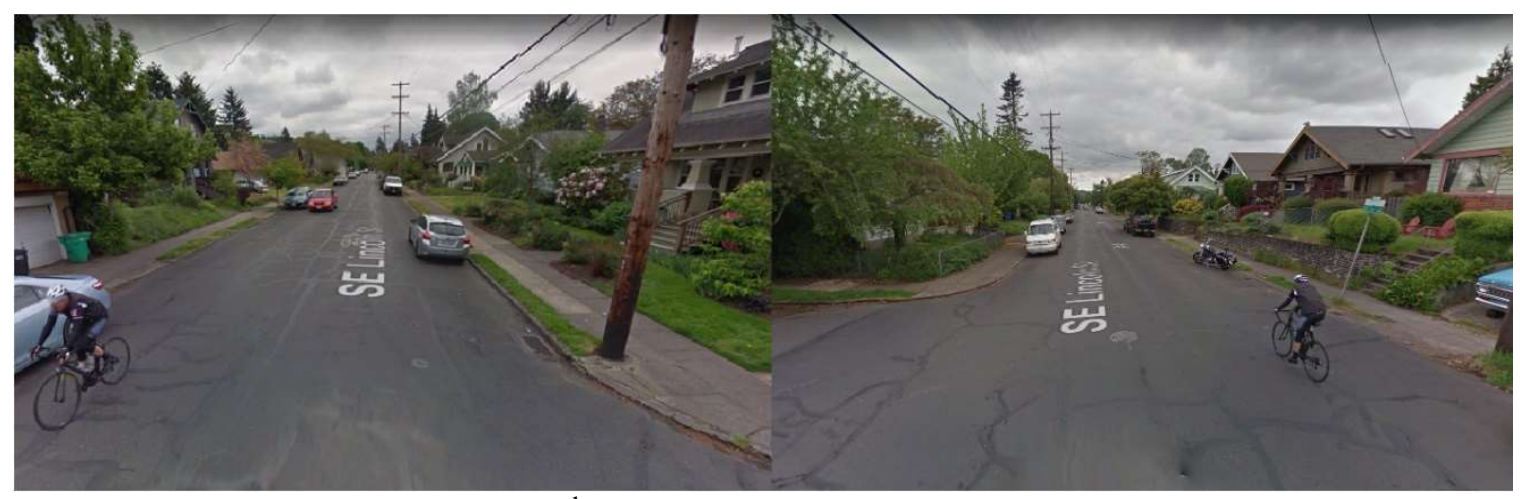

Figure 2.2 SE Lincoln east of $48^{\text {th }}$, looking east (left) and west (right) [18].

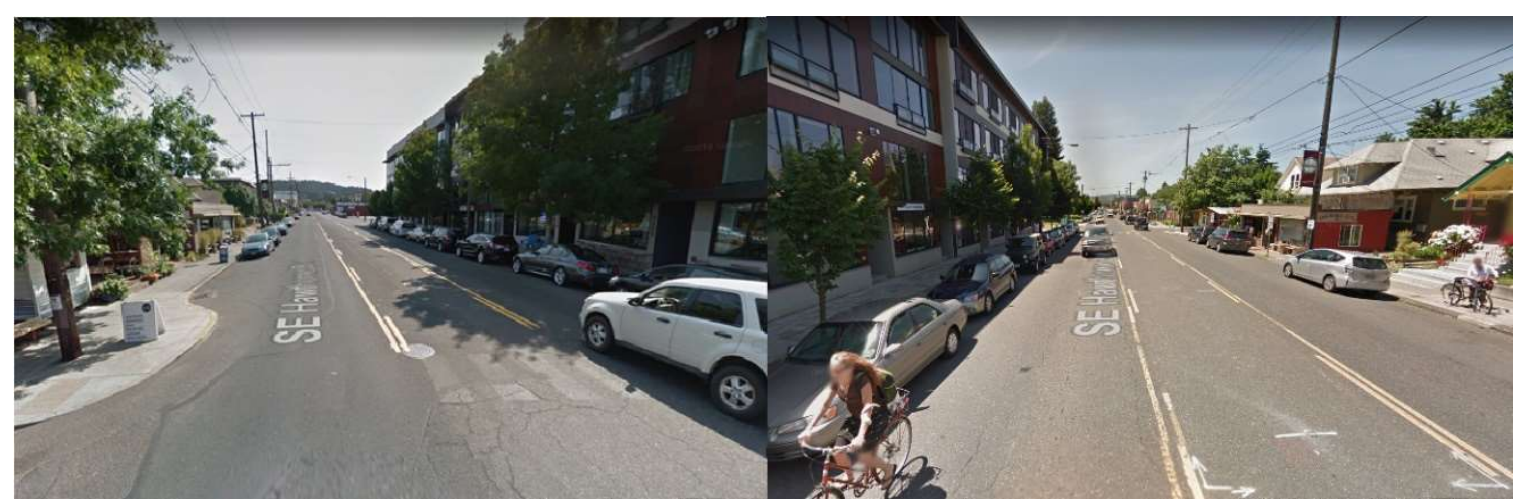

Figure 2.3 SE Hawthorne east of $44^{\text {th }}$, looking east (left) and west (right) [19].

Speed distributions of class one vehicles were inspected as part of the data cleaning process. Vehicle speeds appeared to be normally distributed for all datasets. Figure 2.4 provides a representative example of class one speed distributions, showing those from the SE Harrison west of $30^{\text {th }}$ location. Mean class one speeds at this location were $11.2 \mathrm{mph}(18 \mathrm{~km} / \mathrm{h})$ and $11.9 \mathrm{mph}(19 \mathrm{~km} / \mathrm{h})$ for the eastbound and westbound directions, respectively. 

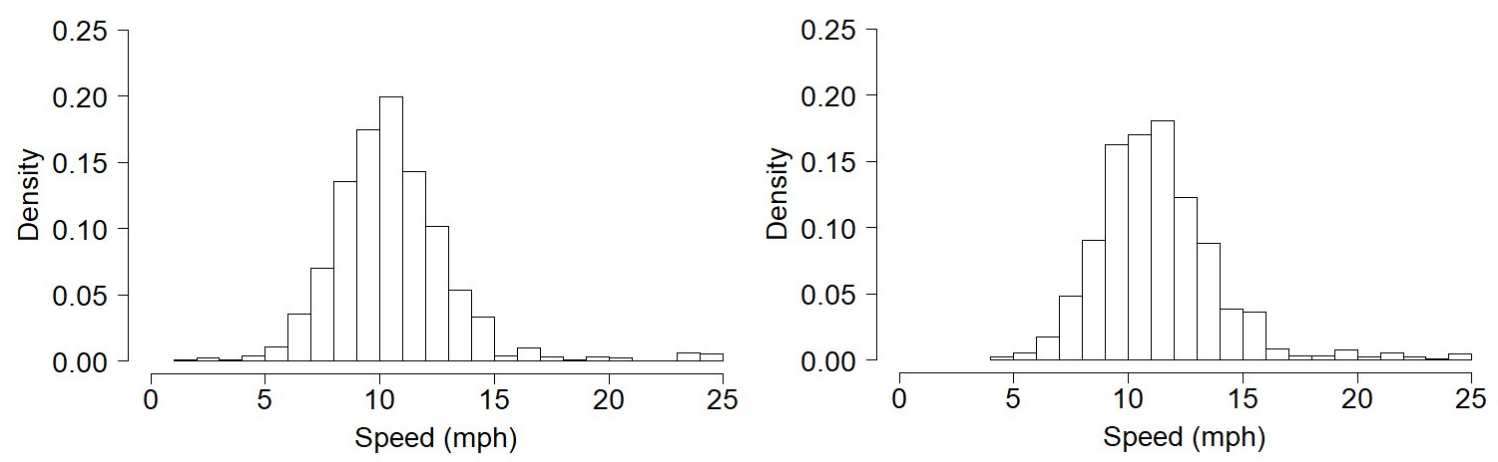

Figure 2.4 Class one speed distributions for the SE Harrison west of $30^{\text {th }}$ location eastbound (right) and westbound (left).

\subsection{Analysis}

Motorized vehicles may be forced to reduce their speed before or during overtaking maneuvers when approaching a slower moving bicycle from behind. The following two scenarios: (i) observations of a class two vehicle (passenger car) that was preceded by a class one vehicle (bicycle) and (ii) observations of a class two vehicle (passenger car) preceded by another class two vehicle (passenger car) were selected for analysis from the datasets supplied. The data were selected as such to test the hypothesis that bicycles cause reduced passenger car travel speeds on roads without bicycle lanes, either by friction or block interference.

The timestamp associated with each observation in the datasets allowed the gap time between the vehicle of interest and the preceding vehicle to be calculated. An analysis of gap time versus speed was performed to determine whether a correlation between them was present. A vehicle with a smaller gap time may be influenced by the preceding vehicle to a greater degree than one with a larger gap time. A series of plots 
were constructed, and linear correlation coefficients were calculated to inspect for a relationship between gap time and speed. Should one such relationship exist, we might expect to see some degree of positive correlation, particularly for vehicles following a bicycle. In traffic engineering and speed studies a gap of 4-6 s is usually used as a threshold to determine if the leading vehicle is affecting the behavior of the follower.

Comparisons of speed between the two vehicle configurations were made in several ways. First, mean speed was calculated for each configuration of class two vehicles in each dataset, and a two-sample $t$-test was performed. To further evaluate the practical implication of any difference in speed for the two configurations, $50^{\text {th }}$ and $85^{\text {th }}$ percentile speeds with $95 \%$ confidence intervals were calculated and compared.

Each dataset was first analyzed for a whole day (24-hour period) and was then analyzed for peak hour traffic separately. A potential limitation of this study is the inability of the traffic monitoring equipment (pneumatic tubes) to differentiate between motorized and non-motorized class one vehicles. This limitation was regarded as irrelevant to this study because of the negligible percentage of traffic that motorcycles typically comprise [20], which is observed to be the case also on Portland urban area roads.

\subsection{Results}

\subsubsection{4-Hour Period}

Figure 2.5 presents the speed-gap plots generated for the SE Harrison west of $23^{\text {rd }}$ westbound dataset and their associated $r$-values noted as a typical example for all sites. 
With $r$-values close to zero, it can clearly be seen that the disaggregated data are highly scattered, and no apparent relationship exists between gap time and vehicle speed for either vehicle configuration. This finding was consistent throughout all of the datasets analyzed where linear correlation coefficients were low and not significant. A subsequent analysis limited to observations with a gap time of $10 \mathrm{~s}$ or less presented comparable results. Figure 2.6 displays the speed-gap plots of the westbound SE Harrison west of $23^{\text {rd }}$ dataset when limited to a $10 \mathrm{~s}$ gap time.
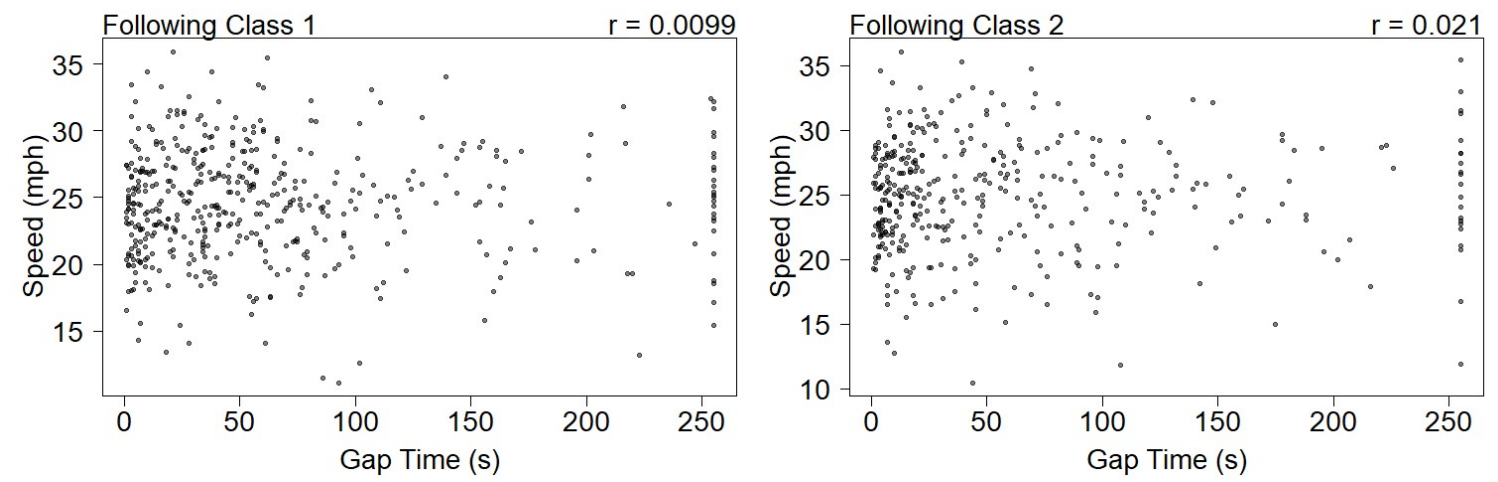

Figure 2.5 Gap analysis plots for SE Harrison west of $23^{\text {rd }}$, westbound. Class two following class one configuration (left) and class two following class two configuration (right). 

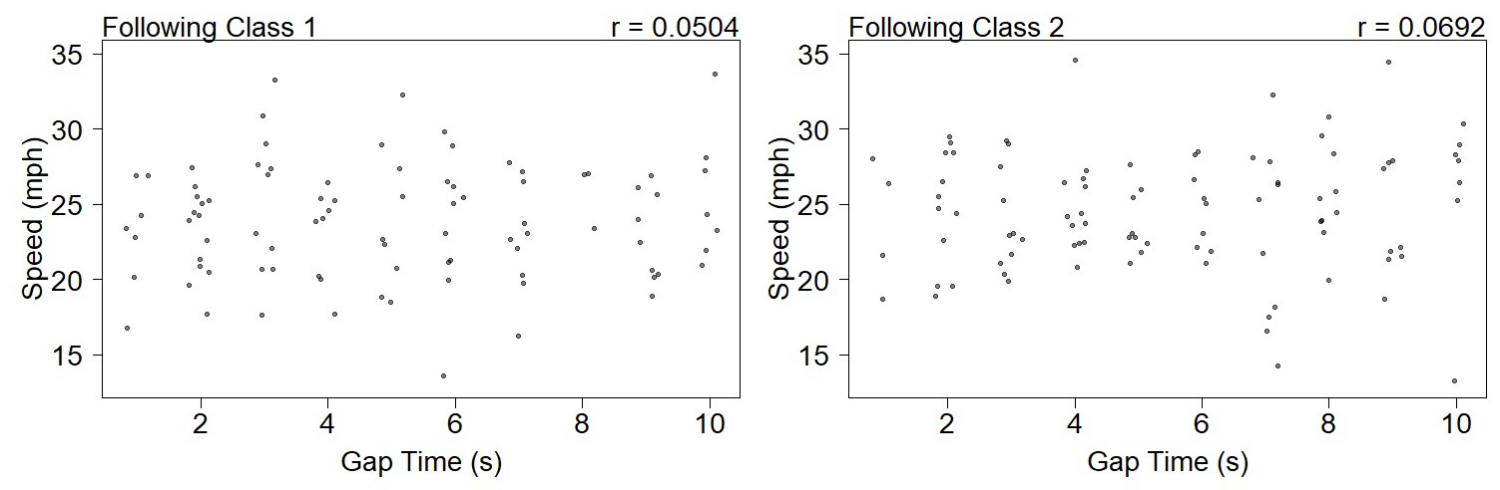

Figure 2.6 Gap analysis plots for SE Harrison west of $23^{\text {rd }}$, westbound limited to observations of a 10 s gap time. Class two following class one configuration (left) and class two following class two configuration (right). Notice the similar data trend as when all observations are retained.

The results of the $t$-tests can be seen in Table 2.2, along with the mean class one speeds for reference. The null hypothesis is defined as scenarios (i) and (ii) having equal mean speeds. The null is rejected when there is a statistically significant difference between the mean speeds. If the difference is not statistically significant, we fail to reject the null. Five of the eleven datasets show a statistically significant difference at the $p=$ 0.05 level, rejecting the null hypothesis. 
Table 2.2 $t$-Test between Mean Speeds

\begin{tabular}{|c|c|c|c|c|c|c|c|c|}
\hline \multirow{2}{*}{\multicolumn{2}{|c|}{ Location }} & \multicolumn{2}{|c|}{$\mathbf{N}$} & \multicolumn{3}{|c|}{ Mean (mph) } & \multirow[b]{2}{*}{$\begin{array}{c}t- \\
\text { Statistic } \\
\end{array}$} & \multirow[b]{2}{*}{$p$-Value } \\
\hline & & \multirow{2}{*}{$\begin{array}{c}\begin{array}{c}\text { Following } \\
\text { Class } \mathbf{1}\end{array} \\
146 \\
\end{array}$} & \multirow{2}{*}{$\begin{array}{c}\begin{array}{c}\text { Following } \\
\text { Class 2 }\end{array} \\
149\end{array}$} & \multirow{2}{*}{$\begin{array}{c}\begin{array}{c}\text { Class } \\
\mathbf{1}\end{array} \\
9.91\end{array}$} & \multirow{2}{*}{\begin{tabular}{|c|}
$\begin{array}{c}\text { Following } \\
\text { Class 1 }\end{array}$ \\
21.77 \\
\end{tabular}} & \multirow{2}{*}{\begin{tabular}{|c|}
$\begin{array}{c}\text { Following } \\
\text { Class 2 }\end{array}$ \\
21.95
\end{tabular}} & & \\
\hline \multirow{2}{*}{$\begin{array}{l}\text { Harrison W } \\
\text { of } 23 \mathrm{rd}\end{array}$} & EB & & & & & & -0.34 & 0.731 \\
\hline & WB & 462 & 379 & 22.10 & 24.54 & 24.88 & -1.16 & 0.246 \\
\hline \multirow{2}{*}{$\begin{array}{l}\text { Harrison W } \\
\text { of 26th }\end{array}$} & EB & 220 & 471 & 14.30 & 21.22 & 21.39 & -0.46 & 0.648 \\
\hline & WB & 350 & 767 & 20.30 & 21.95 & 21.86 & 0.32 & 0.753 \\
\hline \multirow{2}{*}{$\begin{array}{l}\text { Harrison E } \\
\text { of } 27 \mathrm{th}\end{array}$} & EB & 148 & 591 & 9.67 & 22.95 & 23.32 & -0.95 & 0.341 \\
\hline & WB & 181 & 629 & 16.30 & 22.66 & 23.93 & -4.07 & $0.000 *$ \\
\hline \multirow{2}{*}{$\begin{array}{l}\text { Harrison W } \\
\text { of 30th }\end{array}$} & EB & 496 & 1108 & 11.20 & 22.45 & 23.06 & -3.02 & $0.000 *$ \\
\hline & WB & 479 & 980 & 11.90 & 22.58 & 22.99 & -1.99 & $0.047 *$ \\
\hline \multirow{2}{*}{$\begin{array}{l}\text { Lincoln E } \\
\text { of 48th }\end{array}$} & EB & 323 & 2720 & 22.00 & 22.24 & 22.05 & 0.68 & 0.495 \\
\hline & WB & 286 & 2895 & 18.70 & 21.93 & 22.5 & -2.21 & $0.027 *$ \\
\hline $\begin{array}{l}\text { Hawthorne } \\
\text { E of 44th }\end{array}$ & WB & 28 & 9041 & 10.70 & 24.21 & 27.48 & -2.59 & $0.015^{*}$ \\
\hline
\end{tabular}

Note: $\mathrm{N}=$ number of observations.

$*>95 \%$ significance.

Figure 2.7 displays the empirical speed distributions and mean speeds for the westbound SE Harrison east of $27^{\text {th }}$ dataset and the eastbound SE Harrison west of $23^{\text {rd }}$ dataset. These empirical distributions also provide a visual of the level of compliance to the posted speed limit. At the westbound SE Harrison east of $27^{\text {th }}$ location, the proportion of observations exceeding the posted speed limit was $24.9 \%$ and $31.48 \%$ for scenarios (i) and (ii), respectively. At the eastbound SE Harrison west of $23^{\text {rd }}$ location, $24.0 \%$ and $17.45 \%$ of observations exceeded the speed limit for scenarios (i) and (ii), respectively. 

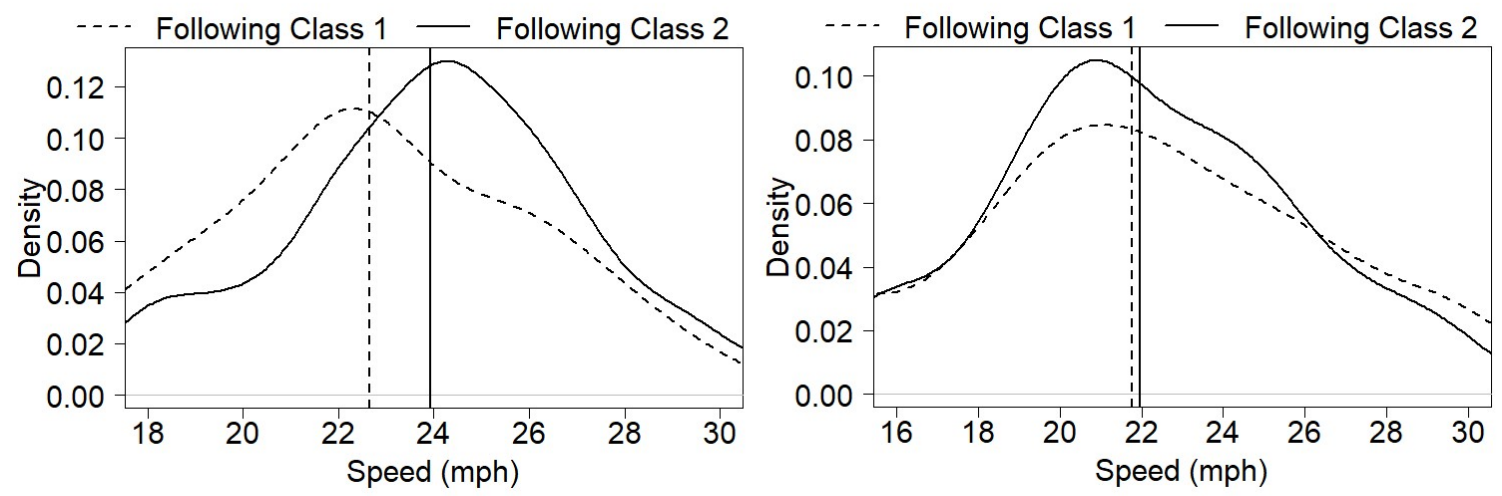

Figure 2.7 Empirical distributions with mean speeds for westbound SE Harrison east of $27^{\text {th }}$ (left) and eastbound SE Harrison west of $23^{\text {rd }}$ (right).

Table 2.3 presents the results of the calculated $95 \%$ confidence intervals for the $50^{\text {th }}$ percentile speeds. Only one dataset, the westbound direction at SE Harrison east of $27^{\text {th }}$, shows non-overlapping confidence intervals for the $50^{\text {th }}$ percentile speeds. Apart from this dataset, a high degree of overlap is observed. It can be observed that the intervals may differ by approximately one mile per hour $(1.6 \mathrm{~km} / \mathrm{h})$ or less for all locations where sharrows are present. A broader confidence interval is given for scenario (i) at the SE Hawthorne location, yet the confidence interval for scenario (ii) remains within these bounds. 
Table 2.3 $50^{\text {th }}$ Percentile Speeds and 95\% Confidence Intervals (in mph)

\begin{tabular}{|c|c|c|c|c|c|}
\hline \multirow{2}{*}{\multicolumn{2}{|c|}{ Location }} & \multicolumn{2}{|c|}{ Following Class 1} & \multicolumn{2}{|c|}{ Following Class2 } \\
\hline & & \multirow{2}{*}{$\begin{array}{c}\begin{array}{c}\mathbf{5 0}^{\text {th }} \\
\text { Percentile }\end{array} \\
21.72\end{array}$} & \multirow{2}{*}{$\frac{\text { CI }}{(20.79,22.61)}$} & \multirow{2}{*}{$\begin{array}{c}\begin{array}{c}\mathbf{5 0}^{\text {th }} \\
\text { Percentile }\end{array} \\
21.53\end{array}$} & \multirow{2}{*}{$\frac{\text { CI }}{(21.08,22.49)}$} \\
\hline SE Harrison $\mathrm{W}$ & EB & & & & \\
\hline of $23^{\text {rd }}$ & WB & 24.56 & $(23.91,25.09)$ & 24.93 & $(24.55,25.57)$ \\
\hline \multirow{2}{*}{$\begin{array}{l}\text { SE Harrison W } \\
\text { of } 26^{\text {th }}\end{array}$} & EB & 21.79 & $(21.05,22.46)$ & 21.85 & $(21.26,22.26)$ \\
\hline & WB & 22.68 & $(21.96,23.08)$ & 22.36 & $(22.10,22.63)$ \\
\hline \multirow{2}{*}{$\begin{array}{l}\text { SE Harrison E } \\
\text { of } 27^{\text {th }}\end{array}$} & EB & 23.10 & $(22.10,24.07)$ & 23.50 & $(22.90,23.78)$ \\
\hline & WB & 22.44 & $(22.17,23.07)^{*}$ & 24.02 & $(23.80,24.33)^{*}$ \\
\hline \multirow{2}{*}{$\begin{array}{l}\text { SE Harrison W } \\
\text { of } 30^{\text {th }}\end{array}$} & EB & 22.90 & $(22.53,23.38)$ & 23.27 & $(23.08,23.57)$ \\
\hline & WB & 22.76 & $(22.49,23.21)$ & 23.24 & $(22.99,23.46)$ \\
\hline \multirow{2}{*}{$\begin{array}{l}\text { SE Lincoln E of } \\
48^{\text {th }}\end{array}$} & EB & 22.50 & $(21.93,23.43)$ & 22.30 & $(22.10,22.50)$ \\
\hline & WB & 21.88 & $(21.21,22.66)$ & 22.71 & $(22.57,22.90)$ \\
\hline $\begin{array}{l}\text { SE Hawthorne E } \\
\text { of } 44^{\text {th }}\end{array}$ & WB & 24.84 & $(21.98,28.45)$ & 28.06 & $(27.93,28.16)$ \\
\hline
\end{tabular}

Note: $\mathrm{CI}=$ confidence interval.

* Non-overlapping confidence intervals.

Table 2.4 gives the results for the $85^{\text {th }}$ percentile speed confidence intervals. As with those of the $50^{\text {th }}$ percentile speeds, the confidence intervals for the two vehicle configurations here correspond well with each other, reinforcing the previous findings of this analysis. The SE Hawthorne east of $44^{\text {th }}$ dataset displays the greatest amount of discrepancy between the two vehicle configurations for the $85^{\text {th }}$ percentile speed confidence intervals while those of the westbound SE Harrison west of $30^{\text {th }}$ dataset are nearly identical. The empirical distributions and $85^{\text {th }}$ percentile speeds for these datasets are plotted in Figure 2.8. Notice the high percentage of observations in excess of the posted speed limit for both scenarios (i) and (ii) at the SE Hawthorne location (50.0\% and $68.88 \%$, respectively) compared to the westbound SE Harrison west of $30^{\text {th }}$ location of $19.0 \%$ for scenario (i) and $19.8 \%$ for scenario (ii). 
Table 2.4 $85^{\text {th }}$ Percentile Speeds and 95\% Confidence Intervals (in mph)

\begin{tabular}{|c|c|c|c|c|c|}
\hline \multirow{2}{*}{\multicolumn{2}{|c|}{ Location }} & \multicolumn{2}{|c|}{ Following Class 1} & \multicolumn{2}{|c|}{ Following Class2 } \\
\hline & & \multirow{2}{*}{$\begin{array}{c}\begin{array}{c}\mathbf{8 5}^{\text {th }} \\
\text { Percentile }\end{array} \\
27.25 \\
\end{array}$} & \multirow{2}{*}{$\frac{\text { CI }}{(26.05,28.72)}$} & \multirow{2}{*}{$\begin{array}{c}\mathbf{8 5}^{\text {th }} \\
\text { Percentile }\end{array}$} & \multirow{2}{*}{$\frac{\text { CI }}{(25.25,27.94)}$} \\
\hline SE Harrison $\mathrm{W}$ & EB & & & & \\
\hline of 2 & WB & 29.03 & $(28.48,29.41)$ & 29.07 & $(28.62,29.82)$ \\
\hline \multirow{2}{*}{$\begin{array}{l}\text { SE Harrison W } \\
\text { of } 26^{\text {th }}\end{array}$} & EB & 25.98 & $(25.32,26.68)$ & 25.60 & $(25.07,26.09)$ \\
\hline & WB & 26.39 & $(25.99,27.10)$ & 26.13 & $(25.54,26.49)$ \\
\hline \multirow{2}{*}{$\begin{array}{l}\text { SE Harrison E } \\
\text { of } 27^{\text {th }}\end{array}$} & EB & 27.44 & $(26.60,28.14)$ & 27.43 & $(27.00,28.07)$ \\
\hline & WB & 26.41 & $(25.95,27.94)$ & 27.27 & $(26.88,27.74)$ \\
\hline \multirow{2}{*}{$\begin{array}{l}\text { SE Harrison W } \\
\text { of } 30^{\text {th }}\end{array}$} & EB & 26.00 & $(25.59,26.50)$ & 26.26 & $(26.03,26.63)$ \\
\hline & WB & 26.07 & $(25.58,26.43)$ & 26.04 & $(25.78,26.44)$ \\
\hline \multirow{2}{*}{$\begin{array}{l}\text { SE Lincoln E } \\
\text { of } 48^{\text {th }}\end{array}$} & EB & 26.93 & $(26.28,27.57)$ & 26.27 & $(26.11,26.50)$ \\
\hline & WB & 26.24 & $(25.36,27.15)$ & 26.46 & $(26.29,26.61)$ \\
\hline $\begin{array}{l}\text { SE Hawthorne } \\
\text { E of } 44^{\text {th }}\end{array}$ & WB & 30.60 & $(29.34,35.50)$ & 32.69 & $(32.53,32.82)$ \\
\hline $\begin{array}{l}\text { SE Hawthorne E } \\
\text { of } 44^{\text {th }}\end{array}$ & WB & 24.84 & $(21.98,28.45)$ & 28.06 & $(27.93,28.16)$ \\
\hline
\end{tabular}

Note: $\mathrm{CI}=$ confidence interval.
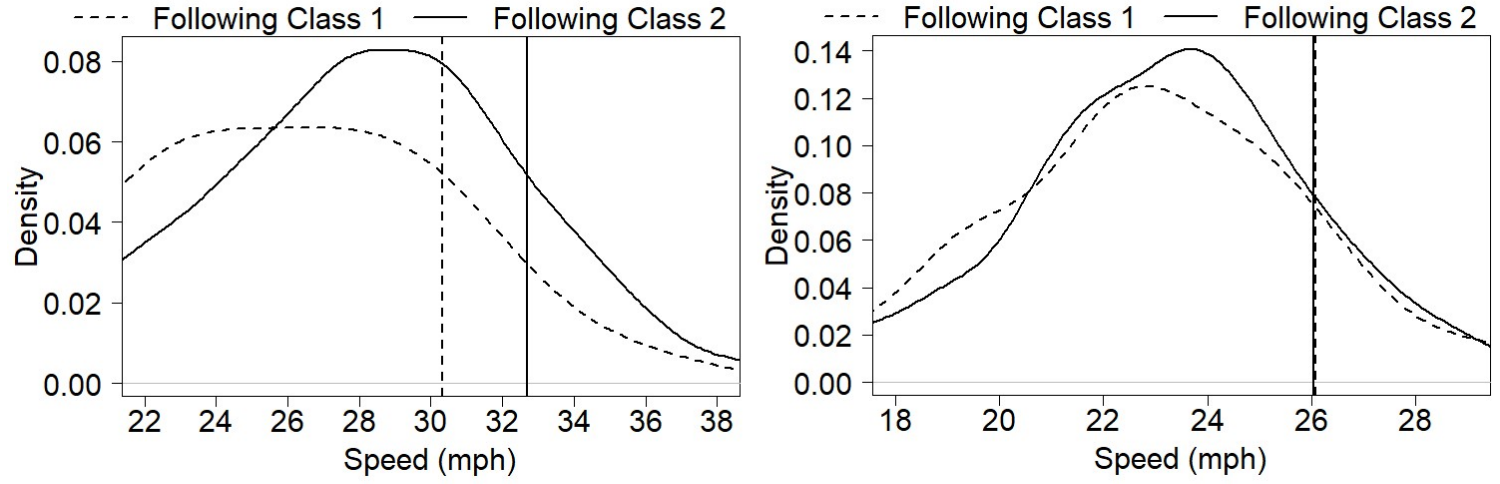

Figure 2.8 Empirical distributions with the $85^{\text {th }}$ percentile speeds for westbound SE Hawthorne east of $44^{\text {th }}$ (left) and westbound SE Harrison west of $30^{\text {th }}$ (right).

\subsubsection{Peak-Hour Period}

To address concerns that changes in passenger car speeds due to bicycles may only occur during peak traffic hours when the volume is highest, a separate analysis was 
performed. The traffic volume distribution by the time of day indicated the morning peak hours to be 7:30 am to 9:30 am and the evening peak hours to be 4:30 pm to $6: 30 \mathrm{pm}$.

Due to an insufficient number of data points, the SE Hawthorne east of $44^{\text {th }}$ location was not evaluated for peak hours.

The speed-gap time analysis was performed again for peak hours. The resulting range of linear correlation coefficients was similar to that of the 24-hour period traffic with low and insignificant coefficients of correlation. This outcome seems to verify the absence of a relationship between gap time and vehicle speed in the data presented here.

The $t$-tests between mean speeds for peak hour traffic (Table 2.5) revealed only one dataset, westbound SE Harrison west of $30^{\text {th }}$, that rejected the null hypothesis with a statistically significant result $(p=0.034)$. The difference in mean speeds was calculated to be less than one mile per hour. Interestingly, this dataset was also one of the five in which the null hypothesis was rejected when the 24-hour period was analyzed.

Table 2.5 $t$-Test between Mean Speeds for Peak Hours

\begin{tabular}{|l|c|c|c|c|c|c|c|}
\hline \multirow{2}{*}{\begin{tabular}{l} 
Location \\
\cline { 3 - 8 }
\end{tabular}} & \multicolumn{2}{|c|}{$\begin{array}{c}\text { Following } \\
\text { Class 1 }\end{array}$} & $\begin{array}{c}\text { Following } \\
\text { Class 2 }\end{array}$ & $\begin{array}{c}\text { Following } \\
\text { Class 1 }\end{array}$ & $\begin{array}{c}\text { Following } \\
\text { Class 2 }\end{array}$ & $\begin{array}{c}\boldsymbol{t} \text { - } \\
\text { Statistic }\end{array}$ & $\begin{array}{c}\boldsymbol{p} \text { - } \\
\text { Value }\end{array}$ \\
\hline $\begin{array}{l}\text { Harrison W } \\
\text { of 23rd }\end{array}$ & EB & 48 & 28 & 20.69 & 21.36 & -0.64 & 0.525 \\
\cline { 2 - 8 } $\begin{array}{l}\text { Harrison W } \\
\text { of 26th }\end{array}$ & WB & 179 & 73 & 24.46 & 25.01 & -1.01 & 0.316 \\
\cline { 2 - 8 } & EB & 91 & 118 & 21.20 & 21.45 & -0.41 & 0.686 \\
\hline $\begin{array}{l}\text { Harrison E of } \\
\text { 27th }\end{array}$ & EB & 131 & 195 & 22.06 & 22.17 & -0.21 & 0.835 \\
\cline { 2 - 8 } & WB & 92 & 199 & 23.16 & 23.56 & -0.83 & 0.407 \\
\hline $\begin{array}{l}\text { Harrison W } \\
\text { of 30th }\end{array}$ & EB & 203 & 262 & 22.15 & 22.88 & -1.95 & 0.051 \\
\cline { 2 - 9 } & WB & 169 & 229 & 22.42 & 23.21 & -2.13 & $0.034 *$ \\
\hline $\begin{array}{l}\text { Lincoln E of } \\
\text { 48th }\end{array}$ & EB & 102 & 897 & 21.90 & 22.10 & -0.40 & 0.687 \\
\cline { 2 - 8 } & WB & 77 & 937 & 21.49 & 22.18 & -1.40 & 0.164 \\
\hline
\end{tabular}


The evaluation of the $95 \%$ confidence intervals for the $50^{\text {th }}$ and $85^{\text {th }}$ percentile speeds continued to be consistent with the previous analyses. No non-overlapping intervals were observed for either percentile. Table 2.6 and Table 2.7 display the confidence intervals of $50^{\text {th }}$ and $85^{\text {th }}$ percentile speeds, respectively. From these tables it can be seen that the confidence intervals for the westbound SE Harrison west of $30^{\text {th }}$ dataset are quite similar when comparing the two vehicle configurations. The $50^{\text {th }}$ percentile confidence intervals in mph were $(22.09,23.55)$ and $(22.96,23.93)$; the $85^{\text {th }}$ percentile confidence intervals were $(25.30,26.70)$ and $(25.51,27.13)$. The largest discrepancy between confidence intervals for the $50^{\text {th }}$ percentile speeds was found with the eastbound SE Harrison west of $23^{\text {rd }}$ dataset. For the $85^{\text {th }}$ percentile speeds, the westbound SE Lincoln east of $48^{\text {th }}$ dataset produced the biggest difference. In both cases, the confidence intervals had a high degree of accordance and differences in bounds were less than two miles per hour $(3.2 \mathrm{~km} / \mathrm{h})$.

Table 2.6 50 ${ }^{\text {th }}$ Percentile Speeds and 95\% Confidence Intervals for Peak Hours (in mph)

\begin{tabular}{|c|c|c|c|c|c|}
\hline \multirow{2}{*}{\multicolumn{2}{|c|}{ Location }} & \multicolumn{2}{|c|}{ Following Class 1} & \multicolumn{2}{|c|}{ Following Class2 } \\
\hline & & \multirow{2}{*}{\begin{tabular}{|c|}
$\begin{array}{c}\mathbf{5 0}^{\text {th }} \\
\text { Percentile }\end{array}$ \\
20.63 \\
\end{tabular}} & \multirow{2}{*}{$\frac{\text { CI }}{(19.93,22.16)}$} & \multirow{2}{*}{$\begin{array}{c}\begin{array}{c}\mathbf{5 0}^{\text {th }} \\
\text { Percentile }\end{array} \\
20.59\end{array}$} & \multirow{2}{*}{$\frac{\text { CI }}{(19.73,24.10)}$} \\
\hline SE Harrisc & EB & & & & \\
\hline & WB & 24.40 & $(23.56,25.36)$ & 25.00 & $(24.26,26.25)$ \\
\hline \multirow{2}{*}{$\begin{array}{l}\text { SE Harrison W } \\
\text { of } 26^{\text {th }}\end{array}$} & EB & 22.05 & $(20.28,22.77)$ & 22.10 & $(20.98,22.76)$ \\
\hline & WB & 22.96 & $(21.63,23.92)$ & 23.17 & $(22.16,23.72)$ \\
\hline \multirow{2}{*}{$\begin{array}{l}\text { SE Harrison E } \\
\text { of } 27^{\text {th }}\end{array}$} & EB & 23 & $(22.12,24.40)$ & 23 & $(22.93,24.23)$ \\
\hline & WB & 23.41 & $(22.05,24.27)$ & 23.84 & $(23.40,24.21)$ \\
\hline \multirow{2}{*}{$\begin{array}{l}\text { SE Harrison W } \\
\text { of } 30^{\text {th }}\end{array}$} & EB & 22.78 & $(22.18,23.46)$ & 23.31 & $(22.67,23.78)$ \\
\hline & WB & 22.62 & $(22.09,23.55)$ & 23.47 & $(22.96,23.93)$ \\
\hline \multirow{2}{*}{$\begin{array}{l}\text { SE Lincoln E } \\
\text { of } 48^{\text {th }}\end{array}$} & EB & 22.47 & $(21.61,23.67)$ & 22.37 & $(22.10,22.71)$ \\
\hline & WB & 21.11 & $(20.04,22.63)$ & 22.35 & $(22.01,22.69)$ \\
\hline
\end{tabular}


Table $2.785^{\text {th }}$ Percentile Speeds and 95\% Confidence Intervals for Peak Hours (in mph)

\begin{tabular}{|c|c|c|c|c|c|}
\hline \multirow{2}{*}{\multicolumn{2}{|c|}{ Location }} & \multicolumn{2}{|c|}{ Following Class 1} & \multicolumn{2}{|c|}{ Following Class2 } \\
\hline & & \multirow{2}{*}{\begin{tabular}{l}
\multicolumn{1}{c}{$\mathbf{8 5}^{\text {th }}$} \\
Percentile \\
25.58
\end{tabular}} & \multirow{2}{*}{$\frac{\text { CI }}{(23.31,27.89)}$} & \multirow{2}{*}{\begin{tabular}{l}
\multicolumn{1}{c}{$\mathbf{8 5}^{\text {th }}$} \\
Percentile \\
26.47
\end{tabular}} & \multirow{2}{*}{$\frac{\text { CI }}{(24.29,28.30)}$} \\
\hline SE Harrison $\mathrm{W}$ & EB & & & & \\
\hline & WB & 29.21 & $(28.50,30.00)$ & 28.88 & $(28.18,30.23)$ \\
\hline \multirow{2}{*}{$\begin{array}{l}\text { SE Harrison W } \\
\text { of } 26^{\text {th }}\end{array}$} & EB & 25.64 & $(24.45,26.83)$ & 25.68 & $(25.01,26.92)$ \\
\hline & WB & 26.88 & $(25.97,28.09)$ & 26.87 & $(26.32,27.26)$ \\
\hline \multirow{2}{*}{$\begin{array}{l}\text { SE Harrison E } \\
\text { of } 27^{\text {th }}\end{array}$} & EB & 26.82 & $(26.17,28.98)$ & 27.91 & $(26.74,28.74)$ \\
\hline & WB & 27.31 & $(26.30,28.32)$ & 26.54 & $(26.07,27.39)$ \\
\hline \multirow{2}{*}{$\begin{array}{l}\text { SE Harrison W } \\
\text { of } 30^{\text {th }}\end{array}$} & EB & 25.86 & $(25.19,26.52)$ & 26.30 & $(25.92,27.09)$ \\
\hline & WB & 25.97 & $(25.30,26.70)$ & 26.25 & $(25.51,27.13)$ \\
\hline \multirow{2}{*}{$\begin{array}{l}\text { SE Lincoln E } \\
\text { of } 48^{\text {th }}\end{array}$} & EB & 26.53 & $(25.61,27.93)$ & 26.32 & $(26.00,26.89)$ \\
\hline & WB & 25.95 & $(24.45,27.62)$ & 26.32 & $(25.87,26.67)$ \\
\hline
\end{tabular}

\subsection{Discussion}

When considered as a whole, the results of the $t$-tests and $95 \%$ confidence intervals indicate that bicycles are not likely to lead to reduced passenger car travel speed, despite their differences in performance capabilities and the absence of bicycle lanes. In most cases, the differences in speed were not significant from a practical standpoint. However, this study did find a few instances where differences were seen.

For the analysis including all 24 hours, the most apparent exception occurred with the SE Harrison east of $27^{\text {th }}$ westbound dataset where the mean speeds between the two class two vehicle configurations were highly statistically different, that is, the null hypothesis was rejected, with $p=0.000$, and the $95 \%$ confidence intervals for the $50^{\text {th }}$ percentile speeds were non-overlapping. At this location, traffic travels downhill at a grade greater than $4 \%$ in the westbound direction which might encourage bicycles to 
travel at a higher speed, thereby lowering the desire of a motor vehicle to overtake immediately and instead be satisfied traveling temporarily at a slightly reduced speed. Additionally, it is possible that the presence of the all-way stop at $26^{\text {th }}$ influences passing behavior, with motor vehicles preferring to delay overtaking a bicycle until after they clear the traffic control device. While the results of the analysis did find a statistically significant difference in speed at this location, the difference is relatively small—a $5.3 \%$ and $6.6 \%$ reduction, or $1.27 \mathrm{mph}(2.04 \mathrm{~km} / \mathrm{h})$ and $1.58 \mathrm{mph}(2.54 \mathrm{~km} / \mathrm{h})$-for mean and 50th percentile speeds, respectively. Moreover, the $95 \%$ confidence intervals for the $85^{\text {th }}$ percentile speeds do not illustrate a distinguishable difference. The peak hour analysis provided additional evidence that bicycles do not cause lower passenger car speeds at this location, as confirmed by the t-test results, which failed to reject the null hypothesis $(p=0.407)$.

The null hypothesis was rejected for both the eastbound and westbound directions at SE Harrison west of $30^{\text {th }}$ and the westbound direction at SE Lincoln east of $48^{\text {th }}$, showing statistically significant differences when the $t$-test was applied in the 24-hour analysis ( $p=0.0026, p=0.047$, and $p=0.027$, respectively). Nevertheless, the $95 \%$ confidence intervals calculated for the $50^{\text {th }}$ and $85^{\text {th }}$ percentile speeds at these locations did not indicate a relevant difference in speed. The difference in mean speed at these sites was limited to roughly $0.5 \mathrm{mph}(0.8 \mathrm{~km} / \mathrm{h})$. For peak hours, only the westbound SE Harrison west of $30^{\text {th }}$ dataset produced a rejection of the null hypothesis, displaying a statistically significant difference in mean speeds equating to less than one mile per hour $(1.6 \mathrm{~km} / \mathrm{h})$. The all-way stop at $30^{\text {th }}$ and the double yellow line just west of it may 
discourage the passing behavior of eastbound traffic on Harrison in a similar manner to that described above, leading to the nominal speed difference when all hours are considered. Westbound traffic at this location may also be influenced by the double yellow line, inhibiting passing behavior. The minor difference observed at the SE Lincoln location could be attributed to the higher occupancy rate of street parking, effectively decreasing the space available for motor vehicles to pass bicycles safely. It bears reiterating that, apart from one dataset, we fail to reject the null hypothesis as no significant differences in speeds were found for peak hour traffic.

The $t$-test for the SE Hawthorne east of $44^{\text {th }}$ dataset did reject the null hypothesis $(p=0.015)$, and a difference in mean speeds of approximately $3 \mathrm{mph}(4.8 \mathrm{~km} / \mathrm{h})$ was observed between scenarios (i) and (ii). Similar differences were seen for the $50^{\text {th }}$ and $85^{\text {th }}$ percentile speeds at this location, although the confidence intervals were found to overlap. SE Hawthorne carries a district collector classification whereas all other locations are lower classed local streets. Traffic volume along SE Hawthorne is well in excess of even the most generous design guidelines for shared roads and motor vehicle operating speeds are above the recommended target of 20-25 mph $(32-40 \mathrm{~km} / \mathrm{h})$. Combined with the high occupancy of street parking which removes effective width for passing, these characteristics likely contributed to the small differences observed between scenarios (i) and (ii).

On Harrison and Lincoln, the road width, low to moderate parking occupancy, and lack of a center lane delineator likely all contribute to the ability of passenger cars to maintain their speed. The low traffic volume provides adequate opportunity for passing, 
and the speed limit of $25 \mathrm{mph}(40 \mathrm{~km} / \mathrm{h})$ helps to mitigate the amount a motor vehicle needs to slow down when approaching or overtaking a bicycle. Although minor differences in speeds were found at a few locations where sharrows were present, the magnitude of the difference was smaller than at the SE Hawthorne location where sharrows are absent. It is likely that the higher speed difference and higher levels of motorized traffic (see Table 2.1) make SE Hawthorne a more stressful roadway for cyclists [21] and this in turn contributes to explain the lower bicycle volumes on SE Hawthorne.

Finally, although concerns have been voiced that increased bicycle volume on shared roads could lead to significantly reduced motor vehicle speeds, the results of this study failed to show a positive correlation between the magnitude of difference in mean speeds between the two scenarios and the percent of traffic comprised of class one vehicles.

\subsection{Conclusions}

Speed distributions, the mean, and the $50^{\text {th }}$ and $85^{\text {th }}$ percentile speeds for two scenarios were examined: (i) a passenger car that was preceded by a bicycle and (ii) a passenger car that was preceded by another passenger car. Peak hour traffic and 24-hour traffic speeds were analyzed.

This paper has presented evidence from urban roads without bicycle lanes in Portland, indicating that bicycles do not reduce passenger car speeds by more than one mile per hour $(1.6 \mathrm{~km} / \mathrm{h})$ at most locations. This finding was reinforced by the results of 
the $95 \%$ confidence intervals for the $50^{\text {th }}$ and $85^{\text {th }}$ percentile speeds and the separate analysis performed for peak hours. While the results of the analysis did find five of the eleven datasets to have statistically significant differences in mean speed, rejecting the null hypothesis when all hours were analyzed, this result is in part because of many observations since the actual speed differences are trivial in a practical sense. Higher speed differences, on the order of $2-3 \mathrm{mph}(3.2-4.8 \mathrm{~km} / \mathrm{h})$, were found only at locations that do not meet the guidelines for a shared road.

Because of the limited variability in roadway characteristics of the sites analyzed, the conclusions drawn may not be directly transferable to all roadways without bicycle lanes. Nonetheless, the results presented here deliver encouragement for incorporating shared roads into urban bicycle networks to support an increasing bicycle mode share without negatively affecting travel speed or creating congestion, provided that cities ensure these shared roads follow recommended bikeway guidelines.

Future work should include roadways with a wider variety of vehicle classifications and roadway characteristics such as ADT, grade, and pavement markings to evaluate the consistency of the findings presented here and to further investigate the effects the roadway environment and traffic composition may have on vehicle-bicycle interactions and resulting travel speed.

\section{Acknowledgments}

The authors acknowledge Tom Jensen and Scott Batson of PBOT for providing the data used in this analysis. 
Author contributions

The authors confirm contribution to the paper as follows: study conception and design: MAF, AU; data collection: PBOT; analysis and interpretation of results: JSS, MAF, AU; draft manuscript preparation: JSS, MAF, AU. All authors reviewed the results and approved the final version of the manuscript. 


\subsection{References}

1. United States Census Bureau. American FactFinder - Commuting Characteristics by Sex, 2017 American Community Survey 1-Year Estimates [Internet].

Washington, D.C.: U.S. Census Bureau; 2017 [cited 2019 Jul 25]. Available from: https://factfinder.census.gov/faces/tableservices/jsf/pages/productview.xhtml?pid =ACS_17_1YR_S0801\&prodType=table.

2. Bicycles in Portland Fact Sheet [Internet]. Portland, OR: City of Portland; 2019 [cited 2019 Jul 25]. Available from:

https://www.portlandoregon.gov/transportation/article/407660.

3. Portland Bicycle Plan for 2030 [pdf] [Internet]. Portland, OR: City of Portland; 2010 [cited 2019 Jul 25]. Available from:

https://www.portlandoregon.gov/transportation/article/289122.

4. Andersen T, Bredal F, Weinreich M, Jensen N, Riisgaard-Dam M, Nielsen MK. Collection of Cycle Concepts 2012. $2^{\text {nd }}$ ed. Denmark: Cycling Embassy of Denmark; 2012. Planning the Cycling Infrastructure; p. 53-4.

5. Andersen M. Real Talk: Bikes Don't Reduce Congestion without Bike Lanes [Internet]. Boulder, CO: PeopleForBikes; 2015 [cited 2019 Jul 25]. Available 
from: https://peopleforbikes.org/blog/real-talk-bikes-cant-reduce-congestionwithout-bike-lanes/.

6. Gosse C, Clarens A. Quantifying the Total Cost of Infrastructure to Enable Environmentally Preferable Decisions: The Case of Urban Roadway Design. Environmental Research Letters. 2013 Mar;8(1):1-9.

7. Turner S, Sandt L, Toole J, Benz R, Patten R. FHWA University Course on Bicycle and Pedestrian Transportation: Student Workbook. McLean, VA: FHWA Turner-Fairbank Highway Research Center; 2006. Report No.: FHWA-HRT-05133. p. 231-2.

8. Schultheiss B, Goodman D, Blackburn L, Wood A, Reed D, Elbech M. Bikeway Selection Guide. Washington DC: Federal Highway Administration Office of Safety; 2019 Feb 1. Report No.: FHWA-SA-18-077. p. 23.

9. National Association of City Transportation Officials. Urban Bikeway Design Guide. 2nd ed. Washington, D.C: Island Press; 2014 Mar 24.

10. Jia S, Peng H, Guo J, Chen H. Quantitative Analysis of Impact of Bicycles on Vehicles in Urban Mixed Traffic. Journal of Transportation Systems Engineering and Information Technology. 2008 Apr 1;8(2):58-63. 
11. Pein WE, Hunter WW, Stewart JR. Evaluation of the Shared-Use Arrow. Tallahassee, FL: Florida Department of Transportation; 1999 Dec.

12. Brady J, Loskorn J, Mills A, Duthie J, Machemehl R, Beaudet A, Barrea N, Wilkes N, Fialkoff J. Effects of Shared Lane Markings on Bicyclist and Motorist Behavior along Multi-Lane Facilities. Austin, TX: Center for Transportation Research, U. of Texas at Austin; 2010.

13. LaMondia J, Duthie J. Analysis of Factors Influencing Bicycle-Vehicle Interactions on Urban Roadways by Ordered Probit Regression. Transportation Research Record. 2012;2314(1):81-8.

14. Oketch, T. C. Modeled Performance Characteristics of Heterogeneous Traffic Streams Containing Non-Motorized Vehicles [CD-ROM]. Presented at 82nd Annual Meeting of the Transportation Research Board, Washington, D.C., 2003.

15. Federal Highway Administration. Traffic Monitoring Guide. Washington, D.C.: Federal Highway Administration, U.S. Department of Transportation; 2016. p. C1. 
16. Nordback K, Kothuri S, Phillips T, Gorecki C, Figliozzi M. Accuracy of Bicycle Counting with Pneumatic Tubes in Oregon. Transportation Research Record. 2016;2593(1):8-17.

17. Google Maps. Google Street View, 2934 SE Harrison St. [Image on internet]. Google; 2017 [cited 2019 Jul 25]. Available from: https://goo.gl/maps/pVE3AsTUu1ZUhDoh6.

18. Google Maps. Google Street View, 4749 SE Lincoln St. [Image on internet]. Google; 2016 [cited 2019 Jul 25]. Available from: https://goo.gl/maps/NxH3nCjBT3C4uwEG7.

19. Google Maps. Google Street View, 4380 SE Hawthorne Blvd [Image on internet]. Google; 2018 [cited 2019 Jul 25]. Available from: https://goo.gl/maps/UeFUXGzze7DyuGeG7.

20. Hallenbeck M, Rice M, Smith BL, Cornell-Martinez C, Wilkinson J. Vehicle Volume Distributions by Classification; 1997 Jul. Report No.: FHWA-PL-97-025. p. 29. 
21. Blanc B, Figliozzi M. Modeling the Impacts of Facility Type, Trip Characteristics, and Trip Stressors on Cyclists' Comfort Levels Utilizing Crowdsourced Data. Transportation Research Record. 2016;2587(1):100-8. 
3 An Empirical Study of the Impacts of Bicycles on Passenger Car Speeds on Urban Roads without Bicycle Lanes

Jaclyn S. Schaefer, Miguel A. Figliozzi, and Avinash Unnikrishnan

This paper has been submitted for publication to the Transportation Research Record. 


\begin{abstract}
Increasing the bicycle mode share has been suggested as part of a solution to reduce the burden of additional traffic that continued urbanization and population growth are creating. As strategies to promote bicycling are implemented, concerns have been raised by researchers at the University of Virginia and some road users that an increase in the bicycle mode share will lead to travel time delays via reduced vehicle speeds and result in more traffic congestion unless bicycle lanes are provided. This research investigates the effects bicycles may have on motorized vehicle speeds on lower speed and volume urban roads without bicycle lanes. A detailed comparative analysis of passenger car speeds was performed using two vehicle scenarios: (i) a passenger car that was preceded by a bicycle, and (ii) a passenger car that was preceded by another passenger car. The mean and $85^{\text {th }}$ percentile speeds of scenarios (i) and (ii) were analyzed using $t$-tests. Relationships between speed and gap times with oncoming (opposite direction) traffic were also investigated. The results indicate that at most sites (92\%), bicycles do not reduce passenger car mean speeds by more than one mile per hour. Significantly reduced speeds were observed less frequently when adequate gaps in oncoming traffic for overtaking were present, and at sites with a lower functional classification or those where sharrows are present.
\end{abstract}




\subsection{Introduction}

Over $76 \%$ of workers in the U.S. commute by single-occupancy vehicles [1]. Combined with rising populations and increasing urbanization, traffic congestion and travel time delay are perpetually growing problems in many cities. In response, solutions, such as encouraging cycling, are being sought to help reduce the use of single-occupancy vehicles. Cycling is typically regarded as a healthy and environmentally friendly form of transportation. Proponents tout its potential role in reducing greenhouse gas emissions, in addition to mitigating traffic congestion. As such, initiatives to promote cycling for transportation have been pushed by cities and cycling advocates in recent years to help achieve goals of increasing the bicycle mode share.

Across the U.S., bicycling is a highly underutilized mode of transportation, with less than $1 \%$ of the commute mode share, on average [1]. Even in cities such as Portland, Oregon, where $6.3 \%$ of workers commuted by bicycle in 2017 [2], there is a huge opportunity to increase bicycle ridership. Portland is renowned throughout the U.S. for its cycling culture. The City continues to push forward projects to build a safe and wellconnected network of bicycle facilities in hopes of reaching a $25 \%$ bicycle mode share by the year 2030 [3]. As of 2019, there were 385 miles of bikeways in Portland. Shared roads are an integral component of this network, constituting $27 \%$ of the bikeway miles $[2]$.

While it is generally preferred to segregate motor vehicles and bicycles by providing designated lanes, creating a separate infrastructure on every road is infeasible and often unnecessary. For example, roadways with speed limits less than approximately 
$35 \mathrm{~km} / \mathrm{h}(22 \mathrm{mph})$ and ADT less than approximately 2,500 vehicles are candidates for mixed-traffic conditions according to Danish bikeway design guidance [4].

Implementing shared-use facilities can be an economical solution to a growing need for bikeways. The differing performance capabilities of motor vehicles and bicycles, and the vulnerable nature of cyclists, creates challenges regarding safety and mobility when roadway space is shared, however. There is a growing body of research related to vehicle-bicycle interactions. Many of these studies focus on lateral positioning and passing behavior, but there has been little empirical research concerning the effects bicycles might have on motor vehicle speed or travel time. As cities like Portland experience a mode shift toward bicycling, it is necessary to study the impacts these changes may have on the existing transportation network and motorized vehicles.

One particular concern of motorists is that unless bicycle lanes are implemented, bicycles will slow down motor vehicles and potentially increase congestion and vehicle emissions - two consequences of urbanization that a larger bicycle mode share seeks to mitigate. Research involving a simulated traffic study has prompted discussions that warn of exacerbated traffic congestion and travel time delay as the bicycle mode share increases if bicycle lanes are not installed [5-6]. Empirical evidence of this claim is lacking, however. Previous work by Schaefer et al. [7] has suggested that the presence of bicycles on low volume, low speed urban roads without bicycle lanes does not meaningfully reduce passenger car speeds at most sites that meet bikeway design guidelines for mixed-traffic roadways. However, this study [7] was limited to six 25-mph $(40 \mathrm{~km} / \mathrm{h})$, rather homogeneous sites. Statistically significant differences in mean speed 
of more than one mile per hour $(1.6 \mathrm{~km} / \mathrm{hr})$ were only found at one site where speeds and traffic volumes exceeded those in the bikeway guidance for shared roads, and at another site with a significant grade. These results provided the motivation for a more extensive study utilizing a more diverse set of data collection locations.

This study significantly extends the previous study [7] by incorporating a large number of study sites (40 locations and 75 directional speed datasets) and presenting more diversity with respect to traffic volumes, posted speed limit (PSL), roadway markings, functional classification, and grade. In addition, this study considers the potential effects of oncoming (opposite direction) traffic on motorists' opportunities to overtake a cyclist. The results of this research are more widely applicable and may help guide decisions regarding the implementation of shared bikeways.

\subsection{Literature Review}

Shared roads or roads without bicycle lanes may contribute to a substantial portion of an urban bikeway network in some cities. World leaders in bicycling culture, the Danish have developed guidelines for when shared or mixed-traffic roads may be appropriate. The Cycling Embassy of Denmark suggests motor vehicle speeds should be less than $35 \mathrm{~km} / \mathrm{h}(22 \mathrm{mph})$, and traffic volumes should be low (less than approximately 2,500 ADT) for mixed-traffic roadways [4]. Similar guidelines are set forth by the FHWA, indicating shared facilities may be acceptable for urban roads with speeds less than $25 \mathrm{mph}(40 \mathrm{~km} / \mathrm{hr})$ and volumes less than 3,000 ADT [8]. The National Association of City Transportation Officials (NACTO) advises a somewhat lower maximum motor 
vehicle volume of only 1,500 vehicles per day [9] but agrees with the Danish and FHWA range of maximum speeds for shared roads.

As cities continue to encourage bicycling as a primary mode of transportation, the need for additional research regarding the impact of bicycles on traffic operations is highlighted, especially in mixed-traffic contexts. In particular, there appear to be relatively few studies in the traffic literature on the impact of vehicle-bicycle interactions on travel speed or delay.

Most existent studies on vehicle-bicycle interactions have focused on rider position in the roadway, lateral clearance when overtaking, or how these factors may influence safety. For example, research has been conducted on the effects of a cyclist's helmet usage, clothing, and apparent gender on overtaking proximity [10-11]. Other studies have concluded that the presence of shared lane markings (also known as sharrows) encourages cyclists to ride in a more central lane position, which may improve their visibility [12-13].

Lane position also affects the type of interference bicycles may impose on motor vehicles. A cyclist riding to the right of a wide lane may impose little friction interference to a passing motor vehicle, which may not need to reduce travel speed significantly if there is room to overtake safely. When a cyclist occupies a more substantial portion of the lane, at the center or left, block interference is more likely to occur, forcing the motorist to reduce their speed and wait for an opportunity to overtake [14].

When block interference occurs on a two-lane road, and a motorist desires to overtake, they must find an appropriate gap in oncoming (opposite direction) traffic. The 
decision to initiate a passing maneuver is guided by the required passing sight distance (PSD), which is a function of the speeds and lengths of the bicycle and motor vehicle, the headways between the bicycle and the motor vehicle before and after overtaking, a minimum clearance interval with oncoming traffic, and the overtaking motorist's perception-reaction time [15].

The effects of block interference were demonstrated in a study using empirical data from three urban road sections in Beijing, China [14]. Researchers found that as bicycle lane widths decreased or bicycle volumes increased, block interference was more likely to occur due to bicycles spilling into the motor vehicle lane, offering insufficient width for motor vehicles to pass. When no interference occurred, mean motor vehicle speeds ranged from $35.15 \mathrm{~km} / \mathrm{h}$ to $41.56 \mathrm{~km} / \mathrm{h}$ (21.84 $\mathrm{mph}$ to $25.82 \mathrm{mph})$. Mean speeds were reduced by $17-21 \%$ under friction interference conditions. Under block interference, mean speeds were reduced by $29-37 \%$. The lane widths were stated to be $3.7 \mathrm{~m} \mathrm{(12} \mathrm{ft.)}$ but the PSL or the roadway volume was not indicated.

When empirical data is unavailable, simulations have been used to model vehiclebicycle interactions. Oketch [16] designed a model to simulate heterogeneous traffic behavior on a two-lane road with three-meter (10 ft.) lane widths. Model parameters included an average desired speed of $80 \mathrm{~km} / \mathrm{h}(50 \mathrm{mph})$ and a flow of 1,000 vehicles per hour to simulate a typical urban arterial road. Compared to a homogeneous traffic stream of private cars, a simulation including $25 \%$ bicycles and $75 \%$ private cars showed a $36 \%$ decrease in capacity. A reduction in the mean free-flow speed was cited as the cause of the decreased capacity. Note, however, that the model parameter values set for speed and 
traffic volume in this simulation are well outside of the mentioned bicycle design recommendations for mixed-traffic roadways.

Gosse and Clarens [6] also used simulations to quantify the effects of bicycles on travel time for a two-lane urban road. The simulations were based on a motor vehicle speed of $37.4 \mathrm{mph}(60 \mathrm{~km} / \mathrm{h})$ and used different combinations of values for motor vehicle lane widths, grades, and bicycle mode share percentages. The researchers concluded travel time delay costs were incurred when the bicycle mode share reached $10 \%$ as a result of a 'stuck vehicle condition,' whereby shared travel lanes did not offer sufficient width for heavy vehicles to pass safely. A positive $4 \%$ grade magnified the effect of the stuck vehicle condition. Alternatively, when adequate space was provided for larger vehicles to pass, travel time delay costs were reduced with a $10 \%$ bicycle mode share. These simulation studies can be useful, but the parameters used to model the roadway, or driver-cyclist interactions do not capture the full spectrum of real-world situations.

\subsection{Data Collection}

Traffic speed data collected from 2015 through 2019, obtained from the Portland Bureau of Transportation (PBOT), was used to study the effects bicycles on roads without bicycle lanes may have on passenger car speeds. PBOT regularly performs traffic data collection throughout the city using pneumatic tubes configured to measure speed and classify vehicles according to a modified FHWA Scheme F [17]. Under the modified classification scheme, bicycles are considered class one vehicles, and passenger cars are considered class two. Pneumatic tubes are commonly used to perform short-term traffic 
counts. The accuracy of pneumatic tubes to count and record speeds of bicycles was investigated by Nordback et al. [18]. The researchers found that the JAMAR brand tubes performed better than two other brands of classification counters tested and that manually computed bicycle speeds were in agreeance with those reported by the JAMAR model. PBOT has been using these JAMAR brand tube counters for many years and crews are skilled in the set-up and placement of these tubes to collect data for both motorized vehicles and bicycles. The data collection equipment records individual vehicles with an associated timestamp, accurate to the second, and speed in one-mile-per-hour increments. Bidirectional speed data were collected at 40 locations for a minimum of one full day. In some cases, only one direction of traffic was analyzed due to the number of observations required. This resulted in 75 datasets available for analysis.

All sites were located along two-way, two-lane urban roads without bicycle lanes in Portland. Sites were chosen to represent a variety of roadway characteristics. Considerations were made for roadway functional class, centerline marking, ADT, PSL, and grade. Local and urban collector roads were represented (with 39 and 36 datasets, respectively), and class two ADT ranged from fewer than 200 up to approximately 4,700 vehicles per day. Parallel parking was permitted at all locations. Road widths ranged from $34 \mathrm{ft}$. to $40 \mathrm{ft}$. (10 $\mathrm{m}$ to $12 \mathrm{~m})$.

Dashed yellow center lines were present in 12 of the datasets, and double yellow center lines were present in two datasets. The remaining 61 datasets did not have a continuous center lane marking, but double yellow lines were present within approximately $40 \mathrm{ft}$. ( $12 \mathrm{~m}$ ) of traffic control devices. Sharrows (shared lane markings) 
were also present along these streets. These datasets were collected from roadways designated as neighborhood greenways - roads with relatively low motorized traffic volumes and speeds, typically meeting the recommendations for mixed-traffic roads. Traffic calming, such as speed humps and mini traffic circles, are usually present along neighborhood greenways to deter speeding and cut-through traffic. Bicycles often comprise a significantly greater portion of the total traffic than the citywide average on these roads. The mean class one percentage for the 61 neighborhood greenway datasets was $43 \%$, compared to an average of $3 \%$ for the remaining datasets.

Grades were estimated from a ten-foot interval contour map [19] and ranged between $-5 \%$ and $5 \%$. Two of the datasets had a speed limit of $30 \mathrm{mph}(48 \mathrm{~km} / \mathrm{h}), 39$ datasets had a $25-\mathrm{mph}(40 \mathrm{~km} / \mathrm{h})$ speed limit, and 34 datasets had a $20-\mathrm{mph}(32 \mathrm{~km} / \mathrm{h})$ speed limit. Figures $3.1-3.3$ provide representative street views of a neighborhood greenway local road, an urban collector with a dotted yellow centerline, and an urban collector with a double yellow centerline, respectively.

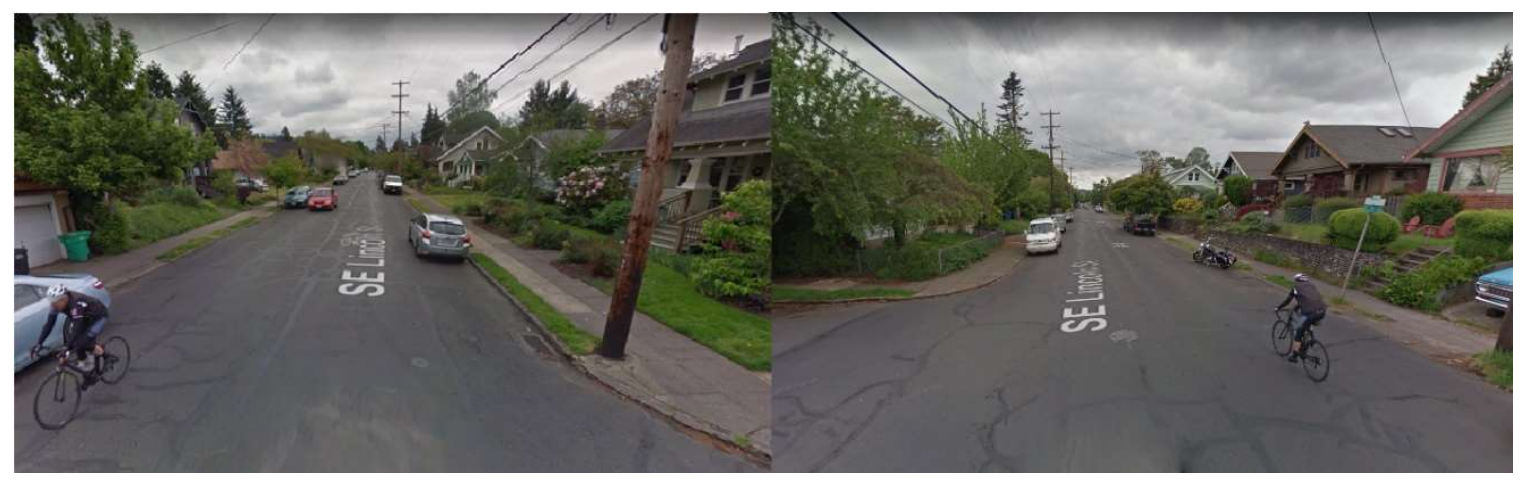

Figure 3.1 Neighborhood greenway local street without a centerline. SE Lincoln east of $48^{\text {th }}$, eastbound (left) and westbound (right) [20]. 


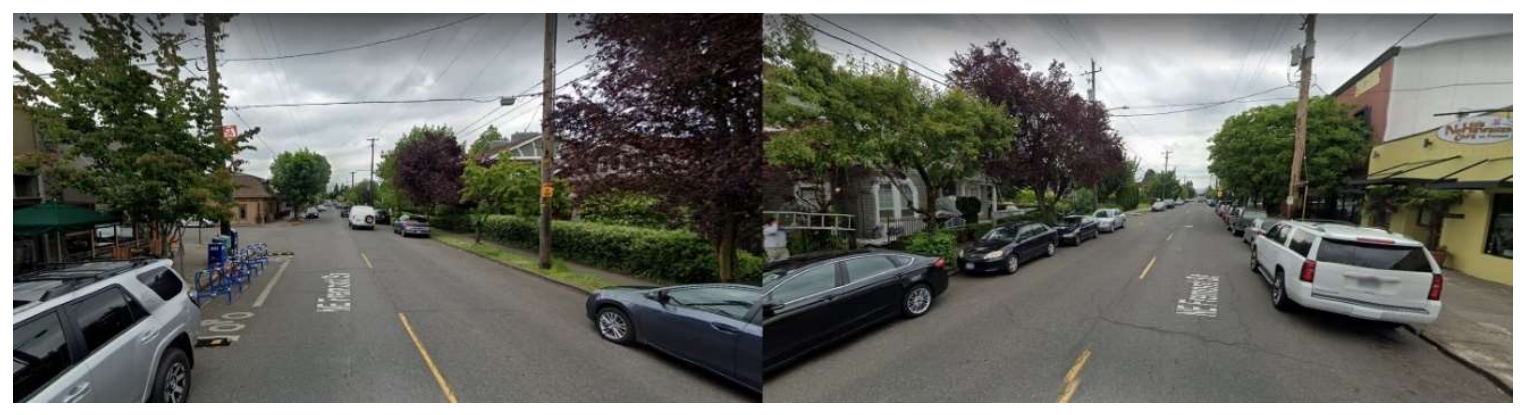

Figure 3.2 Urban collector with dotted yellow centerline. NE Fremont east of $46^{\text {th }}$, eastbound (left) and westbound (right) [21].

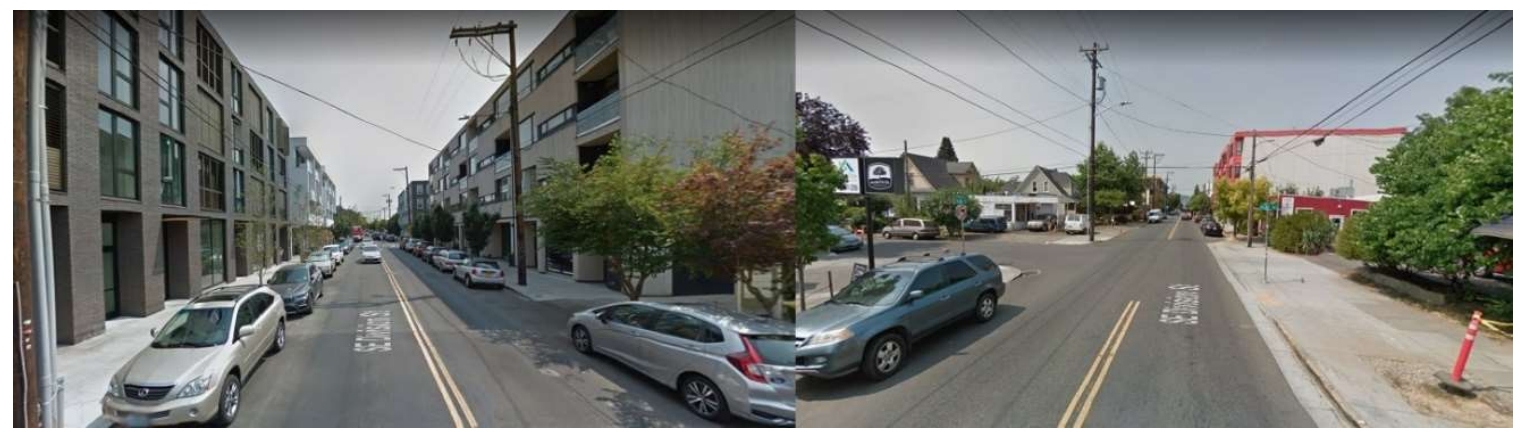

Figure 3.3 Urban collector with double yellow centerline. SE Division east of $33^{\text {rd }}$, eastbound (left) and westbound (right) [22].

Pneumatic tubes for data collection count axels and cannot directly differentiate between motorized class one vehicles such as motorcycles or e-bikes and pedal bicycles. Motorcycles make up a small percentage of traffic and account for less than $1 \%$ of vehicle miles traveled [23-24], and e-bikes still comprise a small fraction of bicycle sales in the U.S. [25-26]. Nonetheless, to prevent artificial inflation of class one speeds, histograms were utilized to filter out observations with speeds higher than would typically be expected of a pedal cyclist. Studies in the U.S. have reported average bicycle speeds ranging between $11 \mathrm{mph}(18 \mathrm{~km} / \mathrm{h})$ and $15.5 \mathrm{mph}(25 \mathrm{~km} / \mathrm{h})$. Faster speeds were 
observed when traveling in bicycle lanes than on off-street paths [27-28]. It is also possible for more advanced cyclists and those riding on a downhill grade to reach speeds up to $30 \mathrm{mph}(48 \mathrm{~km} / \mathrm{h})$ [29]. The class one speed histograms were examined in conjunction with the estimated road grade to ensure only observations with speeds reasonable of pedal cyclists were included. A typical example of a class one speed distribution presenting two modes, corresponding to lower speed bicycles and higher speed motorized class one vehicles is shown on the left of Figure 3.4. Note that the mode on the right side of this histogram coincides with this location's PSL of $30 \mathrm{mph}$ (48 $\mathrm{km} / \mathrm{h}$ ). After the data cleaning, the mean class one speed was approximately equal to 15 $\mathrm{mph}(24 \mathrm{~km} . \mathrm{h})$. The histogram on the right in Figure 3.4 is from a location with a 25 -mph (40 km/h) PSL, at which class one traffic is dominated by bicycles. The mean class one speed for this dataset was approximately $16 \mathrm{mph}(26 \mathrm{~km} / \mathrm{h})$ - slightly higher than the typical range due to a $1 \%$ downhill grade. 

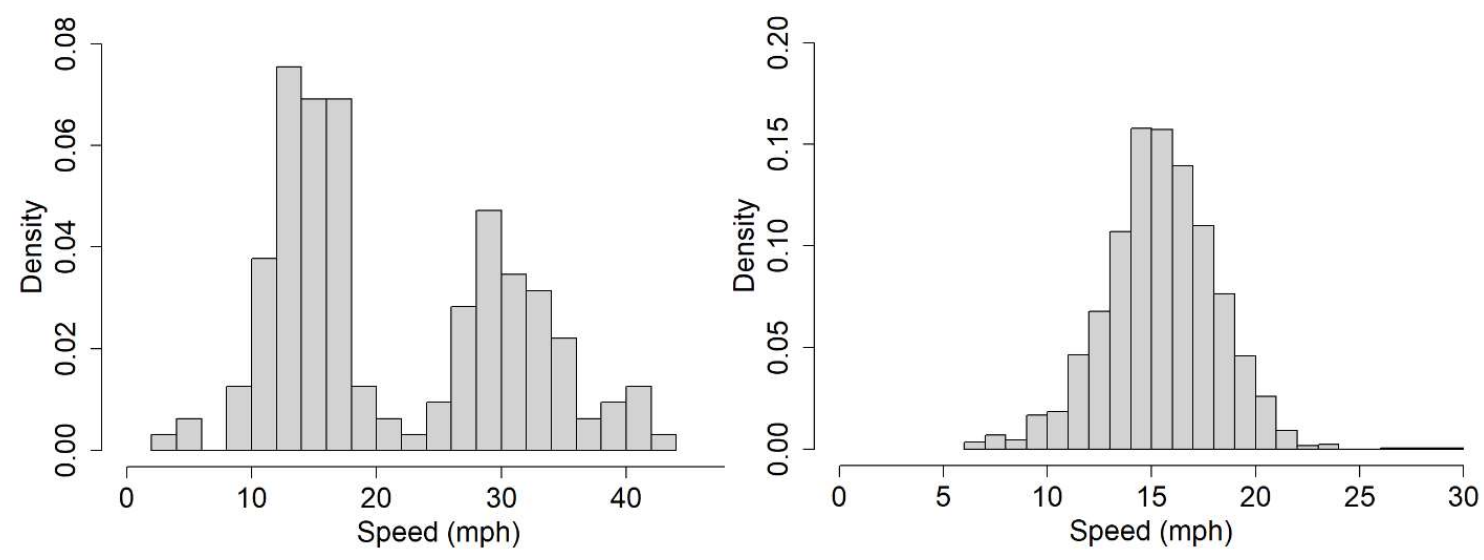

Figure 3.4 Bimodal class one speed distribution indicating the presence of bicycles and motorized class one vehicles (left), and class one speed histogram from a location where bicycles are the dominant class one vehicle type (right).

\subsection{Analysis}

Upon encountering a slower-moving bicycle from the rear, a motorist may be forced to reduce their speed until an opportunity to overtake presents itself. If roadway or traffic conditions do not provide sufficient opportunities for overtaking, delay may occur, and additional motor vehicles may begin to queue behind the cyclist. Based on this premise, observations of class two vehicles (passenger cars) belonging to one of two scenarios were selected from the data. The two scenarios are described as follows: in scenario (i), a passenger car was preceded by a bicycle (class one vehicle), and in scenario (ii), a passenger car was preceded by another passenger car. These data selections enable testing of the hypothesis that bicycles cause reduced passenger car speeds on roads without bicycle lanes due to friction or block interference.

The availability of bidirectional data allowed for an investigation of correlations between scenario (i) speeds and the gap times with oncoming vehicles. Henceforward, an 
"oncoming" vehicle travels in a direction that opposes the direction of travel of the bicycle. Under the assumption that a scenario (i) vehicle must occupy a portion of the oncoming lane to overtake a bicycle, opportunities for passing are dependent on the required passing sight distance (PSD), and subsequently, gaps in oncoming traffic. PSD can be calculated as the sum of four distances, described as follows:

- the distance the passing vehicle travels during a one-second perceptionreaction time,

- the distance traveled by the passing vehicle while occupying the oncoming (opposite direction of travel) lane,

- the clearance distance between the passing and oncoming vehicle that creates a one-second gap, and,

- the distance traveled by the oncoming vehicle during two-thirds of the time the passing vehicle occupies the oncoming lane [15].

The required PSD can be used to calculate the gap time between oncoming vehicles that is necessary to overtake safely - the safe passing gap. The safe passing gap was calculated assuming an overtaking vehicle length of $19 \mathrm{ft} .(6 \mathrm{~m})$, a bicycle length of $6 \mathrm{ft} .(2 \mathrm{~m})$, a one second gap between the overtaking vehicle and the bicycle before and after the maneuver, and an oncoming vehicle speed equal to the PSL. If the existent gaps in oncoming traffic are less than the safe passing gap, it is expected that lower scenario (i) vehicle speeds would result. The timestamps of the observations were used to identify the oncoming vehicles arriving at the pneumatic tubes preceding and succeeding a scenario (i) arrival. It must be noted that the terms "preceding" and "succeeding" refer to 
the timing of the arrival of the oncoming vehicle at the tube in relation to vehicle (i). Class one vehicles were excluded from the oncoming data since they may not occupy the full width of the lane, thereby enabling an overtaking maneuver despite the presence of the oncoming vehicle.

In addition to the safe passing gap, several other gap times between vehicles were measured and are referenced in this paper. The gaps between specific vehicle arrivals at the pneumatic tubes are denoted as follows:

- $\mathrm{PO}-\mathrm{i}-$ between the preceding oncoming vehicle and the scenario (i) vehicle

- SO-i - between the succeeding oncoming vehicle and the scenario (i) vehicle

- 1-i - between the bicycle and the scenario (i) vehicle traveling in the same direction

- 2-ii - between the passenger car and the scenario (ii) vehicle traveling in the same direction.

Figure 3.5 provides a diagram of these gaps, showing the preceding oncoming (opposite direction) vehicle arriving at the tubes prior to the scenario (i) vehicle (top), the succeeding oncoming vehicle arriving at the tubes after the scenario (i) vehicle (top middle), a same-direction bicycle and passenger car scenario (bottom middle), and a same-direction passenger car and passenger car scenario (bottom).

Scenario (i) speeds were plotted against the PO-i and SO-i gaps to investigate if any relationships were present. The PO-i and SO-i gaps were also evaluated against the 
safe passing gap. It should be noted that these plots and evaluations do not account for the 1-i gap. The potential for influence on a passenger car's speed by a slower-moving bicycle decreases as the 1-i gap becomes larger.

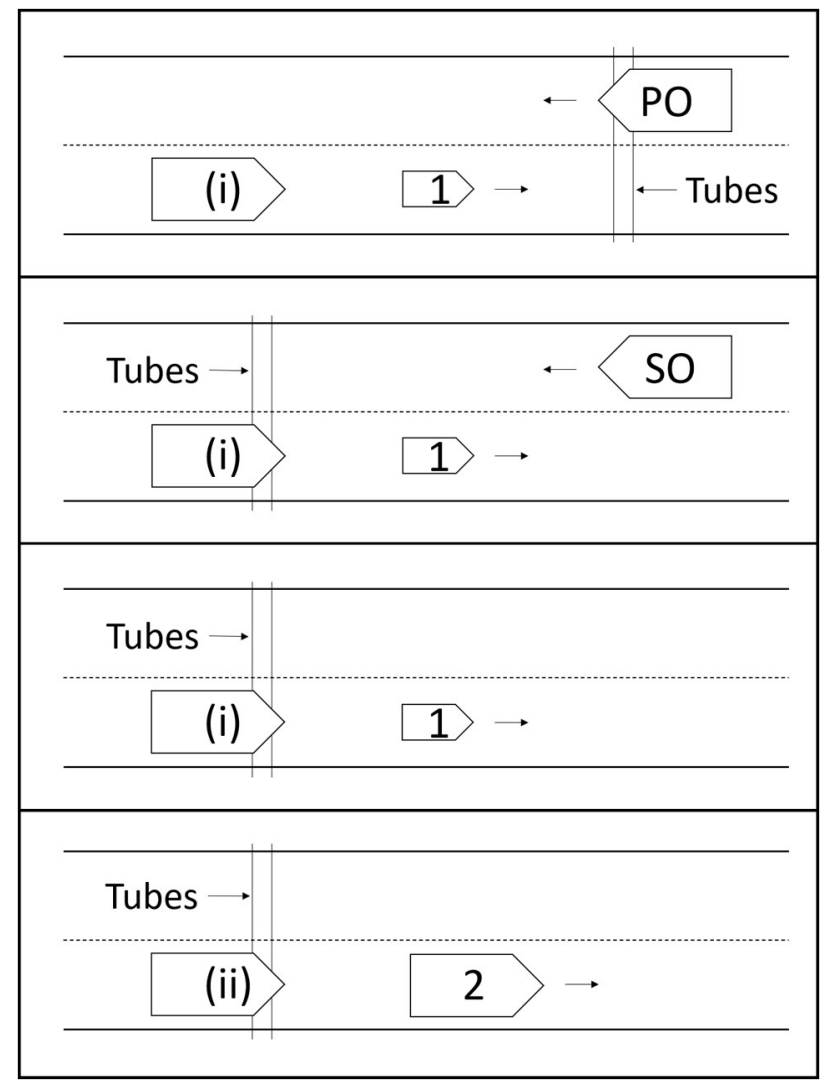

Figure 3.5 Diagram of the PO-i (top), SO-i (top middle), 1-i (bottom middle), and 2-ii (bottom) gaps.

To better understand the possible effects of bicycle presence on passenger car speeds on roads without bicycle lanes, scenario (i) and scenario (ii) mean speeds were compared using two-sample $t$-tests. The null hypothesis states that the mean speed of scenario (i) is equal to the mean speed of scenario (ii), $\mathrm{H}_{0}: \mu_{\mathrm{i}}=\mu_{\mathrm{ii}}$. The alternative hypothesis states that the mean speed of scenario (i) is less than the mean speed of 51 
scenario (ii) by more than one mile per hour $(1.6 \mathrm{~km} / \mathrm{h}), \mathrm{H}_{\mathrm{A}}: \mu_{\mathrm{ii}}-\mu_{\mathrm{i}}>1$. For $p<0.05$, the null hypothesis is rejected. If $p \geq 0.05$, the sample data fail to reject the null hypothesis. Note that a difference of one mile per hour was chosen to match the sensitivity of the data collection equipment, which records speeds in integer values, and because a one-mileper-hour difference is unlikely to be noticed by drivers.

The $85^{\text {th }}$ percentile speed is frequently used as a performance metric and a baseline for determining appropriate speed limits [30]. For this reason, a modified $t$-test was performed with the $85^{\text {th }}$ percentile speeds of scenario (i) and scenario (ii) vehicles. Details of the test can be found in Hou et al. [31]. Similar to the hypothesis test of mean speeds, this null hypothesis states that the $85^{\text {th }}$ percentile speed of scenario (i) is equal to the $85^{\text {th }}$ percentile speed of scenario (ii), $\mathrm{H}_{0}: \zeta_{85, \mathrm{i}}=\zeta_{85}$, ii. The alternative hypothesis states that the $85^{\text {th }}$ percentile speed of scenario (i) is less than the $85^{\text {th }}$ percentile speed of scenario (ii) by more than one mile per hour $(1.6 \mathrm{~km} / \mathrm{h}), \mathrm{H}_{\mathrm{A}}: \zeta_{85, \text { ii }}-\zeta_{85, \mathrm{i}}>1$. Again, for $p$ $<0.05$, the null hypothesis is rejected.

\subsection{Results}

\subsubsection{Oncoming Gap Time Analysis}

Evaluating scenario (i) speeds against the PO-i and SO-i gaps generally produced low to insignificant correlations within the datasets. Calculated correlation coefficients between scenario (i) speed and the PO-i or SO-i gaps ranged from -0.26 to 0.42 . Although low, positive correlations were observed in a few datasets, overall, the mean correlation values between speed and the PO-i or SO-i gap were both equal to 0.05. 
Figure 3.6 displays the scatterplots of an urban collector road with a dotted yellow centerline, showing scenario (i) vehicle speeds according to the PO-i gap (left) and the SO-i gap (right). At this site, the median safe passing gap was $8.6 \mathrm{~s}$; the median safe passing gap is estimated using the PSD and the speed of the passing vehicle and the bicycle. Approximately $40.3 \%$ of the observations at this site displayed PO-i or SO-i gaps less than the median safe passing gap. The percentage of observations with either PO-i or SO-i gaps less than the safe passing gap ranged from $40.3 \%$ to $62.3 \%$ (median $48.1 \%$ ) for non-neighborhood greenways, and $0 \%$ to $30.6 \%$ (median 14.0\%) for neighborhood greenways. Again, it should be noted that the 1-i gap has not been accounted for in these calculations.

To address concerns that reduced passenger car speeds due to bicycles may only occur during peak hours when traffic volumes are highest, a separate evaluation was performed. Class two observations were counted in 15-minute increments, and peak hours were calculated as the two consecutive hours in which cumulative traffic volumes were the highest. Figure 3.7 shows the same scatterplots as in Figure 3.6, when limited to peak hour observations. As with the 24-hour traffic, the evidence is weak that a relationship between the oncoming gaps and scenario (i) speeds exists. This result held for all datasets containing at least 20 peak hour observations. Correlation coefficients between speed and the PO-i or SO-i gaps ranged from -0.37 to 0.39 . The mean correlation value for speed and the PO-i gap was 0.05 , and for speed and the SO-i gap, 0.01 . 

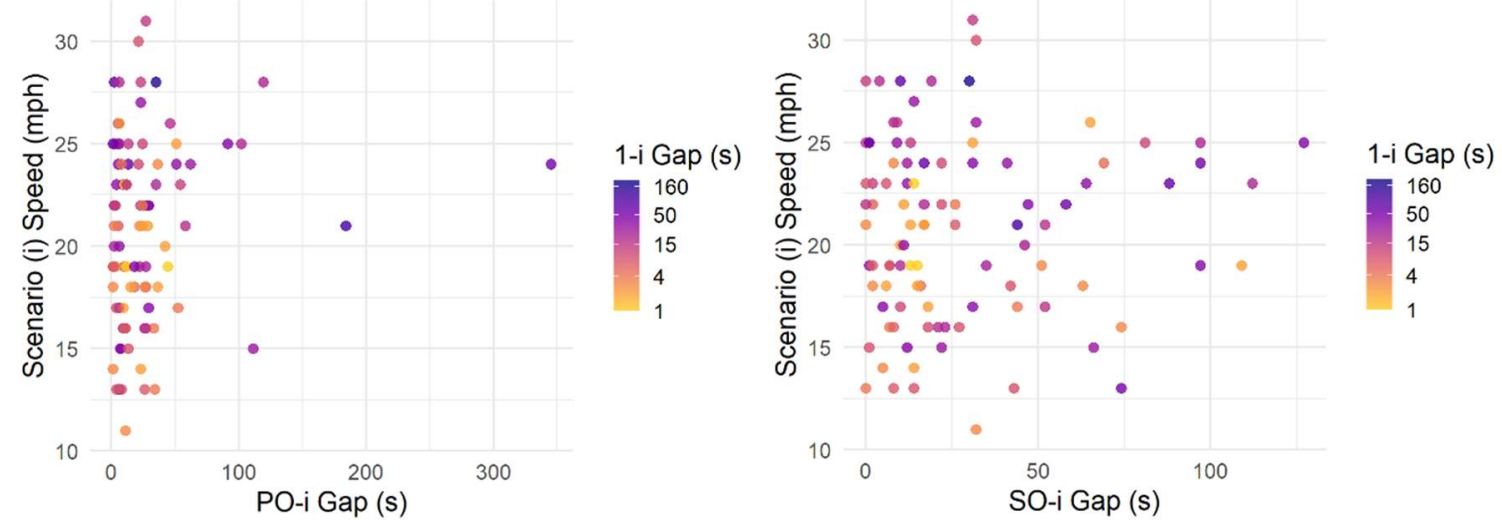

Figure 3.6 Scatterplots showing scenario (i) speeds according to the PO-i gaps (left) and the SO-i gaps (right) for an urban collector road with a dotted yellow centerline.
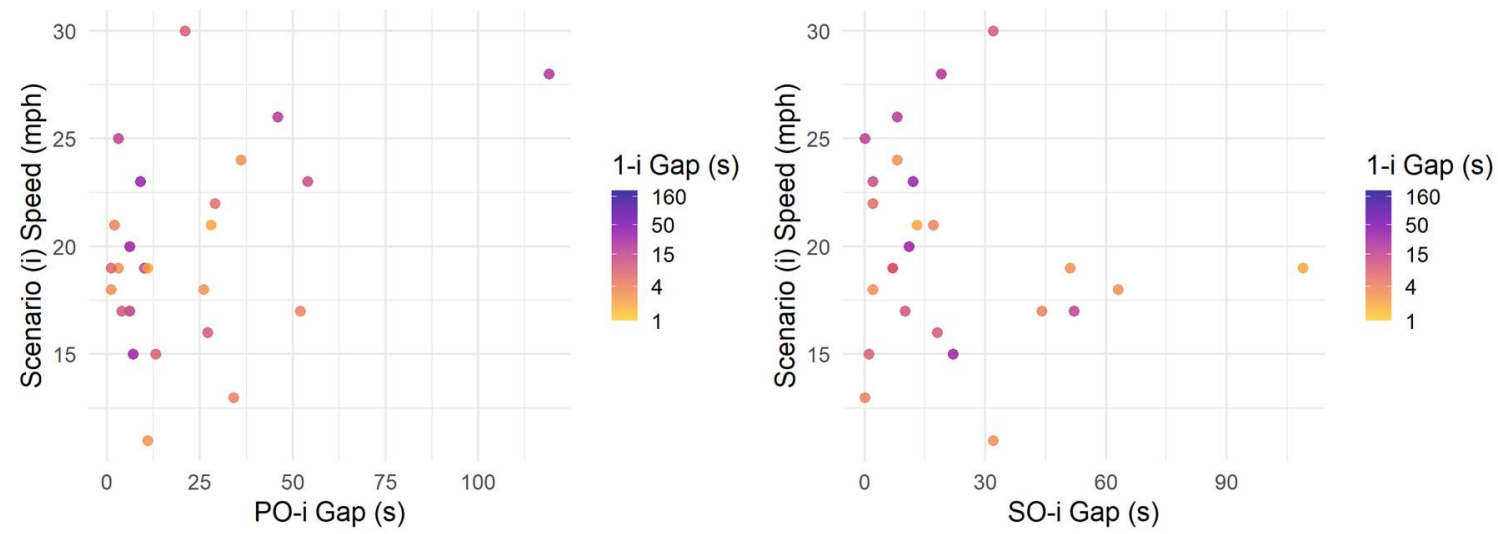

Figure 3.7 Scatterplots showing scenario (i) speeds according to the PO-i gaps and SO-i gaps for peak hours only for an urban collector road with a dotted yellow centerline.

\subsubsection{Hypothesis Testing}

Of the 75 datasets analyzed using all observations, only six (8\%) were found to reject the null hypothesis stating that the mean speeds of scenario (i) and (ii) were equal. Rejection of the null indicates that the mean speed of scenario (i) was more than one mile per hour $(1.6 \mathrm{~km} / \mathrm{h})$ slower than the mean speed of scenario (ii) in these datasets. All six 
datasets were collected from urban collector roads. Table 3.1 provides details of the hypothesis test results for the six datasets that presented significant differences in mean speeds of more than one mile per hour $(1.6 \mathrm{~km} / \mathrm{h})$. The PSL, class one and class two ADT, class one mean speed, grade, and type of road marking at these sites are also given in Table 3.1. Scenario (ii) mean speeds ranged from 1.6 to $3.3 \mathrm{mph}$ (2.6 to $5.3 \mathrm{~km} / \mathrm{h}$ ) higher than scenario (i) mean speeds.

Table 3.1 Hypothesis test results for the six datasets using all observations that reject the null hypothesis of equal mean speeds

\begin{tabular}{|c|c|c|c|c|c|c|c|c|c|}
\hline \multirow[b]{2}{*}{ Dataset } & \multirow[b]{2}{*}{ PSL } & \multicolumn{2}{|c|}{ ADT } & \multicolumn{3}{|c|}{ Mean (mph) } & \multirow{2}{*}{$\begin{array}{c}p \text { - } \\
\text { value }\end{array}$} & \multirow{2}{*}{$\begin{array}{c}\text { Grade } \\
\%\end{array}$} & \multirow{2}{*}{$\begin{array}{c}\text { Road } \\
\text { Marking }\end{array}$} \\
\hline & & Class 1 & Class 2 & Class 1 & (i) & (ii) & & & \\
\hline $\begin{array}{l}\text { Alberta E of 11th } \\
\text { Sep } 2016 \text { WB }\end{array}$ & 25 & 132 & 2949 & 14.54 & 22.89 & 25.01 & 0.039 & -0.4 & $\begin{array}{l}\text { Dotted } \\
\text { Yellow }\end{array}$ \\
\hline $\begin{array}{l}\text { Clinton W of 14th } \\
\text { Sep } 2019 \text { WB }\end{array}$ & 20 & 933 & 428 & 14.52 & 20.04 & 21.62 & 0.027 & -0.7 & Sharrow \\
\hline $\begin{array}{l}\text { Division E of 23rd } \\
\text { Jul } 2015 \text { WB }\end{array}$ & 25 & 124 & 4462 & 18.13 & 23.95 & 26.26 & 0.017 & -4.1 & $\begin{array}{l}\text { Double } \\
\text { Yellow }\end{array}$ \\
\hline $\begin{array}{l}\text { Fremont W of 43rd } \\
\text { Jul } 2019 \mathrm{~EB}\end{array}$ & 20 & 187 & 4689 & 9.42 & 17.65 & 20.97 & 0.000 & 0.0 & $\begin{array}{l}\text { Dotted } \\
\text { Yellow }\end{array}$ \\
\hline $\begin{array}{l}\text { Willamette E of } \\
\text { Mohawk Jul } 2019 \\
\text { EB }\end{array}$ & 30 & 88 & 2958 & 14.93 & 27.50 & 30.12 & 0.030 & 0.8 & $\begin{array}{l}\text { Dotted } \\
\text { Yellow }\end{array}$ \\
\hline $\begin{array}{l}\text { Willamette E of } \\
\text { Mohawk Jul } 2019 \\
\text { WB }\end{array}$ & 30 & 115 & 2937 & 16.26 & 27.22 & 29.77 & 0.005 & -0.8 & $\begin{array}{l}\text { Dotted } \\
\text { Yellow }\end{array}$ \\
\hline
\end{tabular}

When including all observations, only one dataset, collected at eastbound Fremont west of 43rd in July 2019, was found to have a significant decrease in $85^{\text {th }}$ percentile speeds of more than one mile per hour $(1.6 \mathrm{~km} / \mathrm{h})$ for scenario (i) when compared to scenario (ii) $(p=0.01)$. Note that the $85^{\text {th }}$ percentile speeds for scenario (i) and scenario (ii) were higher than the $20 \mathrm{mph}(32 \mathrm{~km} / \mathrm{h}) \mathrm{PSL}$, at $23 \mathrm{mph}(37 \mathrm{~km} / \mathrm{h})$ and $26 \mathrm{mph}(42$ 
$\mathrm{km} / \mathrm{h}$ ), respectively. This dataset also displayed mean speeds for scenario (i) that were approximately three miles per hour $(4.8 \mathrm{~km} / \mathrm{h})$ slower than for scenario (ii) $(p=0.0)$.

To further examine the possible influences of gaps with oncoming traffic (PO-i and SO-i), or gaps between same-direction bicycle and scenario (i) vehicles (1-i), the hypothesis tests were performed again with three subsets of the scenario (i) data. In the first subset, only observations displaying both PO-i and SO-i gaps greater than or equal to the safe passing gap were retained. In the second subset, observations with either a PO-i or SO-i gap less than the safe passing gap were retained. The first and second subsets of scenario (i) observations were evaluated against all scenario (ii) observations. The third subset limited the analysis to observations with 1-i gaps less than $10 \mathrm{~s}$, which were evaluated against scenario (ii) observations also limited to 2-ii gaps less than $10 \mathrm{~s}$. Table 3.2 summarizes the $t$-test results for all observations and each subset. The results are further categorized by the neighborhood greenway designation ( $\mathrm{NN}$ or $\mathrm{G})$ and the functional classification ( $\mathrm{UC}$ or $\mathrm{L}$ ). The percent of datasets producing significant results $(p<0.05)$ out of the datasets tested in each category is shown. For reference, the number of datasets tested in each category is also provided. Only datasets with a minimum of 20 scenario (i) and scenario (ii) observations, each, were tested. 
Table 3.2 Summary of hypothesis testing significant results for all data and all subsets

\begin{tabular}{|c|c|c|c|c|}
\hline \multicolumn{5}{|c|}{ Number of Datasets Tested } \\
\hline & All Observations & PO-i and SO-i $\geq$ SPG & PO-i or SO-i < SPG & 1-i and 2 -ii $<10$ s \\
\hline NN & 14 & 14 & 14 & 14 \\
\hline G & 61 & 61 & 46 & 49 \\
\hline $\mathrm{UC}$ & 36 & 36 & 35 & 35 \\
\hline $\mathrm{L}$ & 39 & 39 & 25 & 28 \\
\hline Total & 75 & 75 & 60 & 63 \\
\hline \multicolumn{5}{|c|}{$\mathrm{H}_{0}: \mu_{\mathrm{i}}=\mu_{\mathrm{ii}} ; \mathbf{H}_{\mathrm{A}}: \mu_{\mathrm{ii}}-\mu_{\mathrm{i}}>1$} \\
\hline & All Observations & PO-i and SO-i $\geq$ SPG & PO-i or SO-i < SPG & $1-\mathrm{i}$ and 2 -ii $<10 \mathrm{~s}$ \\
\hline NN & $35.7 \%$ & $28.6 \%$ & $21.4 \%$ & $42.9 \%$ \\
\hline $\mathrm{G}$ & $1.6 \%$ & $0.0 \%$ & $6.5 \%$ & $36.7 \%$ \\
\hline $\mathrm{UC}$ & $16.7 \%$ & $11.1 \%$ & $17.1 \%$ & $40.0 \%$ \\
\hline $\mathrm{L}$ & $0.0 \%$ & $0.0 \%$ & $0.0 \%$ & $35.7 \%$ \\
\hline Total & $8.0 \%$ & $5.3 \%$ & $10.0 \%$ & $38.1 \%$ \\
\hline \multicolumn{5}{|c|}{$\mathrm{H}_{0}: \zeta_{85, \mathrm{i}}=\zeta_{85, \mathrm{ii}} ; \mathrm{H}_{\mathrm{A}}: \zeta_{85, \mathrm{ii}}-\zeta_{85, \mathrm{i}}>1$} \\
\hline & All Observations & PO-i and SO-i $\geq S P G$ & PO-i or SO-i < SPG & 1 -i and 2 -ii $<10$ s \\
\hline $\mathrm{NN}$ & $7.1 \%$ & $7.1 \%$ & $14.3 \%$ & $21.4 \%$ \\
\hline $\mathrm{G}$ & $0.0 \%$ & $0.0 \%$ & $8.7 \%$ & $8.2 \%$ \\
\hline $\mathrm{UC}$ & $2.8 \%$ & $2.8 \%$ & $17.1 \%$ & $17.1 \%$ \\
\hline $\mathrm{L}$ & $0.0 \%$ & $0.0 \%$ & $0.0 \%$ & $3.6 \%$ \\
\hline Total & $1.3 \%$ & $1.3 \%$ & $10.0 \%$ & $11.1 \%$ \\
\hline
\end{tabular}

$\mathrm{NN}=$ non-neighborhood greenway; $\mathrm{G}=$ neighborhood greenway; $\mathrm{UC}=$ urban collector; $\mathrm{L}=$ local; $\mathrm{SPG}=$ safe passing gap

The results in Table 3.2 indicate that for most categories, mean and $85^{\text {th }}$ percentile speeds are less likely to be reduced by one mile per hour $(1.6 \mathrm{~km} / \mathrm{h})$ or more when both PO-i and SO-i gaps are greater than or equal to the safe passing gap compared to when either the PO-i or SO-i gaps are insufficient. The non-neighborhood category (where centerlines are present) displays an exception to this pattern when considering mean speeds. A higher percentage of datasets indicated significantly reduced mean speeds occurred when PO-i and SO-i gaps were greater than or equal to the safe passing gap 
(28.6\%) compared to when PO-i or SO-i gaps were less than the safe passing gap (21.4\%). Smaller 1-i gap times also appear to increase the likelihood of significantly reduced mean or $85^{\text {th }}$ percentile scenario (i) speeds, despite these datasets containing nearly the same percentages of observations with either PO-i or SO-i gaps less than the safe passing gap as the full datasets. Additionally, a higher percentage of nonneighborhood or urban collector datasets displayed significantly different speeds, compared to neighborhood greenways or local roads for all subsets of data.

\subsection{Discussion}

Based on the results of the scenario (i) speed and oncoming vehicle gap time analysis, and the results of the $t$-tests comparing the speeds of passenger cars following bicycles (scenario (i)) and passenger cars following other passenger cars (scenario (ii)), there is little evidence to suggest that bicycles lead to a practical reduction in passenger car speeds on low volume, low speed urban roads without bicycle lanes under general operating conditions.

In traffic literature, free-flow speeds are defined as those occurring when a vehicle is traveling uninhibited by the preceding vehicle. A gap time between vehicles greater than four to six seconds is typically used as a threshold to identify vehicles in free-flow conditions. When motorized vehicles are forced to follow a slower-moving bicycle under inhibited flow conditions, it is expected that mean and $85^{\text {th }}$ percentile speeds will be reduced. This is demonstrated by the results of the $t$-tests on datasets limited to observations with 1-i and 2-ii gaps less than $10 \mathrm{~s}$, showing a somewhat higher 
percentage of significantly reduced mean or $85^{\text {th }}$ percentile speeds than when all observations are tested. However, when overtaking opportunities are sufficiently abundant, a passenger car approaching a bicycle from behind may not need to significantly reduce their speed for a meaningful amount of time. Thus, the overall speed of traffic would be largely unaffected. This outcome is evidenced by the results of the $t$ tests performed when scenario (i) data were subset according to the potential for an opportunity to overtake. When PO-i and SO-i gaps were both greater than or equal to the safe passing gap, fewer total datasets showed evidence that scenario (i) mean or $85^{\text {th }}$ percentile speeds were reduced by one mile per hour $(1.6 \mathrm{~km} / \mathrm{h})$ or more, compared to when either the PO-i or SO-i gap was less than the safe passing gap. The few low, positive correlations observed between scenario (i) speeds and the PO-i or SO-i gaps for the 24-hour period seem to support this conclusion. The peak hour speed-gap analysis did not show evidence of stronger correlations. Due to the directionality that is often present with peak-hour traffic, it is likely that the oncoming traffic peak hours do not coincide with same-direction peak hours, thereby allowing larger oncoming gaps and more opportunities for overtaking, resulting in little to no additional impact on speeds.

Overall, the $t$-test results produced limited evidence that passenger car speeds are reduced on these lower volume, low speed, urban roads without bike lanes. Mean or $85^{\text {th }}$ percentile speed reductions of one mile per hour $(1.6 \mathrm{~km} / \mathrm{h})$ or more appear to occur less frequently on local functionally classed roads and neighborhood greenways, which prioritize active travelers and typically have high bicycle volumes. 
When all observations were considered, only six of the 75 datasets analyzed ( $8 \%)$ indicated that scenario (i) mean speeds were significantly lower than scenario (ii) by more than one mile per hour $(1.6 \mathrm{~km} / \mathrm{h})$. Differences in mean speeds for scenario (i) and scenario (ii) in these datasets ranged from 1.6 to $3.3 \mathrm{mph}(2.6$ to $5.3 \mathrm{~km} / \mathrm{h})$. Only one of these datasets demonstrated a significant difference in $85^{\text {th }}$ percentile speeds when all observations were analyzed. A few common characteristics were present in these datasets that may have contributed to the difference in speeds. All six datasets were collected from urban collector roads, and the $85^{\text {th }}$ percentile speeds for both vehicle scenarios were all in excess of the PSL. Additionally, a high percentage of class two vehicles exceeding the PSL was observed (38\% to $58 \%$ ). Grade did not appear to be a significant factor, however. At five of the sites, the presence of centerlines and class two ADT greater than is recommended by Danish bikeway design guidance for shared roads may have influenced motorists' decision to overtake. Additionally, larger speed differentials were observed between bicycles and passenger cars in two datasets due to PSLs outside the recommended range for shared roads, likely causing motorists to decrease speed when overtaking on account of safety. One site, westbound Clinton west of $14^{\text {th }}$, differed somewhat from the other five sites. At this location, a centerline is absent, and priority is given to bicycles, which comprise nearly $63 \%$ of the total traffic. The class two ADT and PSL for this dataset were within the acceptable range for shared roads. Speed humps are present throughout this segment of the roadway at roughly 400-500 ft. (122-152 m) intervals to calm traffic. Motorists may choose to delay overtaking a bicycle due to the presence of a downstream speed hump and the nature of braking and accelerating 
associated with it. A traffic signal is also present at a T-intersection approximately $425 \mathrm{ft}$. (130 m) downstream of the data collection location. This distance was insufficient for overtaking according to the calculated PSD for $67 \%$ of the observations, likely forcing motorists to delay overtaking until the intersection was cleared.

\subsection{Conclusions}

This research has provided a detailed comparative analysis of passenger car speeds using two vehicle scenarios: (i) a passenger car that was preceded by a bicycle, and (ii) a passenger car that was preceded by another passenger car. This research addressed limitations of a previous study [7] by incorporating a significant number of study sites displaying a wide variety of characteristics with respect to functional class, grade, traffic volume and composition, and PSL. As the bicycle mode share continues to grow, it will be increasingly important to design and maintain robust networks of bicycle facilities, and these results indicate that shared roads can contribute substantially to those networks while preserving the mobility of motorized travelers.

Gaps in oncoming traffic were analyzed for the potential effect of overtaking opportunities on the speed of class two vehicles following bicycles. The mean and $85^{\text {th }}$ percentile speeds of the two vehicle following scenarios were compared using $t$-tests. The results of the analyses presented within this paper predominantly indicate that bicycles are unlikely to lead to reduced passenger car speeds on urban roads without bicycle lanes that meet the guidelines for shared roadways. 
When all observations were considered, a small percentage of datasets did show evidence of significantly different mean speeds, but a significant difference in $85^{\text {th }}$ percentile speeds was only observed in one of the 75 datasets. Overall, the results of the hypothesis testing suggest that scenario (i) speeds are less likely to be reduced by one mile per hour $(1.6 \mathrm{~km} / \mathrm{h})$ or more on streets that are designated as neighborhood greenways or those that carry a local functional classification.

Even if speed reductions are statistically significant, this does not necessarily imply that these reduced speeds have a meaningful impact in terms of travel time. The relationship between travel time and speed is relatively complex, and road users in urban areas generally overestimate the actual time savings associated with higher travel speeds [32-33]. Traffic signals and stop signs are more likely to increase motorists' travel time in streets that meet the guidelines for mixed-traffic roadways. Future studies, like [34], that account for each vehicle travel time between successive data collection locations, can provide additional information about the main sources of delay in low speed, low volume urban roads with a high percentage of active travelers.

\section{Acknowledgments}

The authors acknowledge Tom Jensen and Scott Batson of PBOT for providing the data used in this analysis.

Author contributions 
The authors confirm contribution to the paper as follows: study conception and design: MAF; data collection: PBOT; analysis and interpretation of results: JSS, MAF, AU; draft manuscript preparation: JSS, MAF, AU. All authors reviewed the results and approved the final version of the manuscript. 


\subsection{References}

1. United States Census Bureau. American FactFinder - COMMUTING CHARACTERISTICS BY SEX, 2018 American Community Survey 1-Year Estimates [Internet]. Washington DC: US Census Bureau; 2018 [cited 2020 Jun 21]. Available from: https://data.census.gov/cedsci/table? $\mathrm{q}=\mathrm{S} 08 \& \mathrm{~d}=\mathrm{ACS} \% 201-$ Year\%20Estimates\%20Subject\%20Tables\&tid=ACSST1Y2018.S0801\&vintage= 2018

2. City of Portland Oregon. Bicycles in Portland Fact Sheet [Internet]. Portland, OR: City of Portland; 2019 [updated 2019 Apr; cited 2020 Jun 21]. Available from: https://www.portlandoregon.gov/transportation/article/407660

3. City of Portland Oregon. Portland Bicycle Plan for 2030 [pdf] [Internet]. Portland, OR: City of Portland; 2010 Feb 11 [cited 2020 Jun 25]. Available from: https://www.portlandoregon.gov/transportation/article/289122

4. Andersen T, Bredal F, Weinreich M, Jensen N, Riisgaard-Dam M, Nielsen MK. Collection of Cycle Concepts 2012. $2^{\text {nd }}$ ed. Denmark: Cycling Embassy of Denmark; 2012. Planning the Cycling Infrastructure; p. 53-4. 
5. Andersen, M. Real Talk: Bikes Don't Reduce Congestion without Bike Lanes [Internet]. Boulder, CO: PeopleForBikes; 2015 Apr 22 [cited 2020 Jun 25]. Available from: https://peopleforbikes.org/blog/real-talk-bikes-cant-reducecongestion-without-bike-lanes/

6. Gosse C, Clarens A. Quantifying the Total Cost of Infrastructure to Enable Environmentally Preferable Decisions: The Case of Urban Roadway Design. Environmental Research Letters. 2013 Mar; 8(1):1-9.

7. Schaefer JS, Figliozzi MA, Unnikrishnan A. Evidence from Urban Roads without Bicycle Lanes on the Impact of Bicycle Traffic on Passenger Car Travel Speeds. Transportation Research Record. 2020 Jun 12; 2674(7):87-98.

8. Schultheiss B, Goodman D, Blackburn L, Wood A, Reed D, Elbech M. Bikeway Selection Guide. Washington DC: Federal Highway Administration Office of Safety; 2019 Feb 1. Report No.: FHWA-SA-18-077. p. 23.

9. National Association of City Transportation Officials. Urban Bikeway Design Guide. $2^{\text {nd }}$ ed. Washington DC: Island Press; 2014 Mar 24. 
10. Walker I. Drivers Overtaking Bicyclists: Objective Data on the Effects of Riding Position, Helmet Use, Vehicle Type and Apparent Gender. Accident Analysis \& Prevention. 2007 Mar 1;39(2):417-25.

11. Walker I, Garrard I, Jowitt F. The Influence of a Bicycle Commuter's Appearance on Drivers' Overtaking Proximities: An On-road Test of Bicyclist Stereotypes, High-Visibility Clothing and Safety Aids in the United Kingdom. Accident Analysis \& Prevention. 2014 Mar 1;64:69-77.

12. Brady J, Loskorn J, Mills A, Duthie J, Machemehl R, Beaudet A, Barrea N, Wilkes N, Fialkoff J. Effects of Shared Lane Markings on Bicyclist and Motorist Behavior along Multi-Lane Facilities. Austin, TX: Center for Transportation Research, U. of Texas at Austin. 2010.

13. LaMondia J, Duthie J. Analysis of Factors Influencing Bicycle-Vehicle Interactions on Urban Roadways by Ordered Probit Regression. Transportation Research Record. 2012;2314(1):81-8.

14. Jia S, Peng H, Guo J, Chen H. Quantitative Analysis of Impact of Bicycles on Vehicles in Urban Mixed Traffic. Journal of Transportation Systems Engineering and Information Technology. 2008 Apr 1;8(2):58-63. 
15. Harwood DW, Sun C. Passing Sight Distance Criteria. Transportation Research Board; 2008.

16. Oketch TC. Modeled Performance Characteristics of Heterogeneous Traffic Streams Containing Non-Motorized Vehicles. Transportation Research Board 82nd Annual Meeting [CD-ROM]. 2003.

17. Federal Highway Administration. Traffic Monitoring Guide. Washington DC: US Department of Transportation; 2016. p. C-1.

18. Nordback K, Kothuri S, Phillips T, Gorecki C, Figliozzi M. Accuracy of Bicycle Counting with Pneumatic Tubes in Oregon. Transportation Research Record. 2016;2593(1):8-17.

19. United States Geological Survey. 10 foot contours of the Portland, OR metro area [Internet]. 2011 Jan 24 [modified 2011 May 15; cited 2020 Jun 25]. Available from: https://databasin.org/datasets/e5f48e27860046c6b4bc14d64adf1ceb

20. Google Maps. Google Street View, 4749 SE Lincoln St. [Image on internet]. United States: Google; 2016 Apr [cited 2020 Jul 18]. Available from: https://goo.gl/maps/NxH3nCjBT3C4uwEG7 
21. Google Maps. Google Street View, 4624 NE Fremont St. [Image on internet]. United States: Google; 2019 May [cited 2020 Jul 18]. Available from: https://goo.gl/maps/gmsZy5xw6i2WT6426

22. Google Maps. Google Street View, 3302 SE Division St. [Image on internet]. United States: Google; 2018 Aug [cited 2020 Jul 18]. Available from: https://goo.gl/maps/4Qfv7VLfMo5L9t3T7

23. Hallenbeck M, Rice M, Smith BL, Cornell-Martinez C, Wilkinson J. Vehicle Volume Distributions by Classification; Report No.: FHWA-PL-97-025. 1997 Jul. p. 29.

24. National Highway Traffic Safety Administration. Traffic Safety Facts [pdf] [Internet]. Washington DC: US Department of Transportation; 2013 [cited 2020 Jun 25]. Available from: https://crashstats.nhtsa.dot.gov/Api/Public/ViewPublication/812148\#: :text=Mot orcycles $\% 20$ mama $\% 20$ up $\% 203 \% 20$ percent,of $\% 20$ all $\% 20$ vehicle $\% 20$ miles $\% 20 \operatorname{tr}$ aveled.

25. McFarland M. Electric bicycles emerge as a hot trend in the U.S. [Internet]. CNNMoney. 2018 [cited 2020 Jun 27]. Available from: https://money.cnn.com/2018/01/17/technology/ebikes-electric-bikes/index.html 
26. Wagner I. U.S. Bicycle Industry - Statistics \& Facts [Internet]. Statista. 2019 [cited 2020 June 27]. Available from: https://www.statista.com/topics/1448/bicycle-industry-in-the-us/

27. Miller RE. Width requirements for bikeways: A level of service approach. University of California, Davis; 1976.

28. Opiela KS, Khasnabis S, Datta TK. Determination of the Characteristics of Bicycle Traffic at Urban Intersections. Transportation Research Record. 1980;743:30-8.

29. American Association of State Highway and Transportation Officials. Guide for Development of Bicycle Facilities. $4^{\text {th }}$ ed. Washington, DC: American Association of State Highway and Transportation Officials; 2012.

30. Federal Highway Administration. Manual on Uniform Traffic Control Devices for Streets and Highways. 2009 Ed. Washington, DC: U.S. Department of Transportation; 2009. 
31. Hou Y, Sun C, Edara P. Statistical Test for 85th and 15th Percentile Speeds with Asymptotic Distribution of Sample Quantiles. Transportation Research Record. 2012 Jan; 2279(1):47-53.

32. European Conference of Ministers of Transport, OECD/ECMT Transport Research Centre. Speed Management. OECD Publishing; 2006.

33. Archer J, Fotheringham N, Symmons M, Corben B. The Impact of Lowered Speed Limits in Urban/Metropolitan Areas. Clayton, Australia: Monash University Accident Research Centre. Report No. 276. 2008 Jan.

34. Figliozzi MA, Glick TB. Evaluation of Roadway Reallocation Projects: Analysis of Before-and-After Travel Speeds and Congestion Utilizing High-Resolution Bus Transit Data. NITC-RR-887. Portland, OR: Transportation Research and Education Center (TREC); 2017. 
4 Utilizing Pneumatic Tube Data to Predict Bicycle Speed on Urban Roads

Jaclyn S. Schaefer and Miguel A. Figliozzi 
Abstract

Increasing levels of congestion on urban roadways is often cited by cities as motivation to promote alternative modes of travel, such as cycling. New policies and updates to the roadway infrastructure are being implemented to better serve existing cyclists and encourage new ones. The success of many of these projects depends on a thorough understanding of the dynamics of cycling, including travel speeds. The ability to predict bicycle speeds has implications for bikeway design, signal timing, and tripplanning purposes. Previous research attempts to predict bicycle speeds most frequently include a mix of site-level characteristics and characteristics at the individual level, such as gender, age, type of bicycle, or cycling experience. Collecting data at the individual level is more complex than site-level data, generally requiring cyclists to opt into studies by using GPS tracking devices or smartphone apps, which may bias results. Automatic speed recorders such as pneumatic tubes are easier to administer and are widely used to collect traffic speeds, including those of bicycles. However, data about the individual is unavailable with this data collection method. Therefore, this paper focuses on traffic, geometric, and roadway factors to model bicycle speeds. The results of a regression analysis indicated that bicycle speed is predominantly influenced by grade. Additionally, the average passenger car speed, the segment length, the percentage of bicycles, and the type of bikeway facility were found to have statistically significant $(p<0.05)$ effects on bicycle speeds. On shared roads, the interaction of the bicycle facility type and the percentage of bicycles was found to have a moderating effect on speed. 


\subsection{Introduction}

Traffic congestion is an ever-growing problem in many cities across the U.S., leading to longer commute times, increased fuel costs, and higher levels of greenhouse gas emissions. In an effort to combat the effects of traffic congestion, some cities are aggressively promoting alternative modes of travel, such as cycling. The City of Portland, Oregon is one such city. The Portland Bicycle Plan has established a goal to reach a $25 \%$ bicycle mode share by the year 2030, a significant increase from the $6.3 \%$ bicycle mode share recorded in 2017 [1-2]. Research has indicated that providing more direct routes and building additional separated bikeways or bike boulevards may be key incentives for cycling [3]. Consistent with these findings, the Portland Bicycle Plan recommends a significant expansion of bicycle facilities, as well as developing street design guidelines with provisions for bicycles to help achieve their ambitious mode share goal.

The success of many new policies and updates to roadway infrastructure geared toward increasing bicycle volumes depends, in part, on a thorough understanding of cycling dynamics, especially travel speed. Speed is an important parameter for route choice and mode choice modeling, for example. Furthermore, speed is a key consideration in bikeway design, traffic signal coordination, traffic signal clearance intervals [4], and as an input to simulations modeling flow in mixed-traffic environments.

Typically, bicycle speeds are assumed to be constant for planning and design purposes. However, speeds can vary widely between individuals and among locations. Thus, it is imperative to determine the factors that affect bicycle speeds so that projects to stimulate cycling produce the maximum intended results. 
Many previous studies have been conducted to establish bicycle free-flow speeds and distributions [5]. Far fewer studies have focused on identifying the factors that influence bicycle speeds [6-13]. These factors can be divided into two main categories. The first category pertains to site-level factors, such as grade and bicycle facility type, as well as ADT or mean traffic speed. The second category pertains to factors at the individual level, including age, cycling experience, bicycle type, or trip purpose. Most of the previous studies have included a combination of site and individual factors. Relatively few studies have focused solely on site-level factors. Collecting individuallevel data is more complex than site-level data. The former is typically collected using GPS devices or smartphone apps, which require users to opt-in and may lead to a biased sample. For example, Garber et al. found that smartphone app users road more frequently and were more likely to consider themselves stronger or more fearless riders compared to the general cycling population [14]. Video cameras can also be used to collect certain data about individual cyclists, but this method tends to be labor intensive which may hinder sample size.

Pneumatic tubes are a commonly used and cost-effective method for collecting traffic speeds, including those of bicycles. The Portland Bureau of Transportation (PBOT) frequently employs pneumatic tubes to perform traffic surveys. Unfortunately, data at the individual level is not attainable with this method alone. Considering the prevalence of pneumatic tube use in traffic surveys and acknowledging the challenges with obtaining data at the individual level, this paper focuses strictly on a wide variety of traffic, geometric, and roadway factors to model bicycle speeds on urban roads using 
pneumatic tube data collected by PBOT. The results of this research will enable planners and bikeway designers to create better routes and facilities that increase the appeal or utility of cycling.

\subsection{Literature Review}

Factors affecting motorized vehicle operating speeds have been explored in many previous studies, but due to vast differences in size, performance, and operation, the majority of these factors are not applicable to bicycle speeds.

With few exceptions (e.g., e-bikes), bi cycles are human-powered. Thus, speed is partially limited by physical and health characteristics of the cyclist. Most of the previous studies investigating factors that influence bicycle speed have included one or more variables related to the individual. Of these, a cyclist's gender is frequently considered when modeling bicycle speed, as it is generally accepted that males can generate a higher power output than females, on average. Indeed, several studies have concluded that the average bicycle speed of males is higher than that of females [4, 8-11].

Other factors at the individual level that have previously been investigated include the cyclist's age, type of bicycle, cycling experience, and trip purpose. For example, ElGeneidy et al. explored the possible influences of age, comfort level in traffic, the cumulative distance a cyclist traveled to the beginning of a given segment, and the total trip distance on bicycle speed predictions. Data were collected by GPS units attached to eight participants' handlebars. The results of the generalized speed model showed that age had a minor, although not statistically significant, positive effect on speed. The 
cyclist's comfort level in light traffic was not significant, but the comfort level in heavy traffic did have a positive effect on speed $(p=0.07)$. T he cyclist's cumulative distance traveled to the beginning of a given segment showed a negative influence on speed but was not statistically significant. However, total trip distance was significant $(p=0.00)$ with a positive effect [8].

Strauss and Miranda-Moreno included the person-type variables of age category and trip purpose when analyzing characteristics that may affect bicycle speeds. Data were collected via a GPS smartphone app. The results of their linear regression analyses indicated that cyclists under the age of 25 have a positive effect on speed, and cyclists over the age of 44 have a negative effect on speed. The models also showed trips made for work or school were associated with higher speeds. All variables in the final models were significant at the $p<0.05$ level [11].

Flügel et al. also utilized a GPS smartphone app for data collection to construct a log-linear regression model for regular and e-bike speeds. Trip purpose was included as a person-type independent variable. In the resulting model for regular bicycles, trips related to work were positively associated with speed, although the authors noted some initial uncertainty about the reliability of the app's automatic trip purpose function [9].

Parkin and Rotheram examined several variables related to the individual cyclist such as the cycling experience or frequency, body mass index (BMI), type of bicycle, and the carriage of luggage to determine speed and acceleration characteristics for various gradients. Handlebar mounted GPS units were used to collect data and linear regression models were created. However, due to a small sample size of cyclists $(n=16)$ who were 
generally experienced and cycled regularly, none of the person-type variables were found to significantly influence speed [10].

Compared to the aforementioned studies that involved regression analyses, $\mathrm{Xu}$ et al. took a somewhat different approach to predicting bicycle speed by developing neural network models including different combinations of input variables. Data were collected by video along straight segments of separated bicycle paths. The variables were partitioned into four groups, representing cycleway width, bicycle flow, bicycle type (percentage of electric or scooter style bikes), and cyclist characteristics (age category, carriage of cargo, and gender). The authors concluded that a model combining all four groups of variables resulted the best performance with an $\mathrm{R}^{2}$ of 0.87 [13].

Tengattini and Bigazzi also provided an alternative method for estimating bicycle speed by presenting a mathematical framework based on the mechanics of the bicycle and power output of the cyclist. Several variables at the individual level are necessary to estimate speed using this approach, as bicycle speed is a function of the cyclist's power output and the total resistive force. The total resistive force is dependent, in part, on the cyclist and bicycle weights, the frontal area of the cyclist-bicycle unit, and the bicycle tire width and pressure. Additionally, the resistive force due to grade can be a major factor for bicycle speed [12].

Grade has frequently been included in the literature as a site-level variable when modeling bicycle speed, consistently presenting a significant association. While an uphill grade displayed a relatively linear effect on bicycle speed, the model developed by Flügel et al. [9] and research by Ryeng et al. [15] found downhill grade to have a non-linear 
effect. Other studies [10-11] have also discovered non-linear associations between grade and bicycle speed, as evidenced by a larger magnitude for the uphill coefficients. This non-linear effect may be attributed to safety. As the downhill grade becomes large, speed increases to a limiting point beyond which safety becomes an issue. This threshold grade was estimated to be in the $5 \%$ to $6 \%$ range $[9,15]$.

Facility type is another site-level variable that has been examined in a few of the reviewed studies. Both the OLS and generalized speed models constructed in El-Geneidy et al. suggested that off-street facilities have a positive effect on bicycle speed compared to on-street facilities and regular streets without facilities [8]. Research by Flügel et al. seems to agree with this finding. Dummy variables signifying a cycling only path, a walking and cycling path, a cycling lane, or all other roads were included as independent variables. The resulting model indicated that the highest bicycle speeds would be observed on cycling only paths, followed by cycling lanes and combination walking/cycling paths, when all other variables were held constant [9]. Similarly, Strauss and Miranda-Moreno found the presence of bicycle infrastructure to have a positive and statistically significant effect on bicycle speed $(p<0.001)$ [11]. A $n$ explanation for these results may be seen with research by Bernardi and Rupi, who studied the influence of non-stationary disturbances in off-street and mixed-traffic cycling environments on bicycle speed reductions. The authors concluded that on the separated paths shared with pedestrians, disturbances were more frequent but produced moderate reductions, whereas disturbances due to heavy vehicles in mixed-traffic environments were relatively few but produced the greatest speed reductions [7]. 
Site-level variables such as geometric characteristics, traffic flow, roadway functional class, or the presence of traffic signals have been investigated in addition to grade or facility type in a few of the previous studies.

Segment length, ADT, and traveling during the AM peak period were also included in the models by El-Geneidy et al. Segment length showed a positive influence on bicycle speed but ADT and traveling during the AM peak did not produce significant effects [8].

Strauss and Miranda-Moreno also found segment length to significantly increase bicycle speed, as did the absence of traffic signals at the segment ends, traveling during the AM peak, and traveling on an arterial or collector road. The model also evaluated the effect of bicycle flow, which was not included in the final models [11].

Along with facility type and grade, Flügel et al. examined the influence of horizontal curvature on bicycle speed and found that speeds were reduced when the curvature was greater [9].

Much of the reviewed research used linear regression methods to model bicycle speed. This approach assumes independence between subsequent observations. However, a cyclist's speed on a given segment may also be dependent on the speed of the previous segment, particularly if the previous segment contained a steep grade. With this in mind, Arnesen et al. compared a generalized linear model with slope and horizontal curvature as the independent variables to a forward Markov model that also accounted for dependence between the current and previous segment's speeds. This comparison 
revealed that the forward Markov model outperformed the generalized linear model, displaying a lower standard error [6].

Overall, the explanatory power of the regression models discussed within the literature was quite low. The $\mathrm{R}^{2}$ or adjusted $\mathrm{R}^{2}$ values reported ranged from 0.12 to 0.49 , with a median around 0.25 [7-11]. This suggests that there are factors that affect bicycle speeds that were not accounted for. Additionally, small sample sizes or sampling bias due to the data collection methods may have been a factor.

\subsection{Data Collection}

Traffic data for both bicycle and motorized traffic were collected from 2015 through 2019 by the Portland Bureau of Transportation (PBOT) us ing pneumatic tubes. The tubes were configured to record the speed and vehicle class of each observation. PBOT frequently conducts short-term traffic surveys (minimum of one full day) us ing pneumatic tubes, and the crews are skilled in the proper placement to collect accurate data. Sites were selected to represent a variety of geometric and roadway conditions. A total of 97 directional datasets were obtained.

Vehicle class was determined by a modified FHWA Scheme F [16], with which passenger cars are considered class two and bicycles are considered class one, along with motorcycles. Although motorcycles account for only a minor percentage of the total traffic and VMT [17-18] and e-bikes are still relatively rare compared to standard pedal bicycles [19-20], an attempt was made to filter out class one vehicle observations that appeared to be generated by a motorized vehicle. This was performed by inspection of 
the class one speed histograms in comparison to the class two (passenger car) speed histograms, and by referencing the estimated grade at the data collection location. Figure 4.1 provides an example of a location with a bimodal class one speed distribution, showing the class one speed histogram overlaid by that of class two. Notice that the mode to the right corresponds well with the mode of the class two speed histogram, indicating the presence of motorized class one vehicles. Following the data cleaning process, the class one speed histograms for all datasets were inspected to ensure the data approximated a normal distribution.

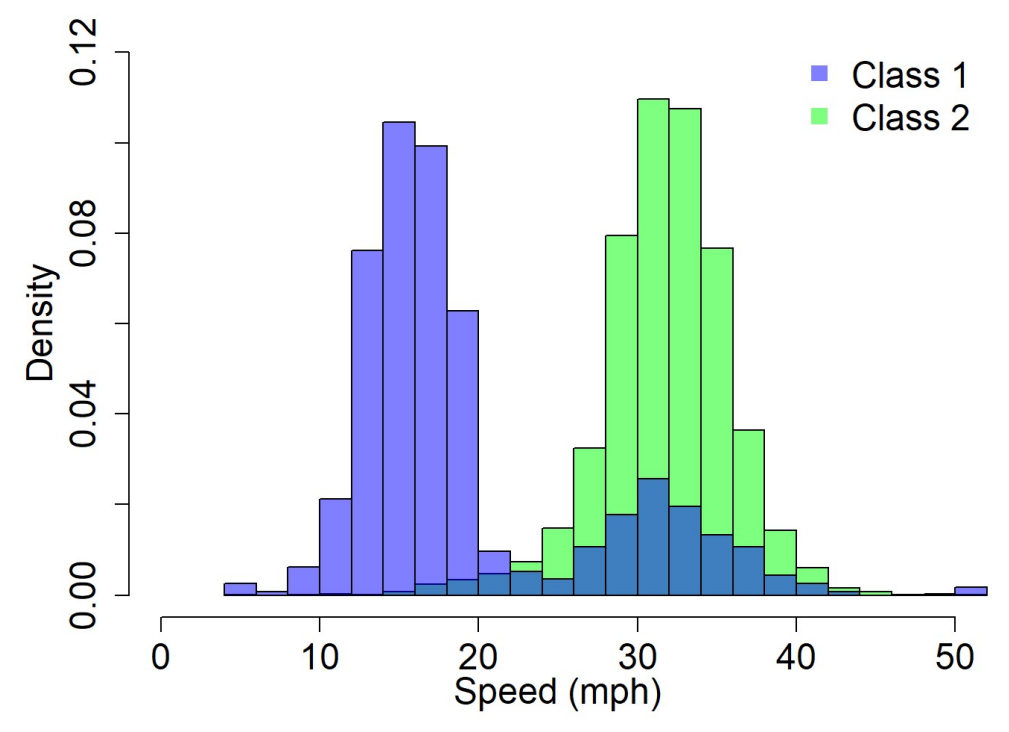

Figure 4.1 Class one speed bimodal distribution with class two speed distribution overlaid.

Nearly $85 \%$ the datasets were collected from two-lane, two-way streets. Only $10 \%$ of the datasets were from multilane streets and $6 \%$ were from one-way streets. Table 
4.1 provides descriptive statistics of the traffic, roadway, and geometric variables collected. The traffic variables including traffic composition, speeds, and ADT were sourced from the pneumatic tube data. The speed limit, road width, functional class, and bicycle facility type were sourced from local GIS database [21]. Bus routes were sourced from the local transit provider [22]. Grades were estimated from a 10-foot contour map and are presented with a negative value for a downhill direction [23]. Distances, lengths, and access densities were determined by inspection of satellite or street view imagery. Previous research has modeled bicycle speed over an entire segment; thus, variable values were averaged over its length. In the current study, the data were collected at a point location. This method may offer a higher level of precision in the measurement of the site-level independent variables, especially when compared to variables measured across longer segment lengths. 
Table 4.1 Descriptive statistics of the collected variables

\begin{tabular}{|l|l|c|c|c|c|l|}
\hline Name & Description & Min. & Max & Mean & St. Dev. & Type \\
\hline PSL & Speed Limit (mph) & 20 & 35 & 24.07 & 3.84 & ratio \\
\hline C1_Pct & $\begin{array}{l}\text { Class 1 Percent of Total Traffic } \\
(\%)\end{array}$ & 0.32 & 80.34 & 29.31 & 24.52 & ratio \\
\hline C1_Mn & Mean Class 1 Speed (mph) & 8.88 & 22.07 & 13.91 & 2.42 & ratio \\
\hline C2_Mn & Mean Class 2 Speed (mph) & 11.02 & 36.83 & 22.23 & 4.68 & ratio \\
\hline ADT_C2 & Class 2 ADT & 79 & 10629 & 2029 & 2306.59 & ratio \\
\hline Grade & Grade (\%) & -5.00 & 5.00 & 0.01 & 1.72 & interval \\
\hline Road_Width & Road Width (ft.) & 28.00 & 76.00 & 38.54 & 8.26 & ratio \\
\hline Dist_To_TC & Distance to Traffic Control (mi.) & 0.00 & 1.53 & 0.22 & 0.23 & ratio \\
\hline Dist_From TC & $\begin{array}{l}\text { Distance from Traffic Control } \\
\text { (mi.) }\end{array}$ & 0.00 & 1.53 & 0.24 & 0.26 & ratio \\
\hline Seg_Length & Segment Length (mi.) & 0.09 & 1.88 & 0.46 & 0.36 & ratio \\
\hline Access_Dens & $\begin{array}{l}\text { Access Density (accesses per } \\
\text { mi.) }\end{array}$ & 0.00 & 127.80 & 66.20 & 34.13 & ratio \\
\hline Bike_Shared & Shared Bikeway Presence & 0 & 1 & 0.64 & - & dummy \\
\hline Bike_Lane & Bike Lane Presence & 0 & 1 & 0.22 & - & dummy \\
\hline Bike_None & No Bike Facility Presence & 0 & 1 & 0.14 & - & dummy \\
\hline Bus_Route & Bus Route Presence & 0 & 1 & 0.47 & - & dummy \\
\hline FC_L & Functional Class Local & 0 & 1 & 0.41 & - & dummy \\
\hline FC_UC & $\begin{array}{l}\text { Functional Class Urban } \\
\text { Collector }\end{array}$ & 0 & 1 & 0.54 & - & dummy \\
\hline FC_A & Functional Class Arterial & 0 & 1 & 0.05 & - & dummy \\
\hline
\end{tabular}

Concerning the bicycle facility types within this study, it is important to highlight the differences in the features and intended purpose of roads with shared bikeways compared to roads with bike lanes or without facilities. All shared bikeways in this study are designated as neighborhood greenways. These are roads that prioritize bicycles and active travel and have relatively low motorized traffic volumes and speeds. These roads lack continuous centerline markings but display sharrows (shared lane symbols). T raffic calming measures such as speed humps and traffic circles are frequently present on these roads to deter speeding and cut-through traffic. Bicycles typically comprise a significantly greater portion of the total traffic on neighborhood greenways than the 
citywide average. Within the 97 datasets collected, bicycles constituted an average of $43 \%$ of the total traffic on neighborhood greenways, compared to $6 \%$ on roads with bicycle lanes, and $3 \%$ on roads without bicycle facilities. The overall mean class one and class two speeds and standard deviations, the mean percentage of class one vehicles, and the mean ADT by facility type are given in Table 4.2. A cross-tabulation of mean class two speeds (rounded to the nearest integer) by bicycle facility type is also displayed. The mean class one and class two speeds are highest on roads with bicycle lanes. These roads also have the highest ADT on average. Mean class one speeds on shared bikeways are slightly less than roads with bicycle lanes, and mean class two speeds differ by nearly nine mph. Roads without bicycle facilities displayed the lowest class one mean speed, differing by almost $1.5 \mathrm{mph}$ from roads with bicycle lanes. The mean class one standard deviations for the facility types range from 2.84 to $3.58 \mathrm{mph}$ while the mean class two standard deviations are somewhat higher at 3.69 to $4.76 \mathrm{mph}$. Figure 4.2 provides example street views for a typical neighborhood greenway, a road without bicycle facilities, and a road with bicycle lanes.

Table 4.2 Cross-tabulation of mean class two speeds by bicycle facility type and select speed and traffic statistics by facility type

\begin{tabular}{|c|c|c|c|c|c|c|c|c|c|c|c|c|c|c|c|c|c|c|c|c|}
\hline \multirow{2}{*}{$\begin{array}{l}\text { Bike } \\
\text { Facility }\end{array}$} & \multicolumn{20}{|c|}{ Mean Class 2 Speeds (mph) } \\
\hline & 11 & 12 & 17 & 18 & 19 & 20 & 21 & 22 & 23 & 24 & 25 & 26 & 28 & 30 & 31 & 32 & 33 & 34 & 36 & 37 \\
\hline Shared & 1 & 1 & 2 & 6 & 8 & 18 & 15 & 6 & 3 & 1 & 1 & 0 & 0 & 0 & 0 & 0 & 0 & 0 & 0 & 0 \\
\hline None & 0 & 0 & 0 & 1 & 2 & 1 & 4 & 0 & 1 & 1 & 1 & 1 & 0 & 2 & 0 & 0 & 0 & 0 & 0 & 0 \\
\hline \multirow[t]{2}{*}{ Lane } & 0 & 0 & 0 & 0 & 0 & 0 & 1 & 1 & 2 & 1 & 2 & 1 & 3 & 2 & 1 & 2 & 2 & 1 & 1 & 1 \\
\hline & \multicolumn{4}{|c|}{ Mean Class 1} & \multicolumn{4}{|c|}{ Mean Class 2} & \multicolumn{3}{|c|}{ Class 1 SD } & \multicolumn{3}{|c|}{ Class 2 SD } & \multicolumn{3}{|c|}{$\%$ Class 1} & \multicolumn{3}{|c|}{ ADT } \\
\hline Shared & \multicolumn{4}{|c|}{14.00} & \multicolumn{4}{|c|}{19.98} & \multicolumn{3}{|c|}{2.84} & \multicolumn{3}{|c|}{3.69} & \multicolumn{3}{|c|}{43.16} & \multicolumn{3}{|c|}{1164} \\
\hline None & \multicolumn{4}{|c|}{12.87} & \multicolumn{4}{|c|}{22.62} & \multicolumn{3}{|c|}{3.58} & \multicolumn{3}{|c|}{4.56} & \multicolumn{3}{|c|}{2.89} & \multicolumn{3}{|c|}{4258} \\
\hline Lane & \multicolumn{4}{|c|}{14.33} & \multicolumn{4}{|c|}{28.63} & \multicolumn{3}{|c|}{3.12} & \multicolumn{3}{|c|}{4.76} & \multicolumn{3}{|c|}{6.02} & \multicolumn{3}{|c|}{7399} \\
\hline
\end{tabular}




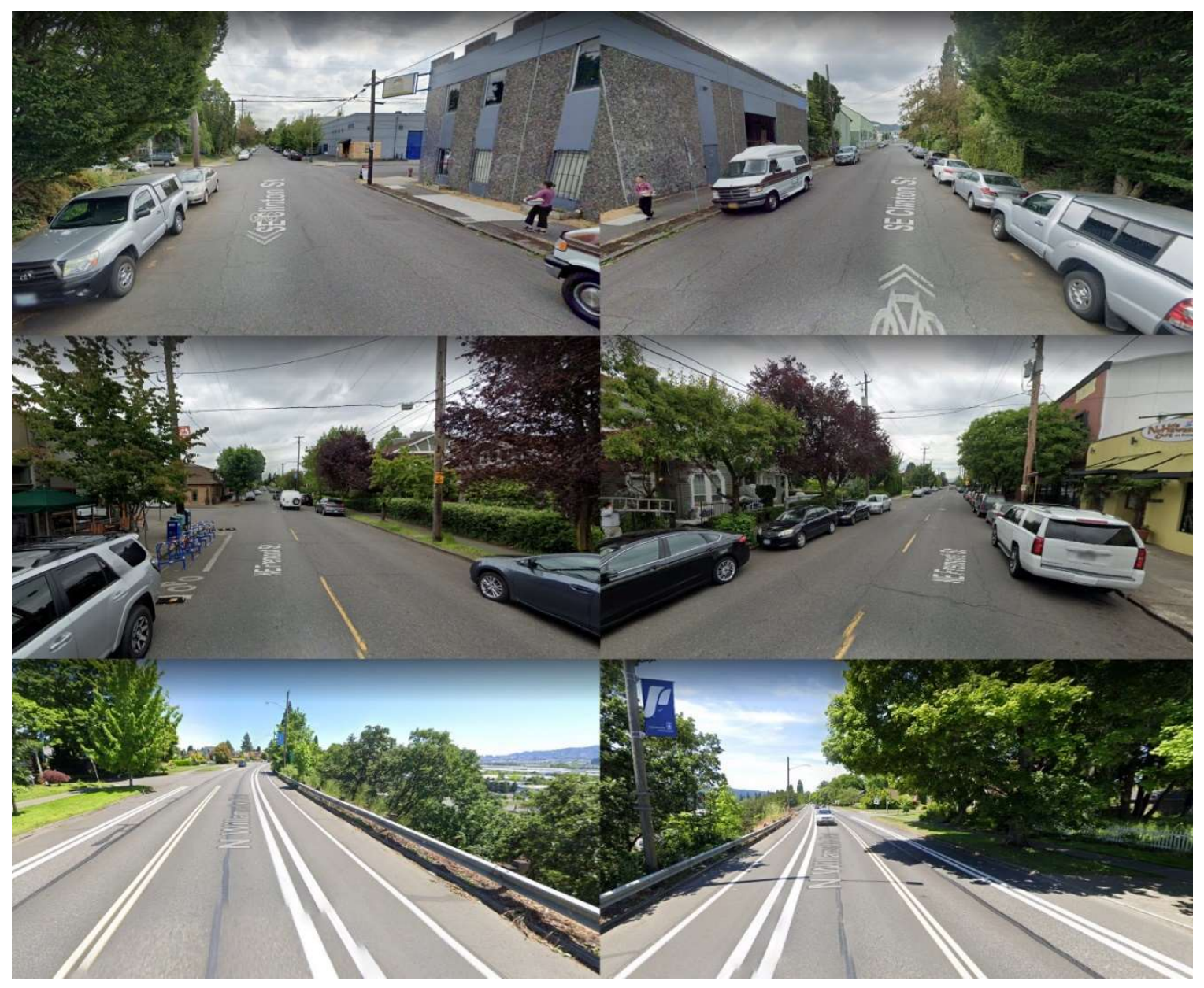

Figure 4.2 Bicycle infrastructure examples, from top to bottom: shared bikeway, no bicycle facilities, and bicycle lanes with a marked buffer.

Several of the site-level variables mentioned in the literature were included for analysis in this study, and several new variables were added. The distance from a traffic control device was included as an independent variable under the assumption that it takes a cyclist some distance to reach their preferred cruising speed after starting from a complete stop. The distance to a traffic control device was included based on empirical 
evidence that cyclists prefer to adjust their speed when approaching a red signal to remain in continuous motion rather than stop and wait [24]. The presence of a bus route was added due to research suggesting heavy vehicles may impede bicycles and cause more pronounced reduced speeds that standard passenger vehicles [7]. The percent of total traffic comprised by bicycles was also considered under the hypothesis that larger percentages may indicate a wider variety of cyclist types and experience levels, which may affect the mean speed. Access density was included in the analysis as cyclists may be more cautious in areas with numerous opportunities for vehicles to enter or exit. For this study, the access density was calculated from the number of driveways on both sides of the road for one block in either direction of the data collection location. The posted speed limit and mean speed of class two vehicles were also included to explore the possibility that cyclists with more experience (and thereby faster) a re more likely to travel on higher speed roads than cyclists with lesser experience.

\subsection{Analysis}

The first step to determine which site-level factors may influence bicycle speed was to conduct a linear correlation analysis. Correlation coefficients between the mean class one (bicycle) speed and all variables were noted, as well as high correlation coefficients $(r \leq-0.50$ or $r \geq 0.50)$ among variables. A correlogram can be seen in Figure 4.3 where the radius of a circle indicates the strength of the relationship and the color indicates the strength and direction of correlation. 


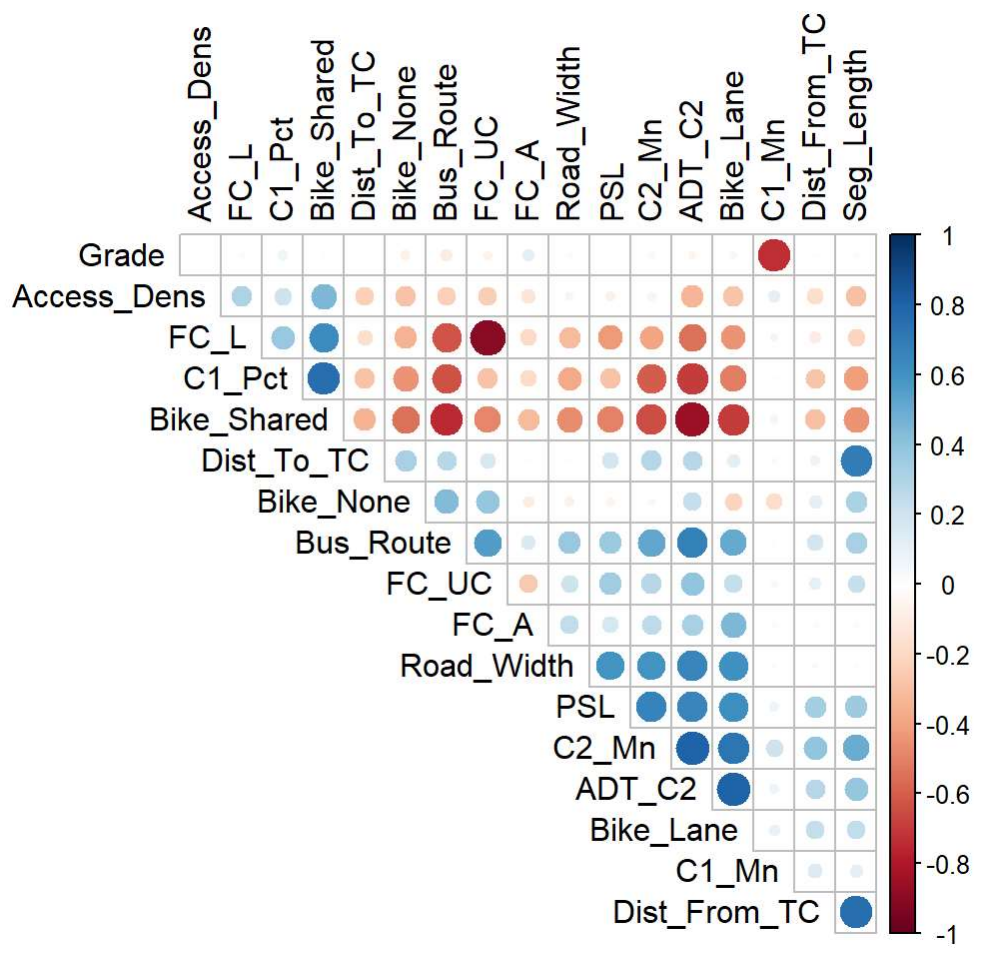

Figure 4.3 Correlogram of the mean class one speed and all collected variables.

The results of the correlation analysis indicated grade to be the only variable with a high degree of correlation to the mean class one speed, with $r=-0.73$. The sign of the correlation coefficient signifies that slower speeds are associated with uphill grades and faster speeds are associated with downhill grades, as expected. Minor correlations were observed between the mean class one speed and the mean class two speed $(r=0.21)$, roads without bicycle facilities $(r=-0.18)$, the distance from a traffic control device $(r=$ $0.15), \mathrm{t}$ he segment length $(r=0.12)$, a nd the access density $(r=0.10)$.

The correlation analysis also revealed that several of the variables could be organized into various groups in which each variable of the group was highly correlated to the others. The mean class two speed, the class two ADT, the road width, and streets 
with bicycle lanes were all highly positively correlated with each other, and to the speed limit or the presence of a bus route. Meanwhile, the class one percentage of traffic and shared bikeway variables were highly positively correlated, and were highly negatively correlated with bus routes, the presence of bicycle lanes, and the class two mean speed and ADT. Shared bikeways also presented a high positive correlation to local functionally classed roads. Other notable associations occurred between the segment length and the class two average speed $(r=0.50)$ or the distances to and from a traffic control device ( $r=0.69$ and $r=0.76$, respectively), and between urban collector functionally classed roads and the presence of a bus route $(r=0.55)$.

The next step in the analysis was to examine the significance and effect of the variables on the predicted bicycle speed. Regression models are commonly used to evaluate a response based on a function of covariates and were also applied to this analysis. The general form of the chosen regression model is shown in Equation 4.1, where $Y$ represents the dependent (or response) variable, $X_{i}$ represents the set of independent variables, $\beta_{i}$ represents the coefficients of these independent variables, and $\varepsilon$ represents an error term. By taking the natural log of both sides of Equation 4.1, the equation can be simplified such that the natural $\log$ of the dependent variable $Y$ is a function of a linear combination of parameters, shown in Equation 4.2.

$$
\begin{aligned}
& Y=e^{\beta_{0}+\sum_{i}\left(\beta_{i} X_{i}\right)+\varepsilon} \\
& \ln (Y)=\beta_{0}+\sum_{i}\left(\beta_{i} X_{i}\right)+\varepsilon
\end{aligned}
$$


Using Equation 4.2, a base model was established with the natural log of the class one mean speed as the dependent variable and grade as the independent variable. Grade was chosen for the base model due to its significant association to the class one mean speed. One at a time, the remaining variables were added to the base model to create linear combinations of two independent variables. The change in the adjusted $\mathrm{R}^{2}$ and the statistical significance of the coefficient for the added variable were recorded. Table 4.3 provides the adjusted $\mathrm{R}^{2}$ and the change in the adjusted $\mathrm{R}^{2}$ compared to the base model, as well as the estimated coefficient and its $p$-value for each variable.

Table 4.3 Results from the two-variable combination regression analyses

\begin{tabular}{|l|c|c|c|c|}
\hline Variable & Adj. $\mathbf{R}^{\mathbf{2}}$ & Adj. $\mathbf{R}^{\mathbf{2}}$ Change & Coeff. & $\boldsymbol{p}$-value \\
\hline Grade (Base Model) & 0.510 & NA & -0.0737 & $0.0000^{*}$ \\
\hline Bike_None & 0.563 & 0.053 & -0.1187 & $0.0000^{*}$ \\
\hline C2_Mn & 0.537 & 0.027 & 0.0067 & $0.0122^{*}$ \\
\hline Dist_From_TC & 0.532 & 0.022 & 0.1098 & $0.0230^{*}$ \\
\hline Seg_Length & 0.524 & 0.014 & 0.0651 & 0.0588 \\
\hline Bike_Lane & 0.523 & 0.013 & 0.0567 & 0.0621 \\
\hline PSL & 0.514 & 0.004 & 0.0041 & 0.2075 \\
\hline Access_Dens & 0.513 & 0.003 & 0.0005 & 0.2138 \\
\hline Bus_Route & 0.512 & 0.002 & -0.0281 & 0.2674 \\
\hline FC_UC & 0.511 & 0.001 & -0.0257 & 0.3085 \\
\hline FC_A & 0.510 & 0.000 & 0.0534 & 0.3506 \\
\hline Bike_Shared & 0.509 & -0.001 & 0.0217 & 0.4082 \\
\hline C1_Pct & 0.508 & -0.002 & 0.0004 & 0.4895 \\
\hline ADT_C2 & 0.507 & -0.003 & 0.0000 & 0.5340 \\
\hline FC_L & 0.507 & -0.003 & 0.0157 & 0.5407 \\
\hline Dist_To_TC & 0.507 & -0.003 & 0.0268 & 0.6206 \\
\hline Road_Width & 0.506 & -0.004 & 0.0004 & 0.8095 \\
\hline
\end{tabular}

${ }^{*} p<0.05$ 
The adjusted $\mathrm{R}^{2}$ of the base model suggests grade alone may explain more than $50 \%$ of the variation in the natural $\log$ of the mean class one speed, shown in Table 4.3. When grade is held constant, the natural log of the mean class one speed is reduced on roads without bicycle facilities and increases with greater class two mean speed or distance from a traffic control device. Each of these variables were significant at $p<0.05$. Positive effects on the predicted speed were estimated with the addition of the segment length, the presence of a bicycle lane, the speed limit, or the access density to the base model, while the presence of a bus route or an urban collector functional class showed negative effects on the predicted speed. Although these variables appeared to provide small increases to the adjusted $\mathrm{R}^{2}$, none of the estimated coefficients were statistically significant. The remaining variables did not produce clear effects on the predicted speed when added to the base model with grade alone.

The development of the final model was the last step in the analysis and involved a dynamic selection process of variables, taking into consideration linear correlations between independent variables, the statistical significance of the estimated coefficients, the change in the adjusted $\mathrm{R}^{2}$ of the model, and the residual plots. During the model specification process, it was decided to include an interaction term between the percentage of class one vehicles and the shared bikeway indicator under the hypothesis that with the typically higher percentages of cyclists on this roadway type, a wider range of experience levels and abilities (and therefore, speeds) i s likely represented.

The final variable selection with the estimated coefficients and $p$-values is provided in Table 4.4. All variables in the final model were significant at the $p<0.05$ 
level. The adjusted $\mathrm{R}^{2}$ of the final model was 0.63 , which indicates a reasonable fit and shows a marked improvement over the base model with grade only (Table 4.3). As expected, the coefficient for grade has a negative sign, indicating speeds decrease when traveling uphill, and increase in the downhill travel direction. The effect of segment length is also consistent with previous research, with longer segments contributing to higher speeds. Furthermore, the mean speed of class two vehicles, the percentage of the total traffic comprised by class one vehicles (bicycles), and the shared bikeway indicator all have a positive effect on the mean bicycle speed. However, for shared bikeways, the effect of the interaction term greatly reduces the positive effect of the class one percentage of traffic variable.

Table 4.4 Coefficients of the regression analysis model

\begin{tabular}{|l|c|c|c|c|c|}
\hline Variable & Estimate & Std. Error & t value & $\boldsymbol{p}$-value & Rela. Imp. \\
\hline Intercept & 2.133 & 0.089 & 24.096 & 0.000 & - \\
\hline C2_Mn & 0.013 & 0.003 & 4.098 & 0.000 & 9.5 \\
\hline Grade & -0.075 & 0.006 & -11.726 & 0.000 & 79.1 \\
\hline Seg_Length & 0.081 & 0.036 & 2.264 & 0.026 & 2.6 \\
\hline C1_Pct & 0.014 & 0.004 & 3.453 & 0.001 & 0.9 \\
\hline Bike_Shared & 0.172 & 0.045 & 3.798 & 0.000 & 2.6 \\
\hline C1_Pct:Bike_Shared & -0.013 & 0.004 & -3.273 & 0.002 & 5.3 \\
\hline
\end{tabular}

The relative importance of each independent variable is also shown in Table 4.4. Intuitively, grade is the most important factor in predicting bicycle speed, accounting for more than $79 \%$ of the explanatory power of the final model. Conversely, the percentage of class one vehicles contributed the least to the overall explanatory power, accounting for about $1 \%$ of the variation. 
Due to the high importance of grade in the final model and findings of previous studies [9-11, 15] indicating non-linear effects of grade on bicycle speed, the grade variable of the final model was replaced by two new variables for uphill (positive) grade and downhill (negative) grade. The resulting coefficients for these new variables did not differ from each other significantly in magnitude. This would suggest a linear effect on speed for the range of grades within this study.

\subsection{Discussion}

The results of the final regression model complement well the existing literature of bicycle speed prediction. In the final model, the significance and sign of the grade variable are intuitive. In contrast to previous studies, non-linear effects of grade on bicycle speed were not observed. However, the range of downhill grades in this study did not include the range of limiting grades (5\% to $6 \%)$ discovered in previous studies [9, $15]$.

The significance and sign of the segment length variable are supported by previous studies. Longer segment lengths may allow cyclists more distance to reach their preferred cruising speed. The final model also seems to validate the hypothesis that cyclists travel faster on roads with higher average passenger car (class two vehicle) speeds. Higher passenger car speeds were typically observed on higher volume roadways where bicycle lanes were present. Although the current research cannot ascertain whether the effect of passenger car speed is indeed due to the influence of cycling experience or comfort level riding in heavier traffic, it remains a possibility that could be further 
explored in future studies. Additionally, the positive effect on bicycle speed of a shared bikeway also appears to corroborate with previous research findings that speeds are higher when bicycle infrastructure is present. Furthermore, the unique characteristics of the shared bikeways in this study (neighborhood greenways) $m$ ay create a cycling environment that is more comparable to a separated path than a typical street with or without bicycle lanes.

While previous research found that bicycle speed was higher on arterial or collector roads, the current study did not find any of the functional class indicator variables to be significant. It is possible that an insufficient number of arterials in the data did not facilitate a reliable conclusion about their influence. Another observation regarding the functional classes of the study sites was that they did not necessarily represent homogeneous characteristics of the roadways. For example, a number of the neighborhood greenway sites were classified as collectors, as were all of the roads without bicycle facilities and several of the roads with bicycle lanes. The speeds, traffic volumes, and general roadway characteristics differed greatly among these roads. Interestingly, the class one percentage variable shows a positive influence on bicycle speed, although the interaction term has a substantial moderating effect on roads with shared bikeways. A higher proportion of bicycles on roads with bicycle lanes or without bicycle facilities may indicate an increased popularity of the route with more experienced cyclists. Conversely, the moderating effect of the interaction term may mean there is a wider range of cyclist experiences and abilities on shared bikeways, with more cyclists at the lower ends. Additionally, higher volumes of leisure cyclists may travel on 
these lower stress roadways, contributing to a reduction in the predicted mean speed. The final model implies that when the percentage of class one traffic is less than approximately $13 \%$, the speeds on shared bikeways will be higher than on roads with bike lanes or without facilities when all other variables are held constant, due to the influence of the shared bikeway indicator. As the class one percentage increases above $13 \%$, the contribution of the class one percentage variable for roads with bicycle lanes or without facilities begins to offset the effect of the shared bikeway indicator when holding all other variables constant. However, recall that the mean class one percentages on roads with bicycle lanes or without facilities were only $6 \%$ and $3 \%$, respectively.

Across the bicycle facility types, the overall mean class one speed from the empirical data was highest on roads with bicycle lanes, followed closely by shared bikeways, and roads without bicycle facilities trailing by approximately $1.5 \mathrm{mph}$. Despite the substantial influence of the shared bikeway indicator, the predominantly higher mean class two speeds and moderate class one percentage on roads with bicycle lanes leads to similarly predicted mean class one speeds for both facility types. Without the positive effects from either the mean class two speed or the shared bikeway indicator, the predicted mean class one speed on roads without bicycle facilities is the lowest.

\subsection{Conclusions}

This research has identified geometric, traffic, and roadway factors that may help predict bicycle speeds using a generalized linear regression approach. In addition to the unrefuted negative association with grade, the results suggest that the mean bicycle speed 
of a given site is increased when the mean speed of passenger cars is higher, the segment is longer, or the road features a shared bikeway. Traffic volumes composed of a larger proportion of bicycles also predict higher mean bicycle speeds, although this effect is significantly moderated on shared bikeways.

The relatively high adjusted $\mathrm{R}^{2}$ of the final regression model (0.63) suggests that bicycle speeds can be reasonably predicted at a given location from site-level factors alone. The results of the regression analysis also indicate that data collection by pneumatic tubes is a viable option for the creation of bicycle speed models, which may reduce bias inherent in other data collection methods that require study participants to opt-in. However, this data collection method also introduces its own limitations as pneumatic tubes alone cannot decipher a traditional bicycle from an e-bike or motorcycle. Even though an attempt was made to filter out observations of class one vehicles that appeared to be traveling faster than reasonably achievable by a pedal cyclist, it is possible that some observations made by a slower e-bike or motorcycle were included, or that some higher speed observations made by a traditional bicycle were excluded from the analysis. Combining pneumatic tubes with an additional data collection method capable of distinguishing motorized and non-motorized class one vehicles (such as video cameras) c ould provide more accuracy of the traffic data, and also deliver insight into the measurement error associated with using pneumatic tubes alone.

Creating accurate predictions of bicycle speed is a difficult task. There are many factors related to the human component that cannot be measured easily or reliably. Individual attitudes and preferences may vary greatly among cyclists with otherwise 
similar physical characteristics and experience levels, and they may even vary within a single individual from day to day. However, the findings of this research may provide a significant improvement over the traditional assumption of a constant bicycle speed for transportation planning and design purposes. The ability to create bicycle facilities more closely attuned to the needs of cyclists could help cities like Portland spark growth in the bicycle mode share and bring it closer to their goal.

\section{Acknowledgments}

The authors acknowledge Tom Jensen and Scott Batson of PBOT for providing the data that was utilized in this project.

\section{Author contributions}

The authors confirm contribution to the paper as follows: study conception and design: MAF; data collection: PBOT; analysis and interpretation of results: JSS, MAF; draft manuscript preparation: JSS, MAF. All authors reviewed the results and approved the final version of the manuscript. 


\subsection{References}

1. City of Portland Oregon. Portland Bicycle Plan for 2030 [pdf] [Internet]. Portland, OR: City of Portland; 2010 Feb 11 [cited 2020 Sep 12]. Available from: https://www.portlandoregon.gov/transportation/article/289122

2. City of Portland Oregon. Bicycles in Portland Fact Sheet [Internet]. Portland, OR: City of Portland; 2019 [updated 2019 Apr; cited 2020 Sep 12]. Available from: https://www.portlandoregon.gov/transportation/article/407660

3. Blanc B, Figliozzi M. Modeling the Impacts of Facility Type, Trip Characteristics, and Trip Stressors on Cyclists' Comfort Levels Utilizing Crowdsourced Data. Transportation Research Record. 2016;2587(1):100-8.

4. Figliozzi M, Wheeler N, Monsere CM. Methodology for Estimating Bicyclist Acceleration and Speed Distributions at Intersections. Transportation Research Record. 2013 Jan;2387(1):66-75.

5. Kassim A, Tayyeb H, Al-Falahi M. Critical Review of Cyclist Speed Measuring Techniques. Journal of Traffic and Transportation Engineering (English edition). 2020 Feb 1;7(1):98-110. 
6. Arnesen P, Malmin OK, Dahl E. A Forward Markov Model for Predicting Bicycle Speed. Transportation. 2019 Jun 14:1-23.

7. Bernardi S, Rupi F. An Analysis of Bicycle Travel Speed and Disturbances on Off-Street and On-Street Facilities. Transportation Research Procedia. 2015 Jan $1 ; 5: 82-94$

8. El-Geneidy A, Krizek KJ, Iacono M. Predicting Bicycle Travel Speeds Along Different Facilities Using GPS Data: A Proof of Concept Model. In Proceedings of the 86th Annual Meeting of the Transportation Research Board, Compendium of Papers 2007 Jan. TRB Washington, DC, USA.

9. Flügel S, Hulleberg N, Fyhri A, Weber C, Ævarsson G. Empirical Speed Models for Cycling in the Oslo Road Network. Transportation. 2019 Aug 1;46(4):1395419.

10. Parkin J, Rotheram J. Design Speeds and Acceleration Characteristics of Bicycle Traffic for Use in Planning, Design and Appraisal. Transport Policy. 2010 Sep 1;17(5):335-41.

11. Strauss J, Miranda-Moreno LF. Speed, Travel Time and Delay for Intersections and Road Segments in the Montreal Network Using Cyclist Smartphone GPS 
Data. Transportation Research Part D: Transport and Environment. 2017 Dec $1 ; 57: 155-71$.

12. Tengattini S, Bigazzi AY. Context-sensitive, first-principles approach to bicycle speed estimation. IET Intelligent Transport Systems. 2017 Jul 18;11(7):411-6.

13. Xu C, Li Q, Qu Z, Jin S. Predicting Free Flow Speed and Crash Risk of Bicycle Traffic Flow Using Artificial Neural Network Models. Mathematical Problems in Engineering. 2015 Jan 1;2015.

14. Garber MD, Watkins KE, Kramer MR. Comparing bicyclists who use smartphone apps to record rides with those who do not: Implications for representativeness and selection bias. Journal of Transport \& Health. 2019 Dec 1;15.

15. Ryeng EO, Haugen T, Grønlund H, Overå SB. Evaluating Bluetooth and Wi-Fi Sensors as a Tool for Collecting Bicycle Speed at Varying Gradients. Transportation Research Procedia. 2016 Jan 1;14:2289-96.

16. Federal Highway Administration. Traffic Monitoring Guide. Washington DC: US Department of Transportation; 2016. p. C-1. 
17. Hallenbeck M, Rice M, Smith BL, Cornell-Martinez C, Wilkinson J. Vehicle Volume Distributions by Classification; Report No.: FHWA-PL-97-025. 1997 Jul. p. 29 .

18. National Highway Traffic Safety Administration. Traffic Safety Facts [pdf] [Internet]. Washington DC: US Department of Transportation; 2013 [cited 2020 Sep 15]. Available from: https://crashstats.nhtsa.dot.gov/Api/Public/ViewPublication/812148\#: :text=Mot orcycles $\% 20$ mama $\% 20$ up $\% 203 \% 20$ percent,of $\% 20$ all $\% 20$ vehicle $\% 20$ miles $\% 20 \operatorname{tr}$ aveled.

19. McFarland M. Electric bicycles emerge as a hot trend in the U.S. [Internet]. CNNMoney. 2018 [cited 2020 Sep 15]. Available from: https://money.cnn.com/2018/01/17/technology/ebikes-electric-bikes/index.html

20. Wagner I. U.S. Bicycle Industry - Statistics \& Facts [Internet]. Statista. 2019 [cited 2020 Sep 15]. Available from: https://www.statista.com/topics/1448/bicycle-industry-in-the-us/

21. PortlandMaps Open Data [Internet]. [cited 2020 Sep 15]. Available from: https://gis-pdx.opendata.arcgis.com/ 
22. TriMet. Maps and Schedules [Internet]. 2020 [cited 2020 Sep 15]. Available from: https://trimet.org/schedules/index.htm

23. United States Geological Survey. 10 foot contours of the Portland, OR metro area [Internet]. 2011 Jan 24 [modified 2011 May 15; cited 2020 Sep 15]. Available from: https://databasin.org/datasets/e5f48e27860046c6b4bc14d64adf1ceb

24. Twaddle H, Schendzielorz T, Fakler O. Bicycles in Urban Areas: Review of Existing Methods for Modeling Behavior. Transportation Research Record. 2014 Jan;2434(1):140-6. 


\section{Summary and Concluding Remarks}

The research presented in this thesis has focused on examining the speed behaviors of passenger vehicles and bicycles through their interactions with each other and with geometric and roadway characteristics. Traffic data collected with widely utilized pneumatic tubes were evaluated to answer two key inquiries: Do bicycles cause reduced passenger car speeds on urban roads without bicycle lanes? and What are the significant geometric, traffic, and roadway characteristics that influence bicycle speed? The answers to these questions have potentially far-reaching benefits, from enhancing bikeway design and improving bicycle routing, to mitigating congestion and reducing the environmental burden of greenhouse gasses.

Chapter two provided a detailed comparative analysis of passenger car (class two vehicle) speeds belonging to one of two vehicle following scenarios: (i) a passenger car following a bicycle (class one vehicle), a nd (ii) a passenger car following another passenger car. The 11 traffic datasets analyzed were collected from six relatively homogeneous low-speed, low-volume urban roadways without bicycle lanes. The mean, the $50^{\text {th }}$, and the $85^{\text {th }}$ percentile speeds of scenario (i) a nd scenario (ii) observations for both peak- and 24-hour traffic were compared using $t$-tests and confidence intervals. A few statistically significant differences were observed; however, the magnitude of these differences was generally one mile per hour or less. Hence, these small differences were deemed negligible from a practical perspective, resulting in an initial conclusion that bicycles are not likely to slow down passenger vehicles on low volume, low speed urban roads without bicycle lanes. 
Following the initial conclusion reached by the research presented in chapter two, a subsequent study, detailed in chapter three, was conducted to address limitations of the initial study. The subsequent study sought to explore whether the initial conclusion would be supported when traffic data from a large number of roads with a variety of functional classes, centerline markings, traffic compositions, ADT, and grades were evaluated. Similar to the initial study, scenario (i) and scenario (ii) $\mathrm{m}$ ean and $85^{\text {th }}$ percentile speeds were compared using $t$-tests. Additionally, relationships between the speeds of passenger cars following bicycles (scenario (i) observations) a nd the availability of adequate gaps in oncoming (opposing direction) traffic for overtaking were examined. Overall, the findings of this second study seem to confirm those of the first study, concluding that bicycles on lower-volume, low-speed urban roads without bicycle lanes are unlikely to cause reduced passenger car speeds. When all observations were evaluated, only $8 \%$ of the datasets indicated statistically significant differences in mean speed of one mile per hour or more, and only one dataset showed evidence of a statistically significant difference in the $85^{\text {th }}$ percentile speed of one mile per hour or more. Characteristics of these datasets that may have contributed to the speed differences included relatively high proportions of vehicles exceeding the speed limit, ADT or speed limits outside the range of recommended values for mixed-traffic roads, and the presence of centerline markings. Relative to the gaps in the oncoming (opposing direction) traffic, fewer significant differences in mean or $85^{\text {th }}$ percentile speeds of one mile per hour or more were observed when scenario (i) v ehicles had sufficient time to overtake a bicycle versus when the gap times with oncoming traffic were insufficient. 
Chapter four then presented an analysis of mean bicycle (class one vehicle) speeds in association with the geometric, traffic, or roadway attributes of the data collection site. The use of pneumatic tube data was unique to this study compared to those reviewed in the literature. This data collection method eliminates the selection bias that may occur when research subjects are required to opt in through the use of special GPS devices or registration on smartphone apps. Additionally, prediction of bicycle speed based only on the site-level characteristics may be more applicable for planning and design purposes. The final regression model developed (adjusted $\mathrm{R}^{2}=0.63$ ) i ndicated that grade is the most important predictor of mean bicycle speed, accounting for $79 \%$ of the model's explanatory power. Intuitively, grade was negatively associated with speed. The final regression model also suggested that the mean bicycle speed increases with higher mean passenger car (class two vehicle) speeds, a higher proportion of bicycle (class one) t raffic, longer segment lengths, and the presence of a shared bikeway. However, an interaction term between the presence of a shared bikeway and the proportion of bicycle traffic showed a moderating effect on speed.

The primary limitation of the research presented in this thesis is the inability of pneumatic tubes to distinguish motorized or motor-assisted class one vehicles from nonmotorized class one vehicles. To help overcome this limitation, class one and class two speed distributions were scrutinized in conjunction with the grade at the data collection location to determine a reasonable upper speed bound by which to filter the class one speed data. Future research comparing class one speed data collected by a method capable of differentiating pedal bicycles from e-bikes or motorcycles to data collected 
with pneumatic tubes alone could shed light on the impact of using pneumatic tube data only for the analyses performed throughout this thesis.

Despite this limitation, this thesis provides a valuable contribution to the bicycle literature. Through a better understanding of the determinants of bicycle speed and how bicycles affect motorized vehicle speeds on roads without bicycle lanes, facilities and routes that make bicycling more attractive while maintaining an appropriate level of motorized vehicle mobility can be implemented. 